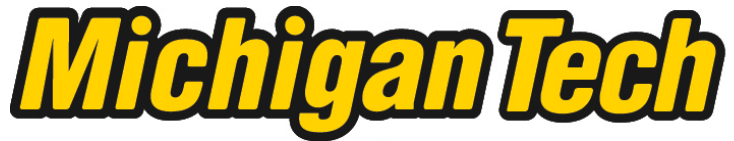 \\ Michigan Technological University Create the Future Digital Commons @ Michigan Tech
}

Dissertations, Master's Theses and Master's Reports - Open

Dissertations, Master's Theses and Master's

Reports

2010

\section{Advanced mechanics of materials with microstructure}

Shreehari Elangovan

Michigan Technological University

Follow this and additional works at: https://digitalcommons.mtu.edu/etds

Part of the Mechanical Engineering Commons

Copyright 2010 Shreehari Elangovan

\section{Recommended Citation}

Elangovan, Shreehari, "Advanced mechanics of materials with microstructure", Dissertation, Michigan Technological University, 2010.

https://doi.org/10.37099/mtu.dc.etds/358

Follow this and additional works at: https://digitalcommons.mtu.edu/etds

Part of the Mechanical Engineering Commons 


\title{
ADVANCED MECHANICS OF MATERIALS WITH MICROSTRUCTURE
}

\author{
by \\ SHREEHARI ELANGOVAN
}

\author{
A Dissertation \\ submitted in partial fulfillment of the requirements \\ for the degree of \\ DOCTOR OF PHILOSOPHY
}

(Mechanical Engineering-Engineering Mechanics)

Michigan Technological University

2010

Copyright (C) Shreehari Elangovan 2010 
This dissertation, "ADVANCED MECHANICS OF MATERIALS WITH MICROSTRUCTURE", is hereby approved in partial fulfillment of the requirements for the degree of DOCTOR OF PHILOSOPHY in the field of MECHANICAL ENGINEERING-ENGINEERING MECHANICS.

DEPARTMENT: MECHANICAL ENGINEERING-ENGINEERING MECHANICS

SIGNATURES:

DISSERTATION ADVISOR: Dr. GREGORY M. ODEGARD

DEPARTMENT CHAIR: Dr. WILLIAM W. PREDEBON

DATE: 


\section{ACKNOWLEDGMENTS}

I am immensely obliged to Prof. Gregory Odegard for mentoring me in my research, for his support and encouragement in various circumstances, for always keeping my interests in mind and for tolerating my Victorian writing style in reports and manuscripts. My Ph.D. journey would not have been so interesting if he were not part of it. I am extremely grateful to Profs. Tammy Haut Donahue, Reza Shahbazian-Yassar and Zhanping You for providing invaluable suggestions periodically on my work and taking the time to serve on my dissertation committee. I am also greatly indebted to my collaborators Robert Spinner, M.D., Marie-Noelle Hebert-Blouin, M.D., Huan Wang, M.D., Ph.D. and Duane Morrow, M.S., from the Mayo Clinic in Rochester, MN for actively and periodically providing crucial comments and suggestions on the clinical aspects of the nerve project. I am also extremely grateful to my collaborator on the cellular materials project Dr. Burhanettin Altan for his active involvement and for patiently answering my questions on strain gradient elasticity during the initial years of my $\mathrm{PhD}$. I want to express my heartfelt thanks to the members of the Odegard research group and the solid mechanics seminar group for their friendship and participation in many technical discussions that greatly benefitted me. My many thanks to Dr. Dennis Kunkel, Dennis Kunkel Microscopy Inc., for allowing me to use his balsa wood image (page-48) in my journal article and dissertation. I gratefully acknowledge financial support from the Mayo Clinic/Mayo Foundation (MTU070817), Michigan Tech research excellence fund, NASA Langley research center (NNL04AA85G) and the 
Michigan Tech graduate student council's finishing fellowship for doing this work. I want to extend my sincere thanks to two other great mentors in my life: Prof. S. Bhaskar from Bharathiar University, India and Dr. C. Varadarajan, Chief Engineer, Research \& Development, Tractors and Farm Equipment Limited, India. Your words of advice have been forever etched onto my mind and have guided me during trying times. I want to thank all my friends and roomies at Michigan Tech for their camaraderie; The great fun I had here is something I will forever miss when I leave. Last but not the least I want to thank my parents and my wife for their great support, understanding and encouragement during the greatest of trials and tribulations in my life. They have given more than they could ever afford to give for me to complete this degree. 


\section{ABSTRACT}

The study of advanced materials aimed at improving human life has been performed since time immemorial. Such studies have created everlasting and greatly revered monuments and have helped revolutionize transportation by ushering the age of lighter-than-air flying machines. Hence a study of the mechanical behavior of advanced materials can pave way for their use for mankind's benefit. In this school of thought, the aim of this dissertation is to broadly perform two investigations. First, an efficient modeling approach is established to predict the elastic response of cellular materials with distributions of cell geometries. Cellular materials find important applications in structural engineering. The approach does not require complex and time-consuming computational techniques usually associated with modeling such materials. Unlike most current analytical techniques, the modeling approach directly accounts for the cellular material microstructure. The approach combines micropolar elasticity theory and elastic mixture theory to predict the elastic response of cellular materials. The modeling approach is applied to the two dimensional balsa wood material. Predicted properties are in good agreement with experimentally determined properties, which emphasizes the model's potential to predict the elastic response of other cellular solids, such as open cell and closed cell foams. The second topic concerns intraneural ganglion cysts which are a set of medical conditions that result in denervation of the muscles innervated by the cystic nerve leading to pain and loss of function. Current treatment approaches only temporarily alleviate pain and denervation which, however, does not prevent cyst 
recurrence. Hence, a mechanistic understanding of the pathogenesis of intraneural ganglion cysts can help clinicians understand them better and therefore devise more effective treatment options. In this study, an analysis methodology using finite element analysis is established to investigate the pathogenesis of intraneural ganglion cysts. Using this methodology, the propagation of these cysts is analyzed in their most common site of occurrence in the human body i.e. the common peroneal nerve. Results obtained using finite element analysis show good correlation with clinical imaging patterns thereby validating the promise of the method to study cyst pathogenesis. 


\section{TABLE OF CONTENTS}

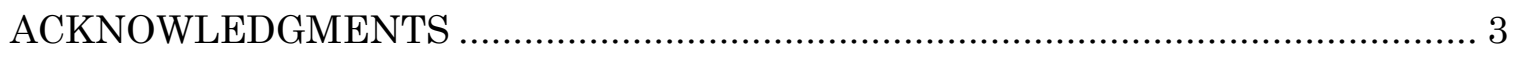

ABSTRACT …......................................................................................... 5

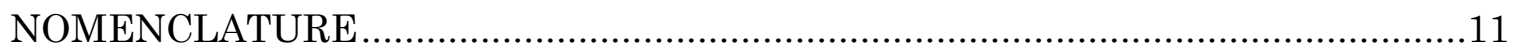

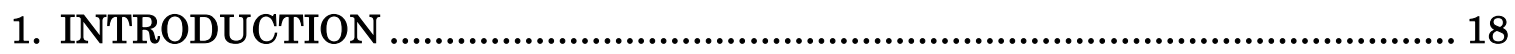

2. CONSTITUTIVE MODELING OF CELLULAR MATERIALS ........................ 21

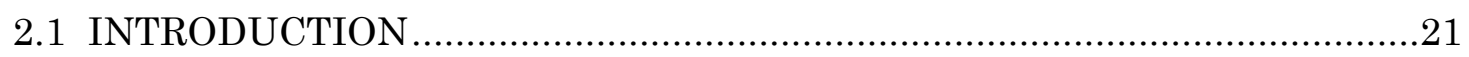

2.2 MICROPOLAR HOMOGENIZATION .....................................................24

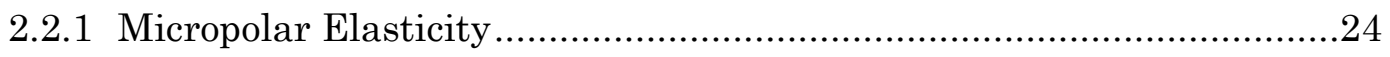

2.2.2 Triangular Lattice Homogenization ..............................................25

2.3 MICROPOLAR MIXTURE HOMOGENIZATION .....................................27

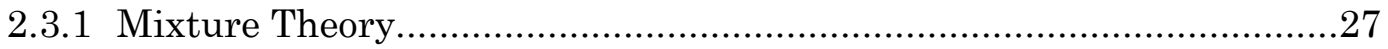

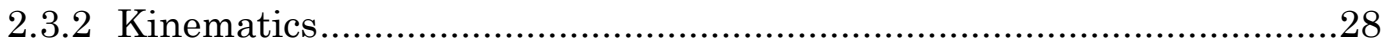

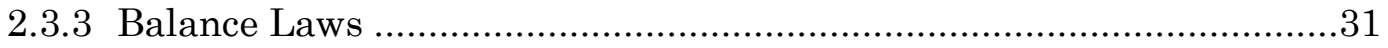

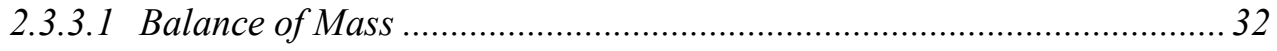

2.3.3.2 Balance of Linear Momentum …....................................................... 32

2.3.3.3 Balance of Angular Momentum .......................................................... 33

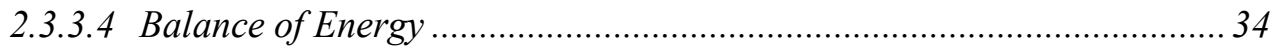

2.3.3.5 Clausius-Duhem inequality ............................................................ 36

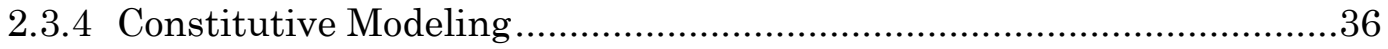

2.4 MICROPOLAR MIXTURE OF TRIANGULAR LATTICES..........................42

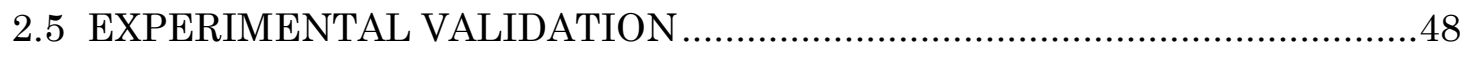

2.5.1 Application of Model to Balsa Wood ............................................49

2.6 SUMMARY ...................................................................................... 51

3. CONSTITUTIVE MODELING OF OPEN CELL FOAMS - CONCLUSIONS .... 52

3.1 RESEARCH SIGNIFICANCE ............................................................... 52

3.2 FUTURE WORK .........................................................................53 
4. FINITE ELEMENT MODELING OF INTRANEURAL GANGLION CYSTS ..... 54

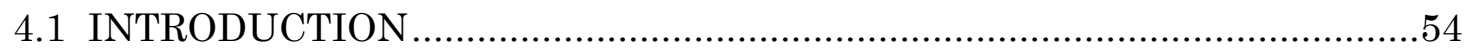

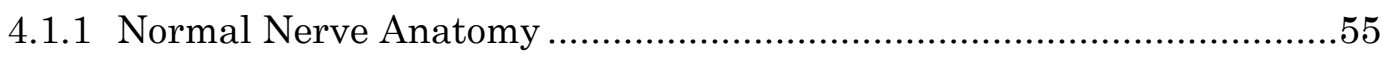

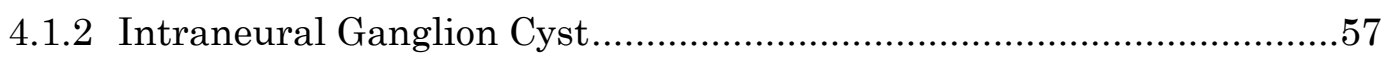

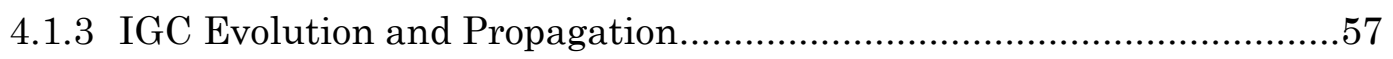

4.1.3.1 Joint-Joint Capsule ..................................................................... 58

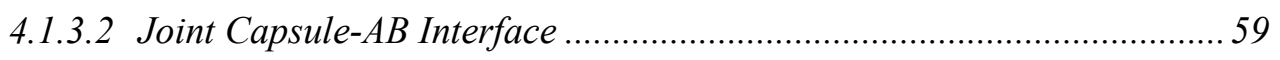

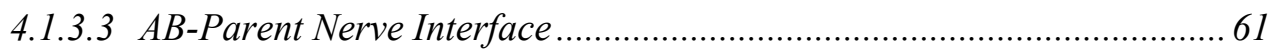

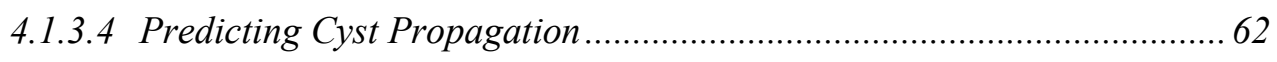

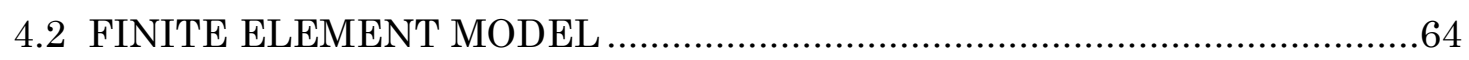

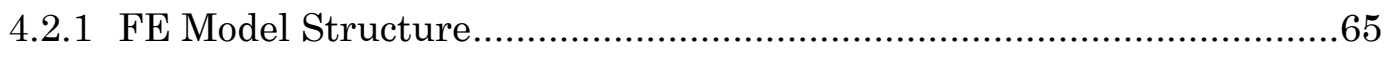

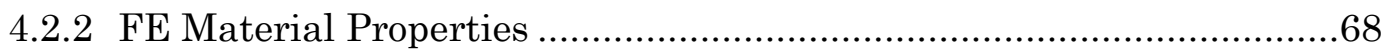

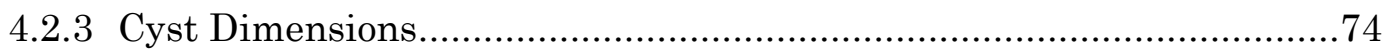

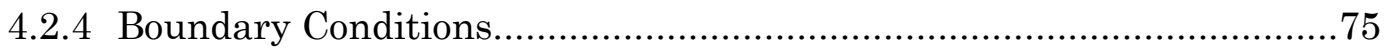

4.2.5 Mesh Sensitivity Analysis.................................................................

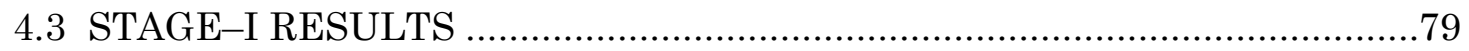

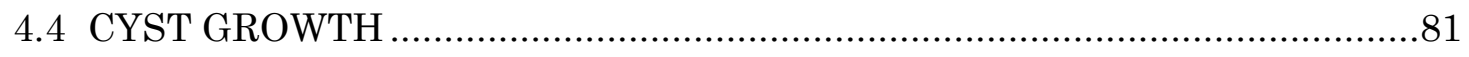

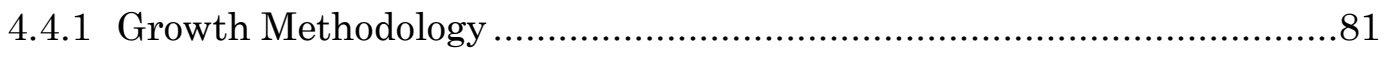

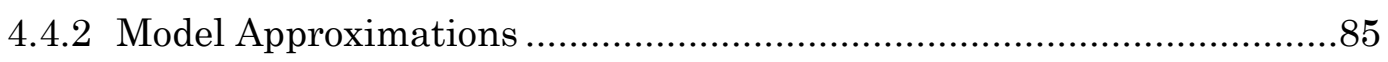

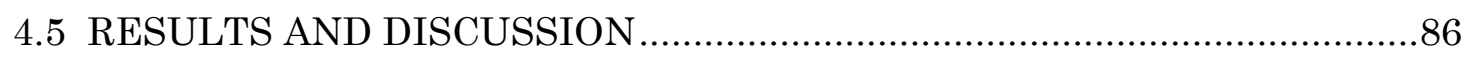

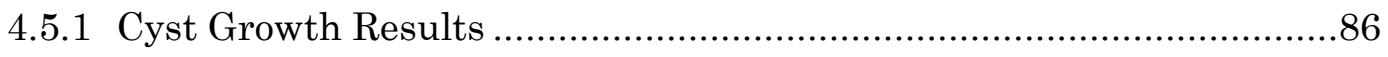

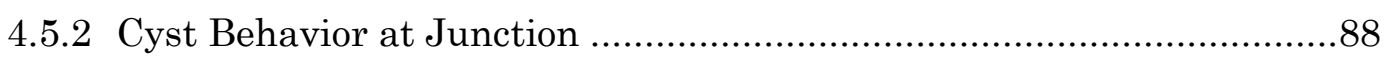

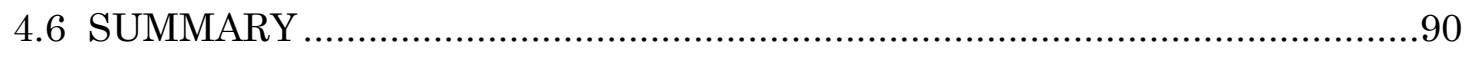

\section{ANISOTROPIC FAILURE ANALYSIS OF INTRANEURAL GANGLION CYSTS}

.

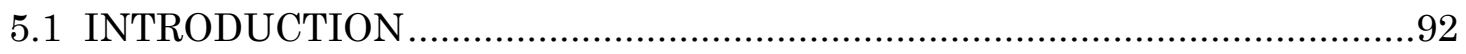

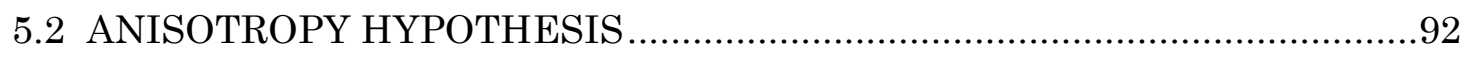

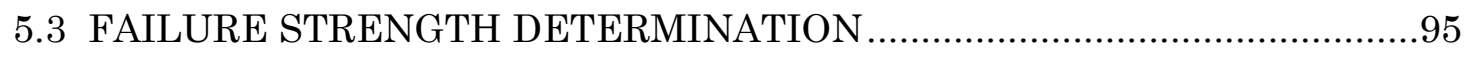

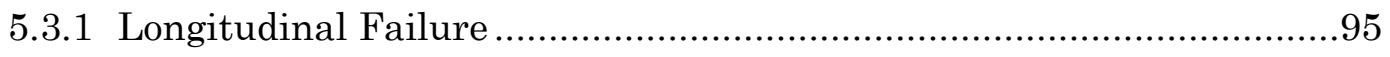

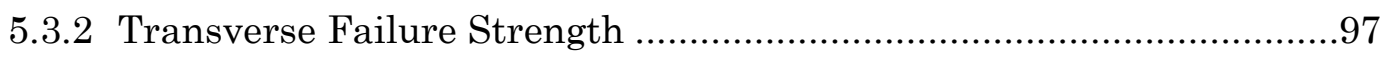

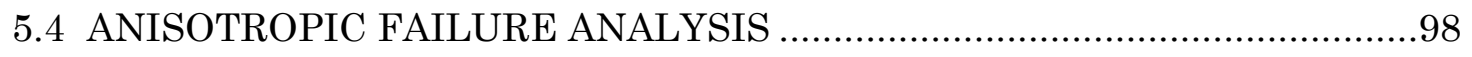

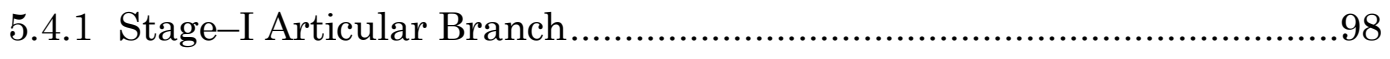

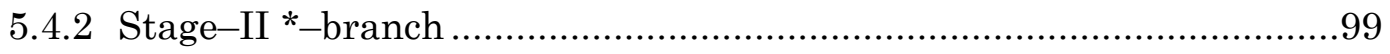


5.5 ANISOTROPIC FAILURE ANALYSIS RESULTS ………..........................100

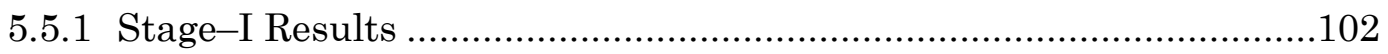

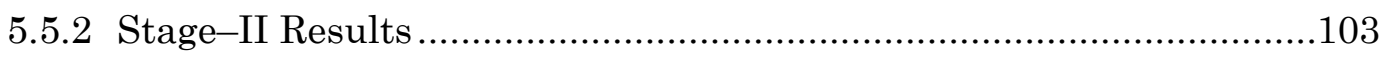

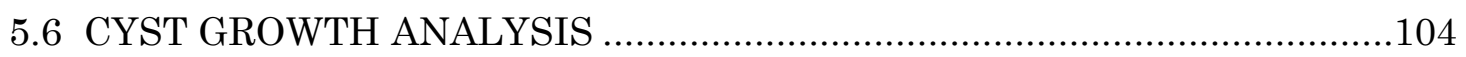

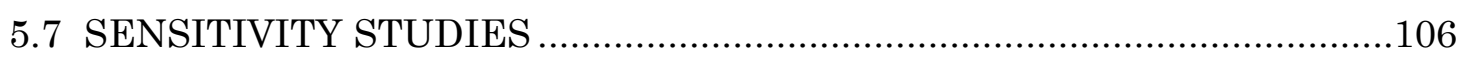

5.7.1 Material Property Sensitivity …………………..............................107

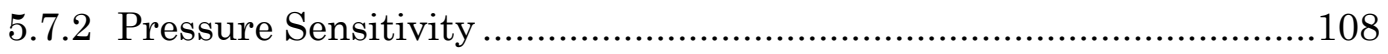

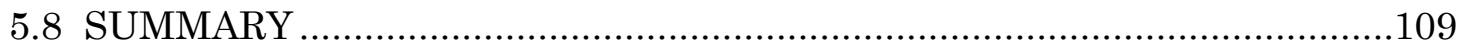

6. CROSS-SECTION ANALYSIS OF AN INTRANEURAL GANGLION CYST

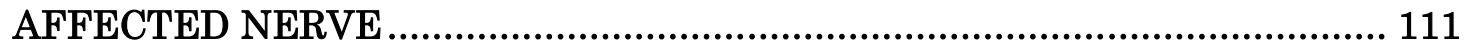

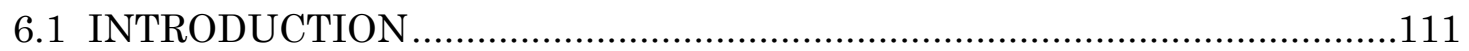

6.2 NERVE CROSS-SECTION DETAILS ……………...............................112

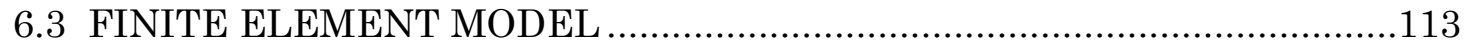

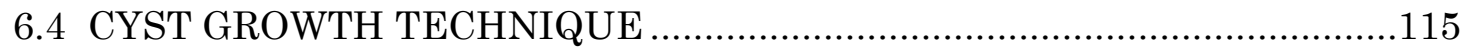

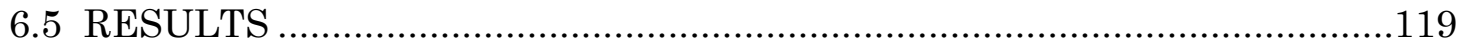

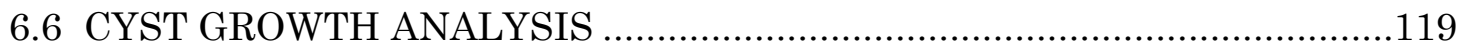

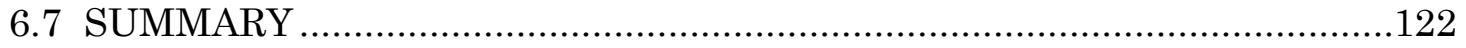

7. FEA OF INTRANEURAL GANGLION CYSTS - CONCLUSIONS ……........... 124

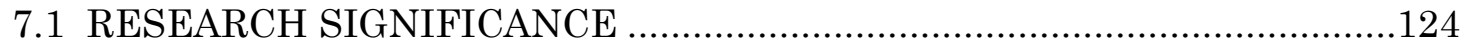

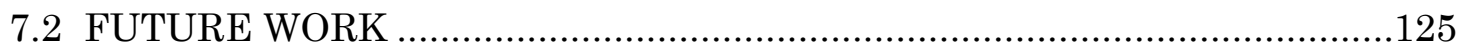

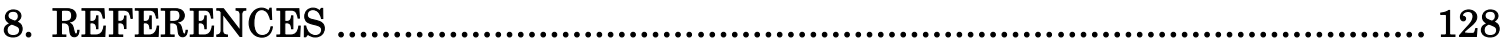

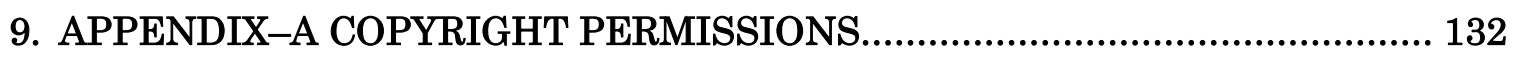

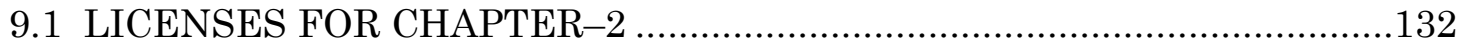

9.1.1 License for Figure 2.1-Figure 2.4 and all text ..................................132

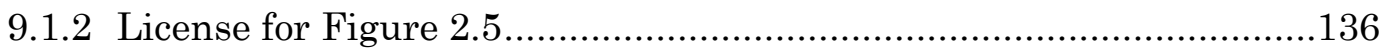

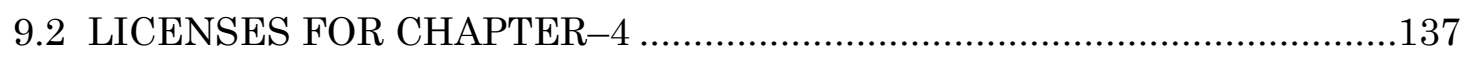

9.2.1 License for Figure 4.1, Figure 4.2, Figure 4.3a \& b, Figure 4.7a........137

9.2.2 License for Figure 4.4 and Figure 4.5 and text in section 4.1.3 .........138

9.2.3 License for Figure 4.6.................................................................. 140

9.2.4 Licenses for other content in Chapter-4...........................................141 


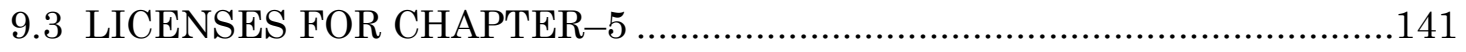

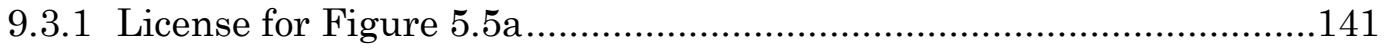

9.3.2 Licenses for other content in Chapter-5..................................... 142

9.4 LICENSES FOR CHAPTER-6 ........................................................... 142

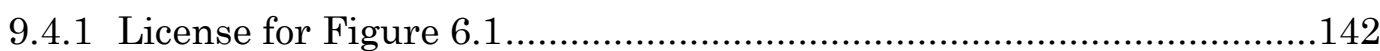

9.4.2 License for Figure 6.5 .............................................................. 144

9.4.3 Licenses for other content in Chapter-6........................................147 


\section{NOMENCLATURE}

$a_{k}^{(n)} \quad$ Acceleration vector component of the $n^{\text {th }}$ constituent

$a_{k l}^{(n)} \quad$ Material derivative of $\varepsilon_{k l}^{(n)}$

$A_{k l}^{(n)}, A_{k l m n}^{(n)}$ Material moduli of the $n^{\text {th }}$ constituent

$A^{(n)} \quad$ Cross-sectional area of the struts of the $n^{\text {th }}$ constituent

$a_{k l} \quad$ Material derivative of $\varepsilon_{k l}$

AB Articular Branch

$\mathrm{B}^{(\mathrm{m})} \quad$ Strain-displacement matrix in FEA

$b_{k l}^{(n)} \quad$ Material derivative of $\gamma_{k l}^{(n)}$

$B_{k l}^{(n)}, B_{k l m n}^{(n)}$ Material moduli of the $n^{\text {th }}$ constituent

$b_{k l} \quad$ Material derivative of $\gamma_{k l}$

Co $\quad$ Constant relating temperature and free energy in the natural state

C Right Cauchy-Green deformation tensor

$\mathrm{C}^{(\mathrm{m})} \quad$ Elasticity matrix in FEA

$C_{k l m n}^{(n)} \quad$ Material moduli of the $n^{\text {th }}$ constituent

$c_{n}^{m} \quad$ Mooney-Rivlin constant corresponding to $I_{n}$ term where $\mathrm{n}$ can be 1 or 2

$C_{x-a v g}^{m} \quad$ Average values of the $\mathrm{x}^{\text {th }}$ Mooney-Rivlin constant obtained from Quapp et.

al. (Quapp \& Weiss, 1998) 
$C_{x-n e w}^{m} \quad$ Re-fit coefficient of the $x^{\text {th }}$ Mooney-Rivlin constant obtained from Quapp et. al. (Quapp \& Weiss, 1998)

CPN Common Peroneal Nerve

$d \quad$ Inverse of pressure applied to maintain incompressibility by the U/P formulation

$D \quad$ Set of all dependent variables

DPN Deep Peroneal Nerve

e Total number of transverse tensile tests performed by Quapp et. al. (Quapp \& Weiss, 1998)

$E_{\text {strut }}^{(n)} \quad$ Young's modulus of the strut material of the $n^{\text {th }}$ constituent

$E^{(n)} \quad$ Young's modulus of the equivalent continuum of the $n^{\text {th }}$ constituent

$E \quad$ Young's modulus of the mixture

$f_{k}^{(n)} \quad$ Body force density vector components of the $n^{\text {th }}$ constituent

$f^{(n)} \quad$ Volume fraction of the $n^{\text {th }}$ constituent

FEA Finite Element Analysis

$G_{\text {strut }}^{(n)} \quad$ Shear modulus of the material of the struts of the $n^{\text {th }}$ constituent

$G^{(n)} \quad$ Shear modulus of the equivalent continuum of the $n^{\text {th }}$ constituent

$G \quad$ Shear modulus of the mixture

$h^{(n)} \quad$ Internal energy source density of the $n^{\text {th }}$ constituent

$h \quad$ Internal energy source density of the mixture

I Identity tensor

$I \quad$ Set of all independent variables 
In First, second and third invariants of the right/left Cauchy-Green deformation tensor for $\mathrm{n}=1,2,3$ respectively

$I^{(n)} \quad$ Moment of inertia of the struts of the $n^{\text {th }}$ constituent

IGC Intraneural Ganglion Cyst

$j^{(n)} \quad$ Microinertia density of the $n^{\text {th }}$ constituent

$J \quad$ Set of all thermodynamic fluxes

$\tilde{J} \quad$ Ratio of volume before and after deformation

K Classical Fourier constant

K Stiffness matrix in FEA

$l_{i}^{(n)} \quad$ Body couple density vector components of the $n^{\text {th }}$ constituent

$l^{(n)} \quad$ Length of the struts of the $n^{\text {th }}$ constituent

$l_{\text {cyst }} \quad$ Length of the cyst

L Left Cauchy-Green deformation tensor

$m_{k l}^{(n)} \quad$ Couple stress tensor components of the $n^{\text {th }}$ constituent

$\hat{m}_{k}^{(n)} \quad$ Internal couple vector components exerted onto $n^{\text {th }}$ constituent by the other constituent

$m_{k l} \quad$ Couple stress tensor components of the mixture

$\hat{p}_{k}^{(n)} \quad$ Internal force density vector components exerted onto $n^{\text {th }}$ constituent by the other constituent

$q_{k}^{(n)} \quad$ Heat flux vector components of the $n^{\text {th }}$ constituent

$q_{k} \quad$ Heat flux vector components of the mixture 


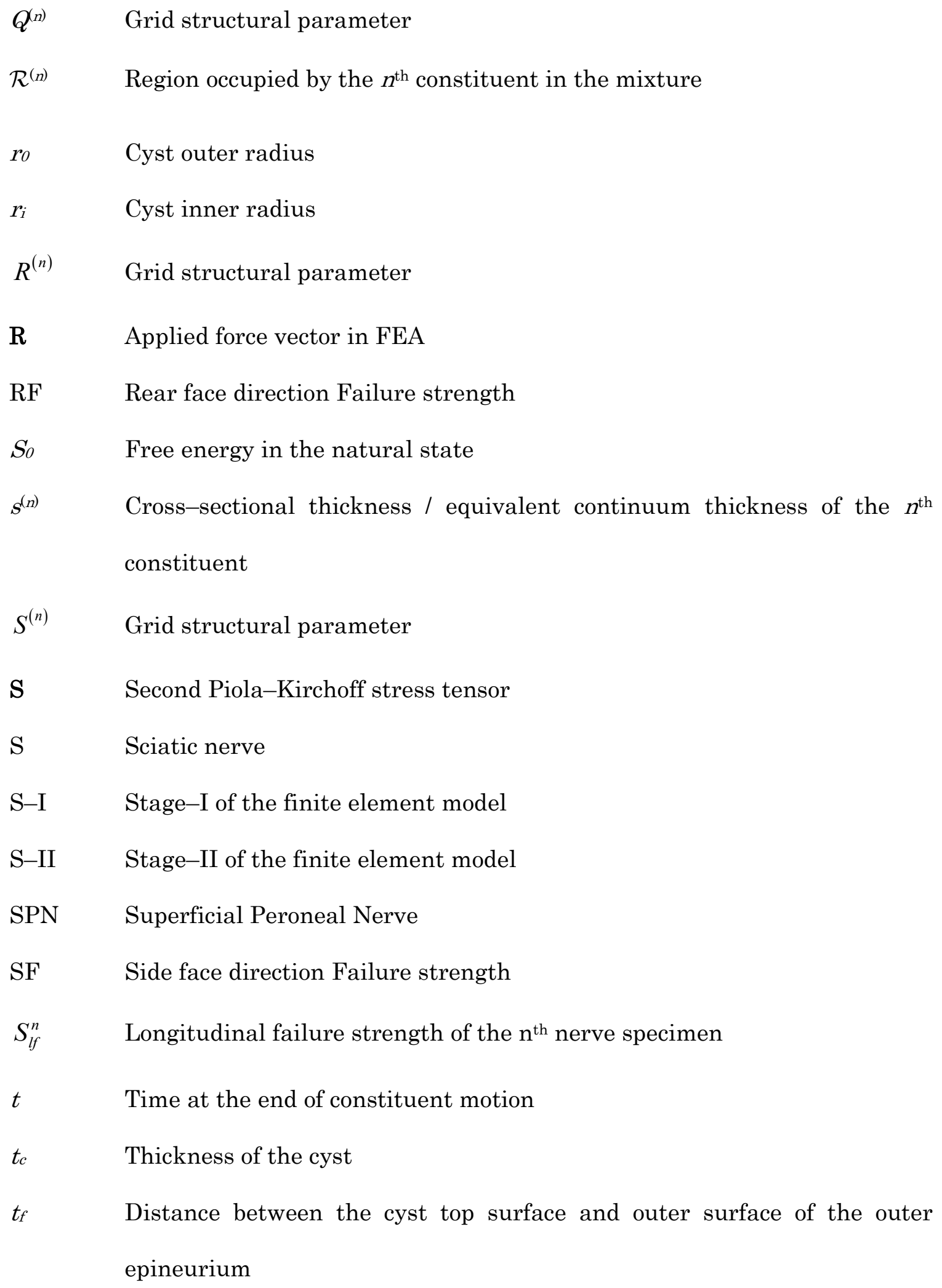




\begin{tabular}{|c|c|}
\hline$t_{k l}^{(n)}$ & Stress tensor components of the $n^{\text {th }}$ constituent \\
\hline$T$ & Change in temperature from ambient temperature \\
\hline$T_{0}$ & Ambient temperature \\
\hline$T^{(n)}$ & Grid structural parameter \\
\hline$t_{k l}$ & Stress tensor components of the mixture \\
\hline$u_{k}^{(n)}$ & Displacement vector components of the $n^{\text {th }}$ constituent \\
\hline$u_{k}$ & Displacement vector components of the mixture \\
\hline $\mathrm{U}$ & Fixed boundary region point \\
\hline $\mathrm{U}$ & Displacement vector in FEA \\
\hline$v_{k}^{(n)}$ & Velocity vector components of the $n^{\text {th }}$ constituent \\
\hline$V_{i}$ & Velocity vector components of the mixture \\
\hline$v_{k}^{(12)}$ & Relative velocity vector components \\
\hline $\mathrm{V}$ & Fixed region boundary point \\
\hline $\mathrm{V}^{(\mathrm{m})}$ & Volume of the $\mathrm{m}^{\text {th }}$ element in FEA model \\
\hline$X_{k}^{(n)}$ & Reference position vector components of the $n^{\text {th }}$ constituent \\
\hline$x_{k}^{(n)}$ & Spatial position vector components of the $n^{\text {th }}$ constituent \\
\hline $\mathrm{X}$ & Point representing $\mathrm{AB}$ end \\
\hline $\mathrm{W}$ & Fixed boundary condition region in stage-I \\
\hline$Y$ & Set of all thermodynamic forces \\
\hline $\mathrm{Z}$ & Fixed boundary condition region in stage-I \\
\hline$\alpha^{(n)}$ & Micropolar elastic constant of the $n^{\text {th }}$ constituent \\
\hline
\end{tabular}


$\alpha \quad$ Failure strength anisotropy ratio

$\beta_{0}^{(n)} \quad$ Thermal expansion constant of the $n^{\text {th }}$ constituent

$\beta^{(n)} \quad$ Micropolar elastic constant of the $n^{\text {th }}$ constituent

$\chi_{k}^{(n)} \quad$ Motion equation components of the $n^{\text {th }}$ constituent

$\Delta l \quad$ Displacement due to a tensile force along a nerve's length

$\delta_{i j} \quad$ Kronecker delta

$\varepsilon_{k l}^{(n)} \quad$ Linear strain tensor components of the $n^{\text {th }}$ constituent

$\delta l_{\text {cyst }} \quad$ Cyst length increase due to cyst propagation

$\delta \theta_{c y s t} \quad$ Cyst arc angle increase due to cyst propagation

$\varepsilon_{i j k} \quad$ Permutation tensor components

$\varepsilon^{(n)} \quad$ Internal energy density of the $n^{\text {th }}$ constituent

$\hat{\varepsilon}^{(n)} \quad$ Energy transferred to $n^{\text {th }}$ constituent from the other constituent

$\varepsilon \quad$ Internal energy density of the mixture

$\varepsilon_{k l} \quad$ Strain tensor components of the mixture

$\phi_{i}^{(n)} \quad$ Microrotation vector components of the $n^{\text {th }}$ constituent

$\Phi \quad$ Dissipation potential

$\phi_{i} \quad$ Microrotation vector components of the mixture

$\gamma_{k l}^{(n)} \quad$ Linear microrotation gradient tensor components of the $n^{\text {th }}$ constituent

$\gamma^{(n)} \quad$ Micropolar elastic constant of the $n^{\text {th }}$ constituent

$\gamma_{k l} \quad$ Linear microrotation gradient tensor components of the mixture

$\eta \quad$ Entropy density of the mixture 
no $\quad$ Entropy density of the mixture in the natural state

$\kappa^{(n)} \quad$ Micropolar elastic constant of the $n^{\text {th }}$ constituent

$\lambda^{(n)} \quad$ Micropolar elastic constant of the $n^{\text {th }}$ constituent

$\lambda \quad$ Stretch along the length of the nerve

$\mu^{(n)} \quad$ Micropolar elastic constant of the $n^{\text {th }}$ constituent

$v^{(n)} \quad$ Poisson's ratio of the equivalent continuum of the $n^{\text {th }}$ constituent

$v \quad$ Poisson's ratio of the mixture

$\theta \quad$ Absolute temperature of the constituents and the mixture

$\theta_{c y s t} \quad$ Angle subtended by the arc of the cyst

$\rho \quad$ Mass density of the mixture

$\rho^{(n)} \quad$ Mass density of the $n^{\text {th }}$ constituent

$\rho_{r e l}^{(n)} \quad$ Relative density of the grid of the $n^{\text {th }}$ constituent

$\sigma \quad$ Cauchy stress tensor

$v_{i}^{(n)} \quad$ Microgyration vector components of the $n^{\text {th }}$ constituent

$v_{k}^{(12)} \quad$ Relative microgyration vector components

$\varpi \quad$ Momentum generation coefficient due to difference in gyrations

$\xi \quad$ Momentum generation coefficient due to velocity difference

$\psi \quad$ Free energy density of the mixture

$\Psi \quad$ Strain energy function of a hyperelastic material

$\zeta \quad$ Heat generation for unit change in velocity 


\section{INTRODUCTION}

The great necessity to understand structural behavior has existed ever since the ancients decided to erect monuments to eulogize, worship or celebrate. It led to the need to perform studies, both experimental and analytical, that has in turn led to some of the greatest architectural wonders of the world. For example, Archimedes (287-212 B.C.) detailed the conditions for equilibrium of levers and methods for calculating the centre of gravity of bodies. These studies helped in the construction of various hoisting devices that helped build the temple of Diana of Ephesus (Timoshenko, 1953). Leonardo da Vinci, considered an outstanding man of the fifteenth century, studied complicated problems in statics and also performed experiments to identify the tensile strength of wires (Timoshenko, 1953). However, it was not until Galileo Galilei documented his experiments on tension and bending of beams that the study of strength of materials is really believed to have arrived.

A watershed moment in the history of structural mechanics was the invention of lighter-than-air flying machines. After the strategic edge they provided to the ground troops in the First World War, these came to be used to transport civilians across cities and continents. It was precisely at this juncture that there began the effort to design materials that were light in weight and yet able to bear the brunt of flight. This ushered the age of composite materials research whose properties could be tailored to have good strength-to-weight and stiffness-to-weight ratios. A composite material consists of two or more materials that are combined to result in a 
new material with properties that represent the better qualities of its constituents (Jones, 1975). The success of the use of composite materials is reflected by their abundant use in the newest generation of civilian and military aircraft (Daniel \& Ishai, 1994).

A specific class of composites is cellular materials. The combination of a structural material and air cells provides for a low-density material with desirable engineering properties such as mechanical durability and porosity. The most readily recognizable cellular material which is also widely prevalent is the honeycomb structure that stores the honey and larvae of bees. Other naturally occurring cellular materials might need a microscope for recognition of their cellular structure. For example, cellular materials like cork, balsa wood, sponge, coral, iris leaf and plant stalks have cell sizes ranging from the micrometer range to a few millimeter (Gibson \& Ashby, 1999). Also, interestingly, foods like bread, meringue, malt balls and cake and biological materials such as cancellous bone and cuttlefish bone have a definite cellular structure (Gibson \& Ashby, 1999). While cellular materials might have humble applications such as the material used in a disposable coffee cup, they also boast of some heady aerospace applications. In particular, honeycomb structures are used in sandwich composites that are heavily used in aerospace structures. Also, metallic foams are used as an energy-absorbing medium for impact in the automobile industry.

Another field of mechanics that has been much researched since the times of Galileo is the field of biomechanics (Fung, 2004). However, until the beginning of the 
twentieth century the practitioners of applied mechanics did not perform research in this area. The role that biomechanics has played in the invention of prosthetic heart valves, heart assist devices, extracorporeal circulation, heart-lung machines and hemo-dialysis machines is significant (Fung, 2004). The mechanics of blood flow plays a crucial role in the identification of stenosis or atherosclerosis in arteries (Fung, 2004). Further, nowhere is the role of biomechanics more pronounced than in the field of orthopedics given that surgeries dealing with musculoskeletal problems outnumber those in other areas (Fung, 2004). Much of the development of prosthesis and implantable materials owes itself to the field of biomechanics.

The subject of this thesis can broadly be considered to be the development and application of novel techniques in applied mechanics to study material behavior with microstructure. Given the great importance that cellular materials occupy in the aerospace and medical fields, an investigation to model their material behavior forms the subject of Chapter 2 of this thesis. Details are provided as to the existing gap in the literature followed by a methodical treatment. This is followed by a section on validating the suggested modeling approach. Chapter 3 discusses the significance of the work done in Chapter 2 and points out some future directions. Chapter 4 focuses on developing a methodology for addressing another important problem, namely, cyst evolution and propagation in nerve tissue. Little is known about the formation and propagation of these cysts, which limits clinical treatment. Chapters 5 and 6 deal with specific studies that are conducted using the frame work developed in Chapter 4. Chapter 7 serves as a concluding chapter for the work done in Chapters 4, 5 and 6. 


\title{
2. CONSTITUTIVE MODELING OF CELLULAR MATERIALS
}

\author{
S. Elangovan, B.S. Altan, G.M. Odegard \\ Michigan Technological University, Houghton MI 49931, USA \\ (Reprinted from Mechanics of Materials, 40(7), Elangovan, S. et. al., An elastic micropolar mixture theory \\ for predicting elastic properties of cellular materials, p. 602-615, 2008, with permission from Elsevier, \\ please refer Appendix-A)
}

\subsection{INTRODUCTION}

Cellular materials have a lattice architecture that in many cases results in high specific stiffness, specific strength, and good thermal insulation properties relative to many engineering materials. Cellular materials have been used in many structural engineering applications, including the core material in composite sandwich panels (Gibson \& Ashby, 1999). The design and implementation of cellular materials relies on accurate and efficient models to relate the lattice microstructure to the bulk mechanical properties.

Cellular materials consist of a complex interconnected framework of either material struts only (open cell foams) or material struts and cell face membranes (closed cell foams) that yields a porous or a closed-cellular material, respectively. For example, the open cell lattice of the polyurethane foam shown in Figure 2.1 has pores and material struts with a range of cell sizes and shapes distributed spatially in the material. This microstructural complexity poses significant problems for accurately modeling the mechanical behavior of cellular materials. 


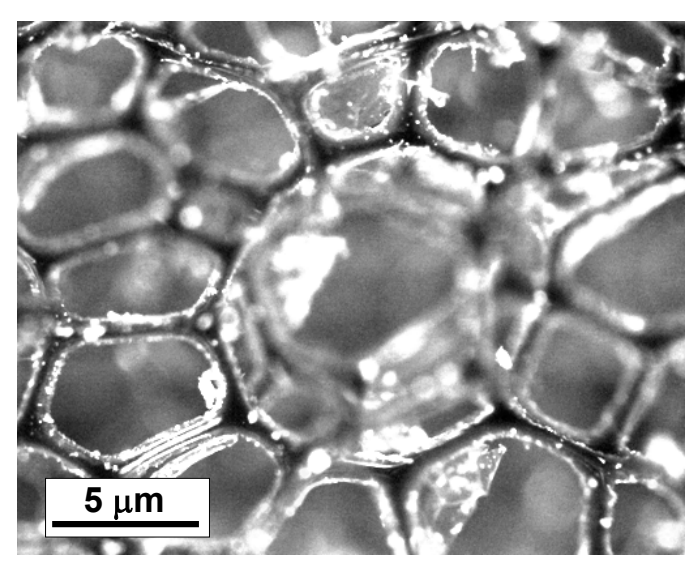

Figure 2.1 Open Cell Polyurethane Foam

Two modeling approaches that have been used to predict the mechanical response of cellular materials are finite element analysis (FEA) and analytical techniques. Numerous studies have been performed to predict the mechanical response of cellular materials using FEA techniques (Kanaun \& Tkachenko, 2006; Li, Gao, \& Subhash, 2006; Roberts \& Garboczi, 2002; Yoo \& Jasiuk, 2006; Zhu, Hobdell, \& Windle, 2000). While this approach has the ability to accurately predict mechanical behavior for a wide range of cellular microstructures, the model building and solution procedures can be time-consuming and expensive, making FEA techniques prohibitive where efficient material design is necessary. Analytical approaches have been developed that are much more efficient than FEA approaches (Gibson \& Ashby, 1999). Although these methods are simple and efficient, they often cannot directly incorporate the microstructural details on non-periodic geometries that are found in a majority of cellular materials without resorting to the use of empirical data. Therefore, there is a need to establish an efficient and accurate modeling approach 
to predict the mechanical response of cellular materials as a function of the random material microstructure.

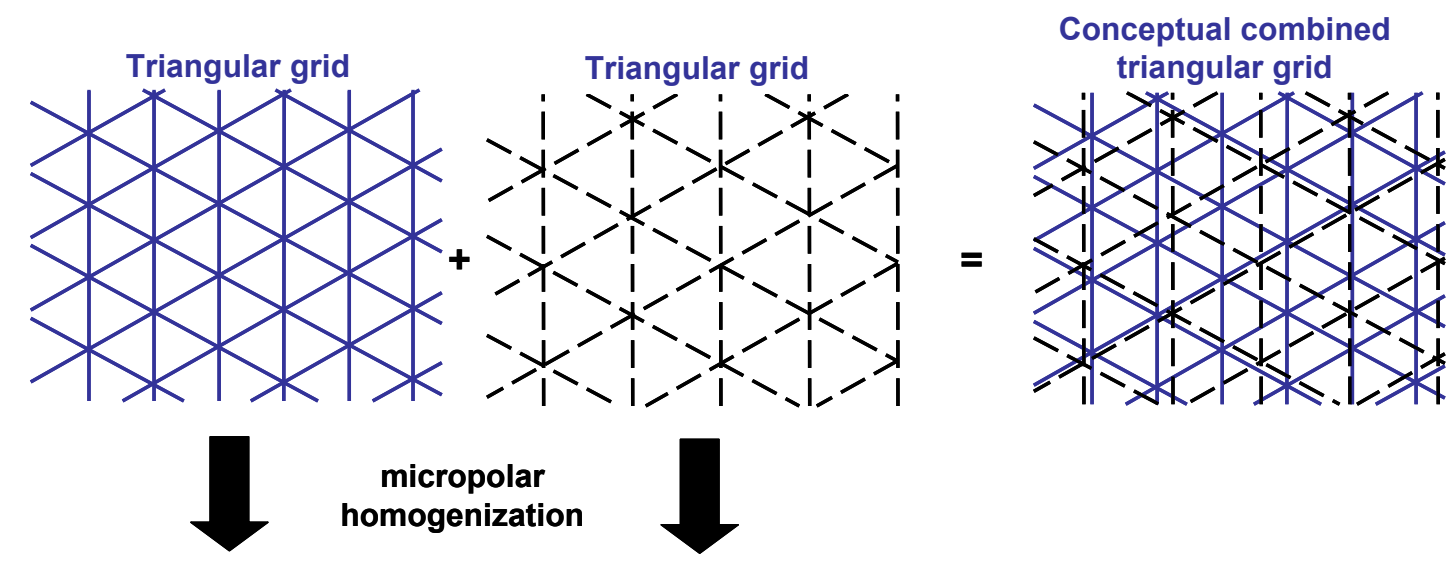

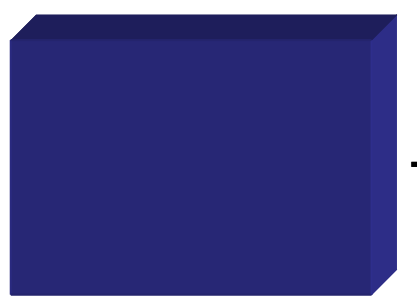

Micropolar constituent

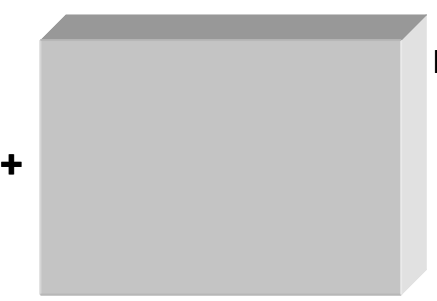

Micropolar constituent

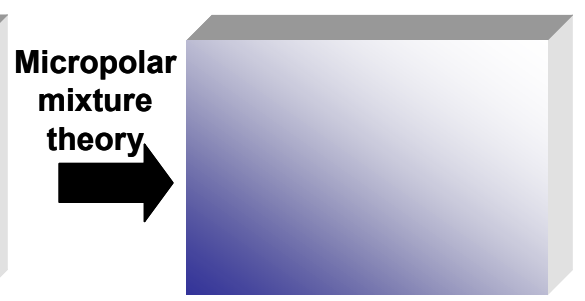

Micropolar mixture

Figure 2.2 Modeling Approach

The objective of this study is to establish a linear-elastic constitutive modeling approach for cellular materials that accounts for distributions of cell size and geometry. The modeling approach consists of two steps. First, two individual lattice geometries with periodic microstructures are modeled as effective micropolar continua. The micropolar elasticity theory is used to enable the effective continua to represent the lattice geometry at the microstructural and bulk-level length scales. An example of this first step is shown in Figure 2.2 for two 2-dimensional triangular grids. In the second step the two effective micropolar continua are combined via 
mixture theory to create a micropolar continuum that effectively models a cellular solid with a distribution of cell geometries, as shown in Figure 2.2.

First, the concepts related to the first step, namely the micropolar homogenization are detailed. Next the schematic of the proposed constitutive theory for a two solid micropolar mixture is outlined, which forms the second step of the homogenization process. Finally the application of the proposed modeling approach to a twodimensional cellular solid is presented.

\subsection{MICROPOLAR HOMOGENIZATION}

\subsubsection{Micropolar Elasticity}

In the theory of micropolar elasticity (Eringen, 1999), the points in a material continuum have six degrees of freedom: three translational components of the classical theory and three rotation components about the coordinate axes. Although the theory of micropolar elasticity has been applied to many fields of engineering, one of its primary uses is to provide a mathematical foundation to describe the mechanical behavior of lattice structures. The micropolar theory is necessary in the analysis of lattice structures because rotations at the strut joints play a significant role in influencing the overall behavior of the lattice at relatively small length scales. For example, a micropolar beam model was developed (Noor \& Nemeth, 1980b) for four different types of planar lattice grids with rigid joints. In a subsequent study (Noor \& Nemeth, 1980a), the model was extended to model three- 
dimensional lattice structures. An energy approach considering in-plane displacements as well as joint rotations was used (Sun \& Yang, 1973) to estimate the dynamic characteristic of a two-dimensional square grid.

\subsubsection{Triangular Lattice Homogenization}

The equivalent micropolar continuum for a single triangular grid composed of Timoshenko beams has been previously established (Ostoja-Starzewski, 2002). In this formulation, given the length of the strut of the $n^{\text {th }}$ constituent $\Lambda^{n}$ ) (Figure 2.3), cross-sectional width and height of the strut of the $n^{\text {th }}$ constituent $s^{(n)}$, the Young's

modulus of the material composing the struts of the $n^{\text {th }}$ constituent $E_{\text {strut }}^{(n)}$, and the shear modulus of the material composing the struts of the $n^{\text {th }}$ constituent $G_{\text {strut }}^{(n)}$, the equivalent in-plane isotropic micropolar elastic moduli for a two-dimensional equivalent continuum of thickness $s^{(n)}$ are

$$
\begin{aligned}
\lambda^{(n)}=\mu^{(n)} & =\frac{3}{8} \frac{Q^{(n)}-R^{(n)}}{S^{(n)}} \\
\kappa^{(n)} & =\frac{3}{2} \frac{R^{(n)}}{s^{(n)}} \\
\gamma^{(n)} & =\frac{3}{2} \frac{S^{(n)}}{S^{(n)}} \\
\alpha^{(n)} & =\beta^{(n)}=0
\end{aligned}
$$

where 


$$
\begin{gathered}
Q^{(n)}=\frac{2 E_{\text {strut }}^{(n)} A^{(n)}}{l^{(n)}(3)^{0.5}} \\
R^{(n)}=\frac{24 E_{\text {strut }}^{(n)} I^{(n)}}{\left[l^{(n)}\right]^{3}(3)^{0.5}} \frac{1}{\left(1+T^{(n)}\right)} \\
S^{(n)}=\frac{2 E_{\text {strut }}^{(n)} I^{(n)}}{l^{(n)}(3)^{0.5}} \\
T^{(n)}=\frac{E_{\text {strut }}^{(n)}\left(s^{(n)}\right)^{2}}{G_{\text {strut }}^{(n)}\left(l^{(n)}\right)^{2}}
\end{gathered}
$$

In Equation (2.2) $A^{(n)}$ and $I^{(n)}$ are the cross-sectional area and moment of inertia of the struts of the $n^{\text {th }}$ constituent, respectively, given by

$$
A^{(n)}=\left[s^{(n)}\right]^{2} \quad I^{(n)}=\frac{\left[s^{(n)}\right]^{4}}{12}
$$

These equations assume a plane state of stress in the plane of the triangular lattice, as shown in Figure 2.3. The relative density of the triangular lattice is (Gibson \& Ashby, 1999)

$$
\rho_{r e l}^{(n)}=2 \sqrt{3} \frac{s^{(n)}}{l^{(n)}}\left[1-\frac{\sqrt{3}}{2} \frac{s^{(n)}}{l^{(n)}}\right]
$$




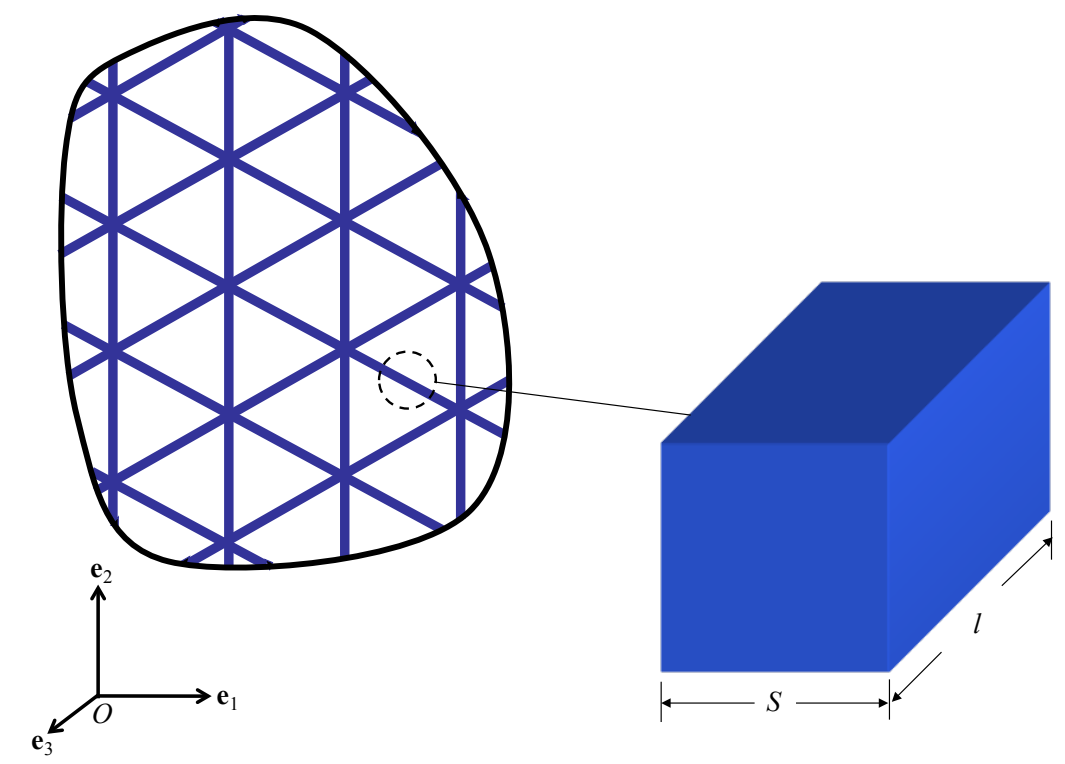

Figure 2.3 Triangular Lattice Strut Dimensions

It is noted that it has been shown (Ostoja-Starzewski, 2002) that for relative densities of $80 \%$ and higher, the strut width becomes too large for Equation (2.1) to accurately predict the elastic properties of the equivalent micropolar continuum.

\subsection{MICROPOLAR MIXTURE HOMOGENIZATION}

\subsubsection{Mixture Theory}

Motivated by Maxwell's kinetic theory of gases, Truesdell and Toupin (Truesdell \& Toupin, 1960) presented an axiomatic mixture theory for interacting continua based on the premise that each point of space is simultaneously occupied by all constituents of the mixture. It has been used with profound success to model the mechanical behavior of composite materials (Bedford \& Stern, 1972; Hegemier, 
Gurtman, \& Nayfeh, 1973; McNiven \& Mengi, 1979a, 1979b, 1979c; Nayfeh \& Gurtman, 1974; Stern \& Bedford, 1972). It is also assumed that the interactions between the constituents of a mixture are accounted for as interaction forces in the appropriate field equations. The mixture theory concept has been used to model the three-dimensional mechanical behavior of a binary mixture (Bedford \& Stern, 1972). In a subsequent study (Stern \& Bedford, 1972), the three-dimensional model predicted wave propagation phenomena in a composite material. It was concluded that in order to accurately predict wave propagation properties in a composite material, the material microstructure must be considered, which can be done with considerable ease by using the elastic mixture theory. An alternative version of the mixture theory was developed (Hegemier et al., 1973) for modeling the wave propagation in laminated and unidirectional fibrous composites. The theory was used to determine the distribution of displacements and stresses within individual constituents. This theory was subsequently applied (Nayfeh \& Gurtman, 1974) for both transversely and horizontally polarized shear waves propagating in the plane of the laminate. A mixture theory was developed (McNiven \& Mengi, 1979a) for twophase materials which was implemented (McNiven \& Mengi, 1979b, 1979c) to study the wave propagation in periodically-structured composites.

\subsubsection{Kinematics}

The following presentation of the kinematic theory of a binary mixture of micropolar solids is similar to that developed for a binary mixture of a solid and fluid previously (Eringen, 2003). Consider regions of two constituents of a mixture $\mathcal{R}^{(1)}$ and $\mathcal{R}^{(2)}$, 
which simultaneously occupy a common volume in the reference configuration (Figure 2.4).

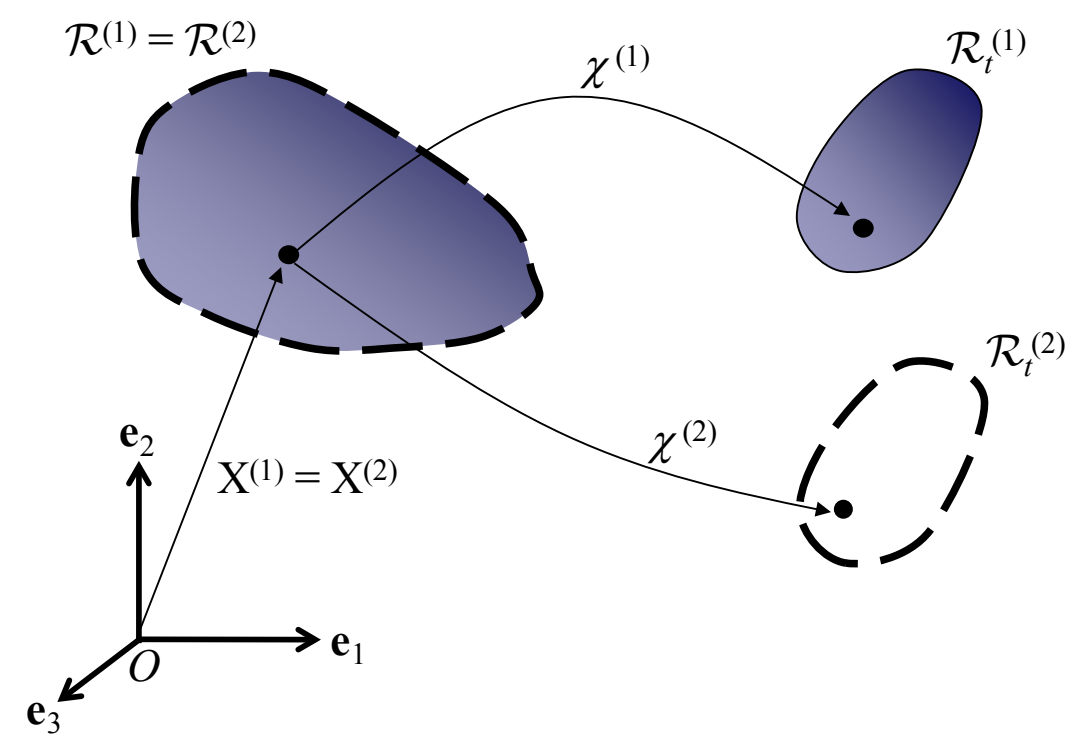

Figure 2.4 Kinematics of the Mixture

A material point of the $n^{\text {th }}$ constituent in the reference configuration has a position denoted by $\mathbf{X}^{(\mathrm{n})}$. After a time $t$, due to a motion denoted by the mapping $\chi^{(n)}$, the position of the point of the $n^{\text {th }}$ constituent in the spatial configuration is given by the motion equation

$$
\mathbf{x}^{(n)}=\chi^{(n)}\left(\mathbf{X}^{(n)}, t\right)
$$

The corresponding velocity and acceleration vector components at time $t$ are given by, respectively, 


$$
\begin{aligned}
& v_{k}^{(n)}=\dot{x}_{k}^{(n)} \\
& a_{k}^{(n)}=\ddot{x}_{k}^{(n)}
\end{aligned}
$$

where the superposed dot denotes the usual material time derivative. The velocity vector components of the mixture are given by

$$
v_{k}=\frac{1}{\rho}\left[\rho^{(1)} v_{k}^{(1)}+\rho^{(2)} v_{k}^{(2)}\right]
$$

where $\rho$ and $\rho^{(n)}$ are the densities of the mixture and the $n^{\text {th }}$ constituent, respectively, and are related by

$$
\rho(x, t)=\rho^{(1)}(x, t)+\rho^{(2)}(x, t)
$$

The linear strain tensor components and the linear microrotation gradient tensor components of the $n^{\text {th }}$ constituent are given by, respectively,

$$
\begin{gathered}
\varepsilon_{k l}^{(n)}=u_{l, k}^{(n)}+\varepsilon_{l k m} \phi_{m}^{(n)} \\
\gamma_{k l}^{(n)}=\phi_{k, l}^{(n)}
\end{gathered}
$$

where $u_{k}^{(n)}$ and $\phi_{k}^{(n)}$ are the displacement and rotation vector components of a point of the $n^{\text {th }}$ constituent and $\varepsilon_{l k m}$ is the permutation symbol. In Equations (2.10) and 
(2.11), and throughout this paper, the usual summation and partial differentiation conventions are used. For the linear theory, the microgyration vector of the $n^{\text {th }}$ constituent is defined as (Eringen, 1999)

$$
v_{k}^{(n)}=\dot{\phi}_{k}^{(n)}
$$

The material derivatives of (2.10) and (2.11) are denoted by

$$
\begin{aligned}
& \dot{\varepsilon}_{k l}^{(n)}=a_{k l}^{(n)} \\
& \dot{\gamma}_{k l}^{(n)}=b_{k l}^{(n)}
\end{aligned}
$$

The motion of the material points of the mixture is influenced by forces and thermodynamic conditions that the mixture is exposed to. The corresponding balance laws are described in the next section.

\subsubsection{Balance Laws}

If it is assumed that microinertia is constant and isotropic, then the remaining balance laws of mass, linear momentum, angular momentum, and energy provide field equations which dictate the kinetic response of the micropolar mixture. Each balance law is individually addressed in this section. The balance laws are similar to those previously proposed by Eringen (Eringen, 2003). 


\subsubsection{Balance of Mass}

The balance of mass for the $n^{\text {th }}$ constituent is given by

$$
\dot{\rho}^{(n)}+\rho^{(n)} v_{k, k}^{(n)}=0
$$

Summing over the two constituents and using Equations (2.8) and (2.9), the balance of mass of the mixture is

$$
\dot{\rho}+\rho v_{k, k}=0
$$

\subsubsection{Balance of Linear Momentum}

The balance of linear momentum for the $n^{\text {th }}$ constituent is

$$
\rho^{(n)} \ddot{x}_{l}^{(n)}=t_{k l, k}^{(n)}+f_{l}^{(n)}+\hat{p}_{l}^{(n)}
$$

where $\ddot{x}_{l}^{(n)}$ is the acceleration of the $n^{\text {th }}$ constituent, $t_{k l}^{(n)}$ are the components of the stress tensor, $f_{l}^{(n)}$ are the components of the body force density vector, and $\hat{p}_{l}^{(n)}$ are the components of the interaction force density vector which represents force exerted on the $n^{\text {th }}$ constituent due to the interaction with the other constituent (terms that represent constituent interactions have the superposed caret). Summing over the two constituents produces the linear momentum balance of the mixture 


$$
\rho^{(1)} \ddot{x}_{l}^{(1)}+\rho^{(2)} \ddot{x}_{l}^{(2)}=t_{k l, k}^{(1)}+t_{k l, k}^{(2)}+f_{l}^{(1)}+f_{l}^{(2)}+\hat{p}_{l}^{(1)}+\hat{p}_{l}^{(2)}
$$

If it is assumed that linear momentum of the mixture is balanced solely by the stresses and body force densities in the constituents then Equation (2.17) becomes

$$
\hat{p}_{k}^{(1)}+\hat{p}_{k}^{(2)}=0
$$

Equation (2.18) indicates that the two interaction force density vectors are of equal magnitude and opposite sign.

\subsubsection{Balance of Angular Momentum}

The balance of angular momentum is given by

$$
\rho^{(n)} j^{(n)} \dot{v}_{l}^{(n)}=m_{k l, k}^{(n)}+\varepsilon_{l m n} t_{m n}^{(n)}+l_{l}^{(n)}+\hat{m}_{l}^{(n)}
$$

where $j^{(n)}$ is the microinertia density (resistance to microrotation), $v_{l}^{(n)}$ is the microgyration (microrotation rate), $m_{k l}^{(n)}$ are the components of the couple stress tensor, $l_{l}^{(n)}$ are the components of the body couple density vector, and $\hat{m}_{l}^{(n)}$ is the components of the interaction couple exerted on the $n^{\text {th }}$ constituent due to interaction with the other constituent. Summing over the two constituents, Equation (2.19) becomes 


$$
\rho^{(1)} j^{(1)} \dot{v}_{l}^{(1)}+\rho^{(2)} j^{(2)} \dot{v}_{l}^{(2)}=m_{k l, k}^{(1)}+m_{k l, k}^{(2)}+\varepsilon_{l m n} t_{m n}^{(1)}+\varepsilon_{l m n} t_{m n}^{(2)}+l_{l}^{(1)}+l_{l}^{(2)}+\hat{m}_{l}^{(1)}+\hat{m}_{l}^{(2)}
$$

If it is assumed that the angular momentum of the mixture is balanced by $m_{k l, k}^{(n)}, t_{m n}^{(n)}$ and $l_{l}^{(n)}$, then Equation (2.20) reveals

$$
\hat{m}_{l}^{(1)}+\hat{m}_{l}^{(2)}=0
$$

Therefore, the interaction couple vectors have equal magnitudes and opposite signs.

\subsubsection{Balance of Energy}

The conservation of energy for the $n^{\text {th }}$ constituent is

$$
\dot{\varepsilon}^{(n)}=t_{k l}^{(n)} a_{k l}^{(n)}+m_{k l}^{(n)} b_{l k}^{(n)}+q_{k, k}^{(n)}+h^{(n)}+\hat{\varepsilon}^{(n)}
$$

where $\varepsilon^{(n)}$ is the internal energy density of the $n^{\text {th }}$ constituent, $q_{k}^{(n)}$ is the heat flux vector, $h^{(n)}$ is the energy source density, and $\hat{\varepsilon}^{(n)}$ denotes the transfer of energy density to the $n^{\text {th }}$ constituent from the other constituent. It has been shown (Eringen, 2003) that by summing Equation (2.22) over the two constituents and utilizing field equations (2.18) and (2.21) the following relationship is established

$$
\dot{\varepsilon}=q_{k, k}+h+t_{k l}^{(1)} a_{k l}^{(1)}+t_{k l}^{(2)} a_{k l}^{(2)}+m_{k l}^{(1)} b_{l k}^{(1)}+m_{k l}^{(2)} b_{l k}^{(2)}-\hat{p}_{k}^{(1)} v_{k}^{(12)}-\hat{m}_{k}^{(1)} v_{k}^{(12)}
$$


where $\varepsilon, h$ and $q_{k}$ are the components of the internal energy density, energy source density and heat flux vector of the mixture, respectively, $v_{k}^{(12)}$ and $v_{k}^{(12)}$ are the components of the relative velocity and relative microgyration vectors, respectively, given by

$$
\begin{aligned}
& v_{k}^{(12)}=v_{k}^{(1)}-v_{k}^{(2)} \\
& v_{k}^{(12)}=v_{k}^{(1)}-v_{k}^{(2)}
\end{aligned}
$$

and

$$
\begin{aligned}
& \varepsilon=\varepsilon^{(1)}+\varepsilon^{(2)} \\
& h=h^{(1)}+h^{(2)}
\end{aligned}
$$

The free energy density of the mixture is defined by

$$
\psi=\varepsilon-\theta \eta
$$

where $\theta$ is the absolute temperature of the constituents and the mixture, and $\eta$ is the entropy density of the mixture. The absolute temperature is assumed to be spatially uniform. Substitution of Equation (2.26) into (2.23) yields

$$
\dot{\psi}+\dot{\theta} \eta+\theta \dot{\eta}=q_{k, k}+h+t_{k l}^{(1)} a_{k l}^{(1)}+t_{k l}^{(2)} a_{k l}^{(2)}+m_{k l}^{(1)} b_{l k}^{(1)}+m_{k l}^{(2)} b_{l k}^{(2)}-\hat{p}_{k}^{(1)} v_{k}^{(12)}-\hat{m}_{k}^{(1)} v_{k}^{(12)}
$$




\subsubsection{Clausius-Duhem inequality}

The second law of thermodynamics is expressed as

$$
\dot{\eta}-\frac{1}{\theta} q_{k, k}+q_{k} \frac{\theta_{, k}}{\theta^{2}}-\frac{1}{\theta} h \geq 0
$$

Substitution of Equation (2.27) into (2.28) yields the Clausius-Duhem inequality

$$
-(\dot{\psi}+\dot{\theta} \eta)+t_{k l}^{(1)} a_{k l}^{(1)}+t_{k l}^{(2)} a_{k l}^{(2)}+m_{k l}^{(1)} b_{l k}^{(1)}+m_{k l}^{(2)} b_{l k}^{(2)}-\hat{p}_{k}^{(1)} v_{k}^{(12)}-\hat{m}_{k}^{(1)} v_{k}^{(12)}+q_{k} \frac{\theta_{, k}}{\theta} \geq 0
$$

\subsubsection{Constitutive Modeling}

The parameters associated with field equations (2.15), (2.18), (2.21), (2.27) and the Clausius-Duhem inequality of Equation (2.29) are related by the constitutive equations. The constitutive independent and dependant variables are the sets $I$ and $D$, respectively, given by

$$
\begin{aligned}
& I=\left(\theta, \varepsilon_{k l}^{(1)}, \varepsilon_{k l}^{(2)}, \gamma_{k l}^{(1)}, \gamma_{k l}^{(2)}, v_{m}^{(12)}, v_{m}^{(12)}\right) \\
& D=\left(\psi, \eta, t_{k l}^{(1)}, t_{k l}^{(2)}, m_{k l}^{(1)}, m_{k l}^{(2)}, q_{m},-\hat{p}_{m}^{(1)},-\hat{m}_{m}^{(1)}\right)
\end{aligned}
$$

All the independent variables are frame-independent except $v_{m}^{(12)}$ and $v_{m}^{(12)}$. The admissibility for using these quantities has been established (Eringen, 2003). The parameters $\rho, \hat{p}_{m}^{(2)}$, and $\hat{m}_{m}^{(2)}$ are uniquely determined by Equations (2.15), (2.18), 
and (2.21), respectively, and thus are not included in sets $I$ and $D$. The free energy density is assumed to be a function of the static independent variables

$$
\psi=\tilde{\psi}\left(\theta, \varepsilon_{k l}^{(1)}, \varepsilon_{k l}^{(2)}, \gamma_{l k}^{(1)}, \gamma_{l k}^{(2)}\right)
$$

where the superposed $\sim$ denotes a response function. Using the chain rule, the material derivative of the free energy is given by

$$
\dot{\psi}=\frac{\partial \tilde{\psi}}{\partial \theta} \dot{\theta}+\frac{\partial \tilde{\psi}}{\partial \varepsilon_{k l}^{(1)}} a_{k l}^{(1)}+\frac{\partial \tilde{\psi}}{\partial \varepsilon_{k l}^{(2)}} a_{k l}^{(2)}+\frac{\partial \tilde{\psi}}{\partial \gamma_{l k}^{(1)}} b_{l k}^{(1)}+\frac{\partial \tilde{\psi}}{\partial \gamma_{l k}^{(2)}} b_{l k}^{(2)}
$$

Substituting Equation (2.32) into Equation (2.29) yields

$$
\begin{aligned}
-\left(\frac{\partial \tilde{\psi}}{\partial \theta}+\eta\right) \dot{\theta}+\left(t_{k l}^{(1)}-\right. & \left.\frac{\partial \tilde{\psi}}{\partial \varepsilon_{k l}^{(1)}}\right) a_{k l}^{(1)}+\left(t_{k l}^{(2)}-\frac{\partial \tilde{\psi}}{\partial \varepsilon_{k l}^{(2)}}\right) a_{k l}^{(2)}+\left(m_{k l}^{(1)}-\frac{\partial \tilde{\psi}}{\partial \gamma_{l k}^{(1)}}\right) b_{l k}^{(1)} \\
& +\left(m_{k l}^{(2)}-\frac{\partial \tilde{\psi}}{\partial \gamma_{l k}^{(2)}}\right) b_{l k}^{(2)}-\hat{p}_{k}^{(1)} v_{k}^{(12)}-\hat{m}_{k}^{(1)} v_{k}^{(12)}+q_{k} \frac{\theta_{, k}}{\theta} \geq 0
\end{aligned}
$$

If Equation (2.33) is to be satisfied for arbitrary values of $\dot{\theta}, a_{k l}^{(n)}$, and $b_{l k}^{(n)}$ then

$$
\eta=-\frac{\partial \tilde{\psi}}{\partial \theta} \quad t_{k l}^{(1)}=\frac{\partial \tilde{\psi}}{\partial \varepsilon_{k l}^{(1)}} \quad t_{k l}^{(2)}=\frac{\partial \tilde{\psi}}{\partial \varepsilon_{k l}^{(2)}} \quad m_{k l}^{(1)}=\frac{\partial \tilde{\psi}}{\partial \gamma_{l k}^{(1)}} \quad m_{k l}^{(2)}=\frac{\partial \tilde{\psi}}{\partial \gamma_{l k}^{(2)}}
$$

Substituting Equation (2.34) back into Equation (2.33) 


$$
-\hat{p}_{m}^{(1)} v_{m}^{(12)}-\hat{m}_{m}^{(1)} v_{m}^{(12)}+q_{m} \frac{\theta_{, m}}{\theta} \geq 0
$$

The inequality of Equation (2.35) implies a set of thermodynamic forces $Y$ and fluxes $J$ (Eringen, 1999) given by

$$
\begin{aligned}
& Y=\left(v_{m}^{(12)}, v_{m}^{(12)}, \frac{\theta_{, m}}{\theta}\right) \\
& J=\left(-\hat{p}_{m}^{(1)},-\hat{m}_{m}^{(1)}, q_{m}\right)
\end{aligned}
$$

Using a similar approach to that used by Eringen (Eringen, 2003) the constitutive equations associated with these quantities are

$$
\begin{aligned}
& \hat{p}_{k}^{(1)}=-\frac{\partial \Phi}{\partial v_{k}^{(12)}} \\
& \hat{m}_{k}^{(1)}=-\frac{\partial \Phi}{\partial v_{k}^{(12)}} \\
& q_{k}=\frac{\partial \Phi}{\partial\left(\theta_{, k} / \theta\right)}
\end{aligned}
$$

where $\Phi$ is the dissipation potential (Eringen, 1999).

The specific free energy of the mixture is 


$$
\begin{aligned}
\psi=S_{0}- & \eta_{0} T-\frac{C_{0}}{2 T_{0}} T^{2}-A_{k l}^{(1)} T \varepsilon_{k l}^{(1)}-A_{k l}^{(2)} T \varepsilon_{k l}^{(2)}-B_{k l}^{(1)} T \gamma_{k l}^{(1)}-B_{k l}^{(2)} T \gamma_{k l}^{(2)} \\
+ & \frac{1}{2}\left(A_{k l m n}^{(1)} \varepsilon_{k l}^{(1)} \varepsilon_{m n}^{(1)}+B_{k l m n}^{(1)} \gamma_{k l}^{(1)} \gamma_{m n}^{(1)}+2 C_{k l m n}^{(1)} \varepsilon_{k l}^{(1)} \gamma_{m n}^{(1)}\right) \\
+ & \frac{1}{2}\left(A_{k l m n}^{(2)} \varepsilon_{k l}^{(2)} \varepsilon_{m n}^{(2)}+B_{k l m n}^{(2)} \gamma_{k l}^{(2)} \gamma_{m n}^{(2)}+2 C_{k l m n}^{(2)} \varepsilon_{k l}^{(2)} \gamma_{m n}^{(2)}\right)
\end{aligned}
$$

where the subscript 0 denotes constants or variables in their natural state, that is, a state that is free of stress and couple stress. $S_{0}$ is the free energy in the natural state, $C_{0}$ is a constant relating temperature and free energy in the natural state, $T_{0}$ is the ambient temperature, $T$ is the change in ambient temperature resulting in the current temperature $\theta\left(\theta=T_{0}+T\right.$, where $|T|$ is much less than $\left.T_{0}, T_{0}>0\right)$, and $A_{k l}^{(n)}, B_{k l}^{(n)}, A_{k l m n}^{(n)}, B_{k l m n}^{(n)}, C_{k l m n}^{(n)}$ are material moduli. The dissipation potential of the mixture is given by

$$
2 \Phi=\xi v_{k}^{(12)} v_{k}^{(12)}+2 \zeta v_{k}^{(12)} \frac{\theta_{, k}}{\theta}+K \frac{\theta_{, k} \theta_{, k}}{\theta^{2}}+\varpi v_{k}^{(12)} v_{k}^{(12)}
$$

where $\xi$ is the momentum generation coefficient due to velocity difference, $\zeta$ is the heat generation for unit change in velocity, $K$ is the classical Fourier constant, and $\varpi$ is the momentum generation due to difference in gyrations. The linear constitutive equations are obtained by substituting (2.38) and (2.39) into (2.34) and $(2.37)$ 


$$
\begin{aligned}
& \eta=\eta_{0}+\frac{C_{0}}{T_{0}} T+A_{k l}^{(1)} \varepsilon_{k l}^{(1)}+B_{k l}^{(1)} \gamma_{k l}^{(1)}+A_{k l}^{(2)} \varepsilon_{k l}^{(2)}+B_{k l}^{(2)} \gamma_{k l}^{(2)} \\
& t_{k l}^{(n)}=-A_{k l}^{(n)} T+A_{k l m n}^{(n)} \varepsilon_{m n}^{(n)}+C_{k l m n}^{(n)} \gamma_{m n}^{(n)} \\
& m_{k l}^{(n)}=-B_{k l}^{(n)} T+B_{l k m n}^{(n)} \gamma_{m n}^{(n)}+C_{k l m n}^{(n)} \varepsilon_{m n}^{(n)} \\
& \hat{p}_{k}^{(1)}=-\xi v_{k}^{(12)}-\zeta \frac{T_{, k}}{T_{0}} \\
& \hat{m}_{k}^{(1)}=-\varpi v_{k}^{(12)} \\
& q_{k}=\zeta v_{k}^{(12)}+K \frac{T_{, k}}{T_{0}}
\end{aligned}
$$

For isotropic constituents (Eringen, 1999)

$$
\begin{aligned}
& B_{k l}^{(n)}=0_{k l} \\
& C_{k l m n}^{(n)}=0_{k l m n} \\
& A_{k l}^{(n)}=\beta_{0}^{(n)} \delta_{k l} \\
& A_{k l m n}^{(n)}=\lambda^{(n)} \delta_{k l} \delta_{m n}+\left[\mu^{(n)}+\kappa^{(n)}\right] \delta_{k m} \delta_{l n}+\mu^{(n)} \delta_{k n} \delta_{l m} \\
& B_{k l m n}^{(n)}=\alpha^{(n)} \delta_{k l} \delta_{m n}+\beta^{(n)} \delta_{k n} \delta_{l m}+\gamma^{(n)} \delta_{k m} \delta_{l n}
\end{aligned}
$$

where $0_{k l}$ and $0_{k l m n}$ are the components of the second- and fourth-order null tensors, respectively; $\alpha^{(n)}, \beta^{(n)}, \gamma^{(n)}, \lambda^{(n)}, \mu^{(n)}, \kappa^{(n)}$ are the six micropolar elastic constants; and $\beta_{0}^{(n)}$ is a thermal expansion constant for determining micropolar isotropic behavior. Substitution of Equation (2.41) into Equation (2.40) yields

$$
\eta=\eta_{0}+\frac{C_{0}}{T_{0}} T+\beta_{0}^{(1)} \varepsilon_{k k}^{(1)}+\beta_{0}^{(2)} \varepsilon_{k k}^{(2)}
$$




$$
\begin{gathered}
t_{k l}^{(n)}=\left[-\beta_{0}^{(n)} T+\lambda^{(n)} \varepsilon_{m m}^{(n)}\right] \delta_{k l}+\left[\mu^{(n)}+\kappa^{(n)}\right] \varepsilon_{k l}^{(n)}+\mu^{(n)} \varepsilon_{l k}^{(n)} \\
m_{k l}^{(n)}=\alpha^{(n)} \delta_{k l} \gamma_{m m}^{(n)}+\beta^{(n)} \gamma_{l k}^{(n)}+\gamma^{(n)} \gamma_{k l}^{(n)} \\
\hat{p}_{k}^{(1)}=-\xi v_{k}^{(12)}-\zeta \frac{T_{, k}}{T_{0}} \\
\hat{m}_{k}^{(1)}=-\varpi v_{k}^{(12)} \\
q_{k}=\zeta v_{k}^{(12)}+K \frac{T_{, k}}{T_{0}}
\end{gathered}
$$

Equation (2.42) - (2.47) describes the constitutive response of the constituents, the entropy density of the mixture, the interaction parameters, and the mixture heat flux vector. The overall behavior of the constituents is governed by the constitutive response as well as the balance equations discussed in Section 4. Substitution of Equations (2.42) - (2.47) into Equations (2.16), (2.19), and (2.27) yield, respectively,

$$
\begin{gathered}
\rho^{(1)} \ddot{x}_{l}^{(1)}-\lambda^{(1)} \varepsilon_{m m, l}^{(1)}-\left[\mu^{(1)}+\kappa^{(1)}\right] \varepsilon_{k l, k}^{(1)}-\mu^{(1)} \varepsilon_{l k, k}^{(1)}+\xi v_{l}^{(12)}=0 \\
\rho^{(2)} \ddot{x}_{l}^{(2)}-\lambda^{(2)} \varepsilon_{m m, l}^{(2)}-\left[\mu^{(2)}+\kappa^{(2)}\right] \varepsilon_{k l, k}^{(2)}-\mu^{(2)} \varepsilon_{l k, k}^{(2)}-\xi v_{l}^{(12)}=0 \\
\rho^{(1)} \dot{j}^{(1)} \dot{v}_{l}^{(1)}-\alpha^{(1)} \gamma_{m m, l}^{(1)}-\beta^{(1)} \gamma_{k l, k}^{(1)}-\gamma^{(1)} \gamma_{l k, k}^{(1)} \\
-\varepsilon_{l m n}\left[\left(\mu^{(1)}+\kappa^{(1)}\right) \varepsilon_{m n}^{(1)}+\mu^{(1)} \varepsilon_{m m}^{(1)}\right]+\varpi v_{l}^{(12)}=0 \\
\rho^{(2)} j^{(2)} \dot{v}_{l}^{(2)}-\alpha^{(2)} \gamma_{m m, l}^{(2)}-\beta^{(2)} \gamma_{k l, k}^{(2)}-\gamma^{(2)} \gamma_{l k, k}^{(2)} \\
-\varepsilon_{l m n}\left[\left(\mu^{(2)}+\kappa^{(2)}\right) \varepsilon_{m n}^{(2)}+\mu^{(2)} \varepsilon_{n m}^{(2)}\right]-\varpi v_{l}^{(12)}=0 \\
\zeta v_{k, k}^{(12)}-\hat{p}_{k}^{(1)} v_{k}^{(12)}-\hat{m}_{k}^{(1)} v_{k}^{(12)}-T \beta_{0}^{(1)} a_{k k}^{(1)}-T \beta_{0}^{(2)} a_{k k}^{(2)}=0
\end{gathered}
$$


where isothermal conditions are assumed and body force densities, body couple densities, heat source densities, and temperature gradients have been neglected.

\subsection{MICROPOLAR MIXTURE OF TRIANGULAR}

\section{LATTICES}

Consider the case of the equivalent micropolar continuum loaded in uniaxial tension parallel to the $\mathbf{e}_{1}$ basis vector shown in Figure 2.3, in which the strains are

$$
\varepsilon_{11}^{(n)} \quad \varepsilon_{22}^{(n)}=\varepsilon_{33}^{(n)} \quad \varepsilon_{23}^{(n)}=\varepsilon_{13}^{(n)}=\varepsilon_{12}^{(n)}=0
$$

where $\varepsilon_{11}^{(n)}$ is the applied uniaxial strain. The transverse stresses are

$$
t_{22}^{(n)}=t_{33}^{(n)}=0
$$

The in-plane Young's modulus $E^{(n)}$ and the Poisson's ratio ${ }^{(n)}$ of the $n^{\text {th }}$ constituent are defined as, respectively,

$$
\begin{gathered}
E^{(n)} \equiv \frac{t_{11}^{(n)}}{\varepsilon_{11}^{(n)}} \\
v^{(n)} \equiv-\frac{\varepsilon_{22}^{(n)}}{\varepsilon_{11}^{(n)}}
\end{gathered}
$$


Isothermal conditions are assumed. Substitution of Equation (2.51) into the $t_{11}^{(n)}$ component of Equation (2.43) yields

$$
t_{11}^{(n)}=\left[2 \lambda^{(n)} \frac{\varepsilon_{22}^{(n)}}{\varepsilon_{11}^{(n)}}+2 \mu^{(n)}+\kappa^{(n)}\right] \varepsilon_{11}^{(n)}
$$

Substituting Equations (2.51) and (2.52) into the $t_{22}^{(n)}$ component of Equation (2.43)

$$
t_{22}^{(n)}=0=\lambda^{(n)} \varepsilon_{11}^{(n)}+\left[2 \mu^{(n)}+2 \lambda^{(n)}+\kappa^{(n)}\right] \varepsilon_{22}^{(n)}
$$

Substitution of Equations (2.55) and (2.56) into (2.53) establishes the Young's modulus of the equivalent continuum of the $n^{\text {th }}$ constituent

$$
E^{(n)}=\frac{\left(2 \mu^{(n)}+\kappa^{(n)}\right)\left(3 \lambda^{(n)}+2 \mu^{(n)}+\kappa^{(n)}\right)}{2 \lambda^{(n)}+2 \mu^{(n)}+\kappa^{(n)}}
$$

Substitution of Equation (2.56) into (2.54) provides

$$
v^{(n)}=\frac{\lambda^{(n)}}{2 \mu^{(n)}+2 \lambda^{(n)}+\kappa^{(n)}}
$$


Now consider the case of pure shear in the $\mathbf{e}_{1}-\mathbf{e}_{2}$ plane of the equivalent micropolar continuum. Again, isothermal conditions are assumed to exist. The corresponding strain field is

$$
\varepsilon_{12}^{(n)}=\varepsilon_{21}^{(n)}=\gamma \quad \varepsilon_{11}^{(n)}=\varepsilon_{22}^{(n)}=\varepsilon_{33}^{(n)}=\varepsilon_{13}^{(n)}=\varepsilon_{23}^{(n)}=0
$$

where $\gamma$ is the engineering shear strain. The in-plane shear modulus of the equivalent continuum of the $n^{\text {th }}$ constituent is defined as

$$
G^{(n)} \equiv \frac{t_{12}^{(n)}}{2 \varepsilon_{12}^{(n)}}
$$

Substitution of Equation (2.59) into (2.43) for the 1-2 component of stress

$$
G^{(n)}=\mu^{(n)}+\frac{\kappa^{(n)}}{2}
$$

It is noted that Equations (2.57), (2.58), and (2.61) are consistent with those reported elsewhere (Eringen, 1999; Gauthier \& Jahsman, 1975, 1976; Nowacki, 1974).

Although the constitutive and field equations govern the response of the micropolar mixture, the nature of the interactions, as represented by $\hat{p}_{k}^{(1)}$ and $\hat{m}_{k}^{(1)}$ have yet to be determined. For simplicity, it is assumed here that 


$$
\begin{aligned}
& u_{k}=u_{k}^{(1)}=u_{k}^{(2)} \\
& \phi_{k}=\phi_{k}^{(1)}=\phi_{k}^{(2)}
\end{aligned}
$$

Therefore

$$
\begin{array}{ll}
\varepsilon_{k l}=\varepsilon_{k l}^{(1)}=\varepsilon_{k l}^{(2)} & a_{k l}=a_{k l}^{(1)}=a_{k l}^{(2)} \\
\gamma_{k l}=\gamma_{k l}^{(1)}=\gamma_{k l}^{(2)} & b_{k l}=b_{k l}^{(1)}=b_{k l}^{(2)}
\end{array}
$$

where $u_{\mathrm{k}}, \phi_{\mathrm{k}}, \varepsilon_{\mathrm{kl}}, \gamma_{\mathrm{kl}}, a \mathrm{kl}$, and $b_{\mathrm{kl}}$ are the kinematic quantities associated with the mixture. Hence by virtue of Equation (2.62) and in the absence of temperature gradients

$$
v_{k}^{(12)}=\hat{p}_{k}^{(1)}=0_{k} \quad v_{k}^{(12)}=\hat{m}_{k}^{(1)}=0_{k}
$$

The elastic mixture theory assumes that the stress $t_{\mathrm{ij}}$ and couple stress $m_{\mathrm{ij}}$ of the mixture are given by

$$
\begin{gathered}
t_{i j}=f^{(1)} t_{i j}^{(1)}+f^{(2)} t_{i j}^{(2)} \\
m_{i j}=f^{(1)} m_{i j}^{(1)}+f^{(2)} m_{i j}^{(2)}
\end{gathered}
$$

where $f^{(1)}$ and $f^{(2)}$ are the volume fractions of constituents 1 and 2 , respectively, in the mixture. For the binary mixture considered in this study $f^{(1)}+f^{(2)}=1$. 
The assumptions of Equations (2.62) and (2.65) are the simplest assumptions for the interaction of the constituents. In fact, Equations (2.62) implies that no internal interactions exist between the micropolar continua. A possible physical interpretation of this assumption with regards to the conceptual combined triangular grid shown in Figure 2.2 is that there are no locations in which the two grids are bonded together. If on the other hand, the grids are "welded" at their junction points, then the assumption of Equation (2.62) must be modified appropriately.

Consider again the uniaxial deformation described by Equations (2.51) and (2.52). If the same deformation field (here $\varepsilon_{\mathrm{ij}}$ are the components of strain of the mixture) is applied to the binary mixture, the Young's modulus $E$ and Poisson's ratio $v$ of the mixture are, respectively,

$$
\begin{gathered}
E \equiv \frac{t_{11}}{\varepsilon_{11}} \\
v \equiv-\frac{\varepsilon_{22}}{\varepsilon_{11}}
\end{gathered}
$$

Substitution of Equations (2.57) and (2.65) $)_{1}$ into (2.66) reveals 


$$
\begin{aligned}
E=f^{(1)} E^{(1)}+f^{(2)} E^{(2)} & \\
=f^{(1)} \frac{\left(2 \mu^{(1)}+\kappa^{(1)}\right)\left(3 \lambda^{(1)}+2 \mu^{(1)}+\kappa^{(1)}\right)}{2 \lambda^{(1)}+2 \mu^{(1)}+\kappa^{(1)}} & \\
& +f^{(2)} \frac{\left(2 \mu^{(2)}+\kappa^{(2)}\right)\left(3 \lambda^{(2)}+2 \mu^{(2)}+\kappa^{(2)}\right)}{2 \lambda^{(2)}+2 \mu^{(2)}+\kappa^{(2)}}
\end{aligned}
$$

Since the normal strains in the constituents are equal to those in the mixture, Equation (2.58) is equal to Equation (2.67)

$$
\begin{aligned}
v & =v^{(1)}=v^{(2)} \\
& =\frac{\lambda^{(1)}}{2 \mu^{(1)}+2 \lambda^{(1)}+\kappa^{(1)}}=\frac{\lambda^{(2)}}{2 \mu^{(2)}+2 \lambda^{(2)}+\kappa^{(2)}}
\end{aligned}
$$

When the strain field described by Equation (2.59) is applied to the mixture for the case of pure shear, the shear modulus of the mixture $G$ is

$$
G \equiv \frac{t_{12}}{2 \varepsilon_{12}}
$$

Substitution of Equations (2.60), (2.61), and (2.65) 1 into (2.70)

$$
G=f^{(1)} G^{(1)}+f^{(2)} G^{(2)}=f^{(1)}\left[\mu^{(1)}+\frac{\kappa^{(1)}}{2}\right]+f^{(2)}\left[\mu^{(2)}+\frac{\kappa^{(2)}}{2}\right]
$$

In a similar manner, the micropolar moduli of the mixture can be determined. 


\subsection{EXPERIMENTAL VALIDATION}

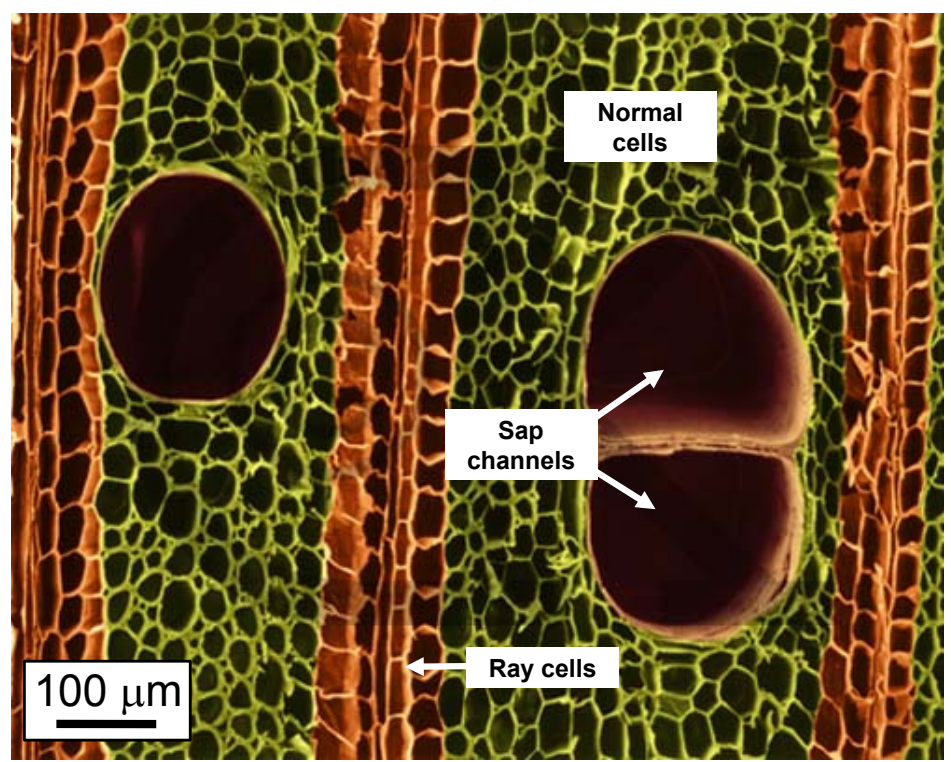

Figure 2.5 SEM Image of a Longitudinal Cross-Section of Balsa Wood (Image copyright Dennis Kunkel Microscopy, Inc., printed with permission, see Appendix-A)

The constitutive framework developed in Section 2.3.4 is for a general mixture of two micropolar elastic solids. To demonstrate the application of the proposed theory, the constitutive response of a two-dimensional cellular material with a distribution of cell sizes is determined. Such material structures are found in many varieties of wood. For example, the microstructure of a cross-sectional slice of balsa wood is shown in Figure 2.5. To determine the constitutive response of this twodimensional natural cellular material, its cell size distribution is matched with the cell size distribution of the conceptual combined triangular grid (Figure 2.2). The conceptual triangular grid, which then represents the microstructure in Figure 2.5, is homogenized in two steps, namely, the micropolar homogenization step in which each individual grid is converted to an effective micropolar continuum and the 
micropolar mixture theory homogenization step where the individual micropolar continua are superimposed using the micropolar mixture theory. This yields the equivalent continuum whose mechanical behavior represents the mechanical behavior of the natural two-dimensional cellular material. It is important to note that since the micropolar mixture theory combines two equivalent micropolar continua and not the individual lattices, the model does not directly model the conceptual combined triangular grid shown at the top of Figure 2.2. In the current section, the micropolar homogenization of a single triangular grid is discussed followed by the details of the micropolar mixture theory homogenization and the resulting constitutive response of the mixture.

\subsubsection{Application of Model to Balsa Wood}

A cross sectional slice of balsa wood closely approximates a two-dimensional cellular structure with a distribution of cell sizes. Figure 2.5, which is an image of an axial cross-section of balsa wood, shows three types of cells. Most of the volume is occupied by nearly hexagonal normal cells, with parallel bands of rectangular ray cells. The larger sap cells occupy a much smaller volume than the normal and ray cells over the entire cross section (Figure 2.5 is focused on an area crowded with sap cells), thus their relative volume fraction is insignificant compared to those of the normal and ray cells.

A binary mixture model was constructed in which the $1^{\text {st }}$ and $2^{\text {nd }}$ constituents were the equivalent continua of the normal and ray cells, respectively. The structural and 
mechanical parameters for the two lattices are shown in Table 2.1. The values of $s^{(n)}$, $E^{(n)}$, and $f^{n}$ were previously determined by Easterling et al. (Easterling, Harrysson, Gibson, \& Ashby, 1982). The values of $X^{(n)}$ were determined by equating the average cell areas reported by Easterling et al. (Easterling et al., 1982) with triangular cell areas for the triangular lattice. The values of $G^{(n)}$ were calculated assuming a cell wall Poisson's ratio of 0.33 .

\begin{tabular}{ccc}
\hline & Normal Cells & Ray Cells \\
\hline$n$ & 1 & 2 \\
$S^{(n)}$ & $1.5 \mu \mathrm{m}$ & $1.5 \mu \mathrm{m}$ \\
$x^{(n)}$ & $44 \mu \mathrm{m}$ & $29 \mu \mathrm{m}$ \\
$f^{(n)}$ & $86 \%$ & $14 \%$ \\
$E_{\text {strut }}^{(n)}$ & $10 \mathrm{GPa}$ & $10 \mathrm{GPa}$ \\
$G_{\text {strut }}^{(n)}$ & $3.8 \mathrm{GPa}$ & $3.8 \mathrm{GPa}$
\end{tabular}

Table 2.1 Properties of Equivalent Lattices of Balsa Wood

Using Equations (2.1) - (2.3), (2.57), (2.58), (2.61), (2.68), (2.69), and (2.71), the inplane Young's modulus, Poisson's ratio, and shear modulus of balsa wood were predicted to be $376 \mathrm{MPa}, 0.25$, and $150 \mathrm{MPa}$, respectively. Experimental measurements of in-plane Young's modulus of balsa wood range from $10-300 \mathrm{MPa}$ (Easterling et al., 1982). Therefore, the predicted Young's modulus is in reasonable agreement with the empirical value. The model did not take into consideration the 
presence of sap channels and imperfections in the material, which may explain slight overestimate of the predicted properties. Of course, more constituents can be added to the model to account for these structural effects, if a more accurate prediction is needed.

\subsection{SUMMARY}

An analytical modeling approach has been developed to predict the elastic properties of cellular materials without the need for complex and inefficient FEA modeling. The modeling approach directly accounts for the distribution of cell geometries that are present in most cellular materials. The approach combines mixture theory and micropolar elasticity theory to predict elastic response of cellular materials to a wide range of loading conditions. The modeling approach was applied to the twodimensional balsa wood material. Predicted properties were in good agreement with experimentally-determined properties. This agreement demonstrates that the model has the potential to predict the elastic response of other cellular solids, such as open cell and closed cell foams. 


\section{CONSTITUTIVE MODELING OF OPEN CELL FOAMS - CONCLUSIONS}

\subsection{RESEARCH SIGNIFICANCE}

A novel two step analytical technique has been suggested for predicting the behavior of cellular materials. The method unlike previous analytical models demonstrates the ability to incorporate material microstructure. FEA studies of cellular materials tend to be accurate but time consuming and computationally intensive. This analytical technique provides a simpler and yet accurate method for studying cellular material behavior. The second step of the homogenization which outlines the micropolar mixture homogenization is very general. This is indeed applicable to any two micropolar solids, not just this case. While mentioning significance, it is important to note the capabilities of the mixture theory. In a fiber-reinforced composite material it has been shown to account for the interaction between the fiber and the matrix at the interface (Bedford \& Stern, 1972). This is an example of a mechanical interaction. Another advantage of using the mixture theory is its ability to represent the dynamic behavior of materials. Stern et. al. (Stern \& Bedford, 1972) studied elastic wave propagation in a laminate using mixture theory. They were able to predict wave properties like attenuation and dispersion which the classical theory could not. The first step to studying dynamic behavior is to establish a constitutive equation; the constitutive equation designed in this study can form a platform for such a dynamic study. 


\subsection{FUTURE WORK}

Levels of complexity can be added to the homogenization process to improve predictions. The two stages of the homogenization processes allow flexibility for making changes. For example, in the first stage of the homogenization process a hexagonal grid formulation may be used. The hexagonal grid will more closely approximate the normal cells of balsa wood. To add another level of complexity, cell size randomness in each individual grid may be considered. This will help represent the cell size randomness at the individual grid level itself. However, a homogenization for such a grid has to be established using available techniques (Nemat-Nasser \& Hori, 1993) first. The constitutive equation designed in this study may be used to study the propagation of waves in a cellular material. This will eventually have important applications in studying the porosity of a cellular material using wave propagation e.g. ultrasound testing of bone. 


\title{
4. FINITE ELEMENT MODELING OF INTRANEURAL GANGLION CYSTS
}

\author{
Shreehari Elangovan, Gregory Odegard, \\ Michigan Technological University, Houghton, MI 49931, USA \\ Duane Morrow, Huan Wang, Marie-Noëlle Hébert-Blouin and Robert \\ Spinner, MI, USA \\ Mayo Clinic, Rochester, MN 55905, USA
}

(Material in section 4.1.3, reprinted from Neurosurgical Focus, 26(2), Elangovan, S. et. al., Intraneural Ganglia: A Clinical Problem Deserving A Mechanistic Explanation and Model, Article Number-E11, 2009, with permission from the American Association of Neurosurgeons, please refer Appendix-A)

\subsection{INTRODUCTION}

Intraneural ganglion cysts (IGC) have remained curiosities for centuries in the clinical world. They occur most commonly in the nerves of the lower leg, but have been described in many nerves in the vicinity of joints. Their occurrence can lead to neuropathy, which can lead to muscle weakness, sensory abnormalities and pain. When IGC occur at their most common site of occurrence in the human body namely the common peroneal nerve, they can lead to a condition called 'foot drop'. Foot drop is characterized by the inability of the patient to dorsiflex the foot. If they remain undetected, they can spread to nearby nerve branches and cause further problems. Not understanding the root cause of these cysts can cause recurrence of these cysts after initial medical treatment/surgery. This means that the symptoms associated with their occurrence will persist. Effective patient treatment strategies will greatly depend on how well clinicians understand the pathogenesis of these cysts. The aim 
of the study in this chapter is to investigate the pathogenesis of IGC using a computational tool called finite element analysis (FEA).

\subsubsection{Normal Nerve Anatomy}

The cross section of a nerve is shown in Figure 4.1 (Spinner, Amrami, et al., 2007). The following information about nerve constituents was obtained from Sunderland et al. (Sunderland \& Bradley, 1961) and Topp et al. (Topp \& Boyd, 2006). The outer epineurium is the outermost sheath of the nerve which is composed primarily of connective tissue and serves to encase the nerve contents. Filling the inner cavity of the outer epineurium is the inner epineurium, which is composed of loose connective tissue. Embedded in the inner epineurium are fascicles, which are bundles of axons. Axons are nerve fibers that conduct electrical impulses between the brain and the muscles. The inner epineurium cushions individual nerve fascicles. The fascicles are capable of extending and contracting longitudinally during normal nerve function. A frequent site of IGC in the peripheral nervous system is the common peroneal nerve (CPN) (Spinner, Atkinson, Scheithauer, et al., 2003), which originates from the sciatic nerve (S) as shown in Figure 4.2 (Spinner, Atkinson, Tiel, \& Tn, 2003). At the fibular neck, the CPN branches into the articular branch $(\mathrm{AB})$, the deep peroneal nerve (DPN) and the superficial peroneal nerve (SPN). The superior tibiofibular joint is formed at the meeting point between the tibia and the fibula, just below the knee joint. It is encapsulated by a capsule containing synovial fluid which is generated by the synovium of the joint that lubricates the contact between the tibia and fibula. 


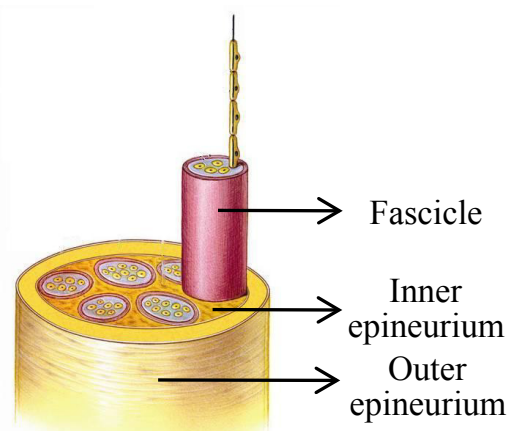

Figure 4.1 Nerve Structure

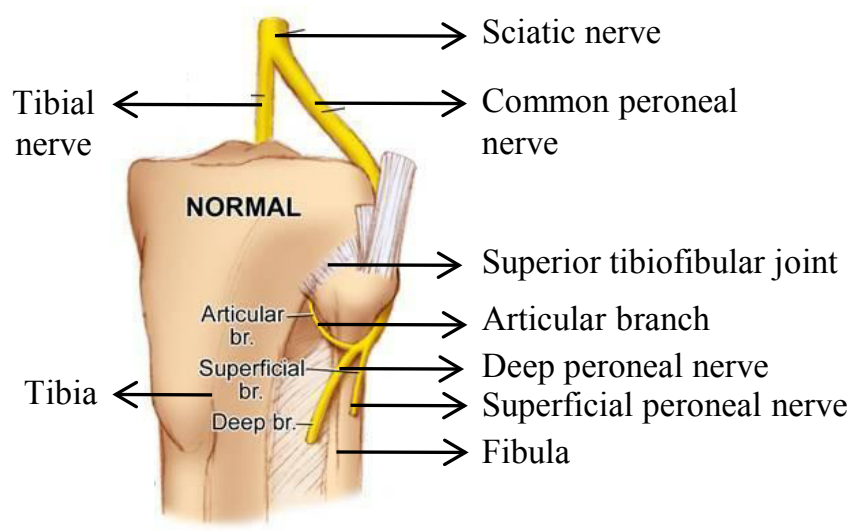

Figure 4.2 Superior Tibiofibular Joint Anatomy

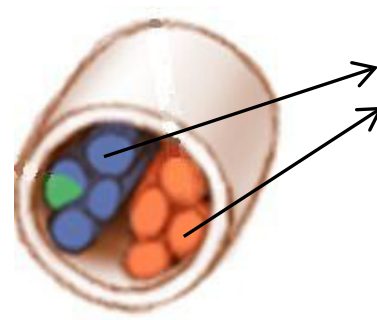

a. Normal nerve
Normal

fascicles

Compressed fascicles

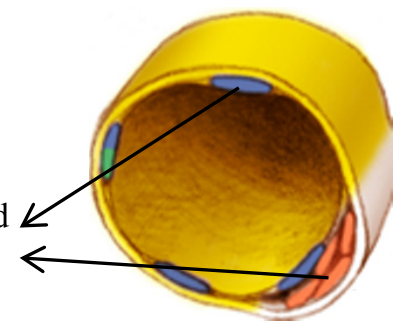

b. Cystic nerve

\section{Figure 4.3 Cross-Sectional Appearance of a Normal Nerve and an IGC}

(Figure 4.1, Figure 4.2 and Figure 4.3 are copyrighted and used with permission of the Mayo Foundation for medical education and research, all rights reserved, see Appendix-A) 


\subsubsection{Intraneural Ganglion Cyst}

Figure 4.3a (Spinner, Atkinson, Tiel, et al., 2003) shows a healthy nerve where the differently colored tubes represent the fascicles. These fascicles in Figure 4.3 have been assigned colors depending on which nerve branch they belong to. The blue fascicles belong to the DPN and the orange fascicles belong to the SPN. The green fascicle belongs to the AB. An IGC is a condition of fluid accumulation within a nerve which causes fascicles and the inner epineurium to be compressed against the periphery of the nerve as shown in Figure 4.3b (Spinner, Atkinson, Tiel, et al., 2003). The specific details about how these blue and orange fascicles are compressed will be discussed in section 4.1.3. Compression of fascicles prevents them from functioning normally and it could lead to a dysfunctional nerve.

\subsubsection{IGC Evolution and Propagation}

The mechanistic explanation for IGC pathogenesis consists of the analysis of the mechanical interactions of the cyst fluid, the nerve tissue (e.g. epineurium), the tissue surrounding the nerve (e.g. muscle, bone, soft tissue) in relation to the environment (e.g., gravity). As the mechanical interactions are specific to each interface (1. joint/capsule, 2. capsule/AB, 3. AB/parent nerve), each will be described individually. Parent nerve refers to a major nerve e.g. CPN. For simplicity, the peroneal nerve, the most common site for an IGC, will be used as the prototype. However, this mechanistic explanation can be applied to IGC of any nerve. 


\subsubsection{Joint-Joint Capsule}

A hypothesis based on a multitude of clinical experiences for the pathogenesis of IGC is provided by the articular theory (Spinner, Atkinson, Tiel, et al., 2003). According to this theory, the formation of an IGC occurs at the joint-joint capsule interface. The synovial fluid escapes through a capsular defect (a slit) into the AB. The capsular defect may be preexisting and is probably the result of a traumatic, degenerative or congenital process (Desy, Amrami, Spinner, \& Mp, 2006; Spinner, Atkinson, Scheithauer, et al., 2003; Spinner, Atkinson, Tiel, et al., 2003). Evidence suggests that direct or indirect cumulative trauma (Ellis, 1936; Faivre, 1975; Gurdjian, 1965; Spinner, Atkinson, Scheithauer, et al., 2003) to the superior tibiofibular joint itself or in relation to the neighboring knee joint is important in the development of these cysts. Intraarticular pressure in the capsule can increase due to the following reasons:

a) Continued production of synovial fluid within the joint

b) Dynamic increase in intraarticular pressure associated with loading of the joint and joint mechanics

Prior to the escape of the fluid through the defect, increased intraarticular pressure may lead to bulging of the joint capsule. This is possibly due to the relative ease to expand the capsular tissue initially. As the intraarticular pressure increases, the potential energy of the system increases. In accordance with the principle of minimum potential energy (Beer, Johnston Jr., Mazurek, Cornwell, \& Eisenberg, 2010), it is then easier for the fluid to escape through the capsular defect than to expand the capsule further. The synovial fluid "chooses" the path of least resistance. 
In the absence of a capsular defect, increased pressure could result in rupture of the capsule.

\subsubsection{Joint Capsule-AB Interface}

In IGCs the capsular defect is closely associated with the AB. While a joint "connection" of the $\mathrm{AB}$ to a neighboring synovial joint can be well seen on imaging and at surgery, the direct "communication" between the joint and the cyst has been demonstrated on arthrography (De Schrijver, 1998; Godin, 1985; Huaux J.P., 1986; Lagarrigue, 1982; J. Malghem, Vande Berg, B.C., Lebon, C., Lecouvet, F.E., Maldague, B.E., 1998; J. Malghem, Vande, B. B., Lecouvet, F., et. al., 2002; Spinner, Amrami, Kliot, Johnston, \& Casanas, 2006; Spinner, Amrami, \& Rock, 2006). Increase in intraarticular pressure would logically lead to an increase in the pressure within the newly initiated cyst. Resulting forces from the joint promoting cyst formation (driving forces) are greater than the resisting forces (Figure 4.4).

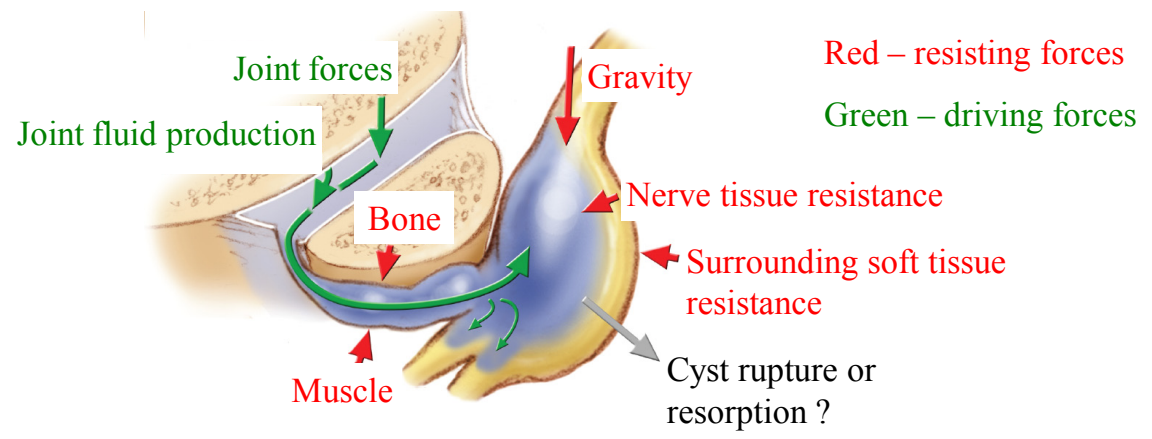

Figure 4.4 IGC Driving and Resisting Forces

(Image copyright Journal of Neurosurgery, used with permission, see Appendix-A) 
Driving forces are those that lead to an increase in intraarticular pressure namely points 4.1.3.1a and b. Resisting forces can be either intrinsic or extrinsic. Intrinsic resisting forces relate to the resistance to the elastic deformation of the nerve. Extrinsic resisting forces come from the surrounding tissue such as bone, muscle, or soft tissue (e.g., compartments). Gravity can also play a role in facilitating or resisting cyst propagation. The role of cyst resorption and/or the potential for rupture is unknown. Cyst resorption refers to the body's ability to absorb the cyst fluid.

It seems intuitive that in clinically apparent, persistent cysts, the intra-articular pressure remains larger than the resisting forces, resulting in further cyst formation: expansion (in diameter) and extension (in length). Expansion refers to the distension of the nerve cross-section similar to what is seen in Figure 4.3b. Extension refers to the growth along the length of the nerve and is shown in Figure 4.5 .

Expansion and extension are further favored for two reasons: 1) maintenance of joint forces (i.e., synovium continues to produce fluid, in fact probably at an increased rate due to the association of joint-related disease), and 2) the relative ease of further cyst growth (i.e., increased volume of the cyst results in a reduction of the intrinsic resisting forces). This observation would be consistent with the path of least resistance, which is illustrated by the well established principle of potential energy minimization (Beer et al., 2010). Lesser energy is required for cyst expansion and extension, in view of the relatively weak neural tissue (especially in the 
epineurium), than for fluid re-entry into the joint. The presence (or absence of) and type of valve is unknown.

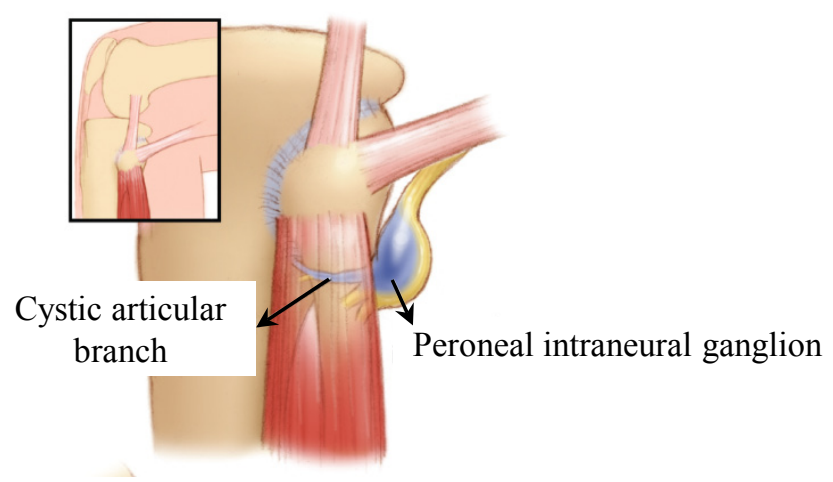

Figure 4.5 Intraneural Ganglion Cyst Propagation

(Image copyright Journal of Neurosurgery, used with permission, see Appendix-A)

\subsubsection{AB-Parent Nerve Interface}

At the $\mathrm{AB} /$ parent nerve interface, the same factors as those discussed above apply. With continued cyst growth, extension occurs within the confines of the epineurium into a parent nerve (Figure 4.5). At the $\mathrm{AB} /$ parent nerve junction, the cyst again follows the path of least resistance. Cysts can either extend proximally and/or distally to varying levels. Contributing factors could include: 1) the degree of angulation of the $\mathrm{AB}$ to the parent nerve; 2) the relative location of the cyst within the $\mathrm{AB}$ when it reaches the $\mathrm{AB} /$ parent nerve junction (favoring growth along rather than around strong and stiff fascicles); and 3) increased additional resistances from intrinsic or extrinsic factors (e.g., scarring, ligation, etc.). Any combination of these factors could dictate directionality. 
As clinical observation suggests, cyst expansion tends to be eccentric, displacing nerve fascicles (“signet ring” sign)(Spinner, Desy, \& Amrami, 2006). Figure 4.3b indicates eccentric displacement of orange fascicles. This along with the distended cyst region looks like a signet ring and hence has been coined so by Spinner et. al. Assuming the lack of a morphological defect, the intraepineurial cleavage plane (specifically, within the outer epineurium) seems to be favored clinically. This could be explained by dissection according to the path of least resistance: 1) the outer epineurium is composed of looser connective tissue than the inner epineurium, and 2) the continued forces promote cyst propagation within the same neural compartment.

The $\mathrm{AB}$ is a small nerve branch and the diameter of its cystic enlargement in IGC is relatively small compared to that of the parent nerve. This gives rise to the characteristic imaging features of IGCs: a tubular cyst constrained by the epineurium with a small neck (tail sign) and balloon-like cystic involvement of the parent nerve. The size and shape of the cyst in different regions is dictated by the architecture and diameter of respective neural branches and extrinsic forces overlying the neural tissues. The multilobulated but elongated appearance often seen clinically can potentially be due to the dynamic nature of the intra-articular pressures and variable effects from other forces.

\subsubsection{Predicting Cyst Propagation}

The term 'cyst propagation' is used to refer to the combined effects of cyst expansion and extension. For example, in Figure 4.5 the cyst is said to have propagated from 
the $\mathrm{AB}$ to the $\mathrm{CPN}$. The word 'growth' is also used synonymously with 'propagation'. A previously used method for predicting the path of cyst propagation is to conduct a dye experiment (Figure 4.6) (Spinner, Atkinson, Tiel, et al., 2003). In this experiment, a dye is injected into the $\mathrm{AB}$ and its path of propagation in the nerve is observed. A dye experiment can only indicate the presence of a communication channel. It cannot quantitatively indicate why a certain path is preferential compared to another.

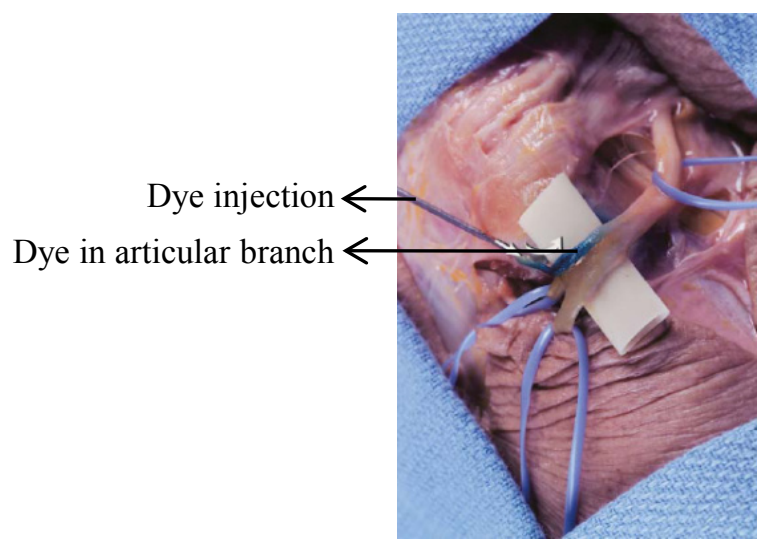

Figure 4.6 Dye Experiment

(Image copyright Journal of Neurosurgery, used with permission, see Appendix-A)

On the other hand, computational techniques like FEA consider the influence of dimensions, material properties and various phenomena involved in the propagation of a cyst. Therefore, such a technique can quantitatively predict why a certain path of propagation is preferential to another. A widely used computational technique in biomechanics is FEA (Hirokawa \& Tsuruno, 1997; Valencia \& Solis, 2006; Weiss \& Gardiner, 2001). 
Finite element analysis (FEA) is a computational method where if forces applied on a solid object are known, then forces generated in various regions of the solid object in response to the applied forces can be predicted. The predictions are based on properties of the material e.g. stiffness. In IGCs the applied force is the intraarticular pressure. If the material properties and the dimensions of the nerve are known then forces generated in the nerve can be predicted. The generated forces in a nerve likely influence the propagation of the cyst and therefore might help throw light on the propagation of IGC. A complete theoretical treatment of FEA is not in the scope of this dissertation; however, numerous textbooks provide exhaustive details on FEA.

The objective of the research discussed in this chapter is to devise a method using FEA to simulate the path of cyst propagation in the $A B$. The details of the finite element model are outlined first, including the assumed material properties, dimensions, and boundary conditions. This is followed by a presentation of the simulation results, including the predicted cyst growth behavior.

\subsection{FINITE ELEMENT MODEL}

The peroneal nerve, the most common site for an IGC, will be used as the prototype for the FEA studies. A solid model of the junction between the AB, DPN, and SPN branches indicated by the box on Figure 4.7a (Spinner, Atkinson, Tiel, et al., 2003) was created as shown in Figure 4.7b. Dimensions for the model were averages of the dimensions measured from the two limbs of one cadaveric specimen using a digital 
caliper with $0.01 \mathrm{~mm}$ accuracy (Industrial Direct Co., Inc.) by Drs. Wang and Spinner, and are shown in Figure 4.8. In view of the computational effort required to solve the model, it is divided into two stages as shown in Figure 4.7b. All studies performed in this chapter pertain to stage-I.

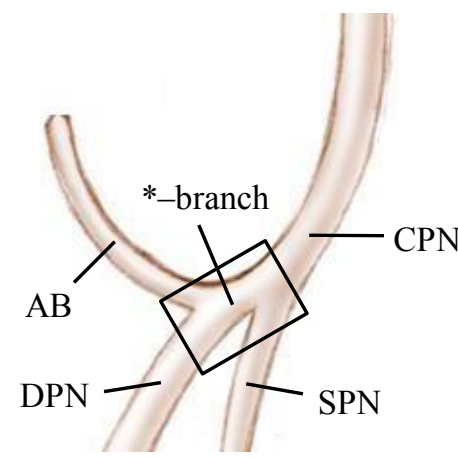

a. $A B-D P N-S P N$ junction

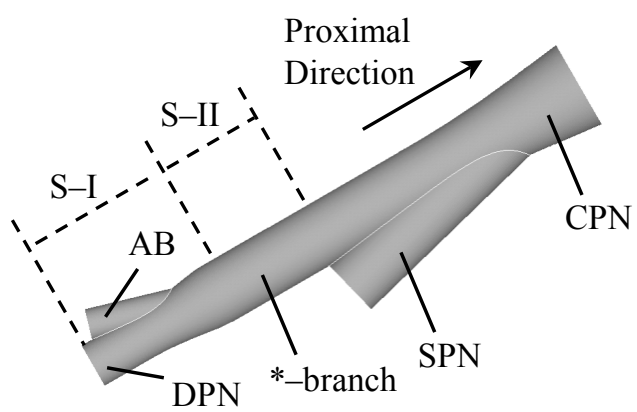

b. Junction model

$\mathrm{AB}-$ Articular branch, DPN - Deep peroneal nerve, SPN - Superficial peroneal nerve, S-I = Stage-I, S-II = Stage-II

\section{Figure 4.7 Finite Element Model}

(Figure 4.7 a copyrighted and used with permission of Mayo Foundation for medical education and research, all rights reserved, see Appendix-A)

\subsubsection{FE Model Structure}

A FE model of the stage-I region was constructed and meshed as shown in Figure 4.9. The outer blue region represents the outer epineurium and the inner region represents a single fascicle. The inner red region is in reality composed of both inner epineurium and multiple fascicles. However, because it is known that the fascicle is much stiffer than the inner epineurium (Topp \& Boyd, 2006), the red region's mechanical response is dominated by fascicle properties. Hence the red region only represents the response of the fascicles. Further, including individual fascicles will complicate the modeling process and introduce additional detail. 


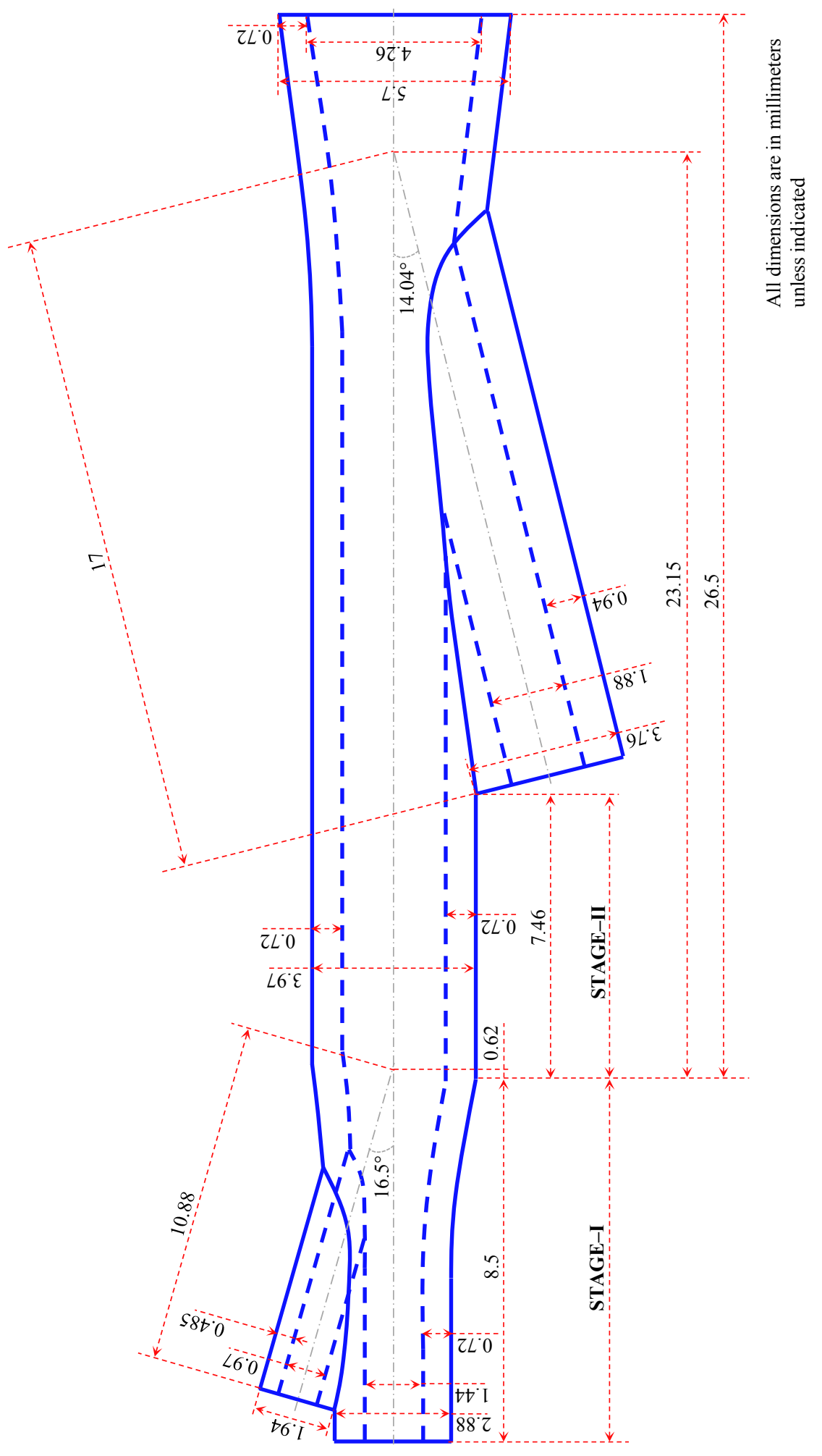

Figure 4.8 FEM Dimensions 
This additional detail is not warranted since the global response of the nerve is more important than the stresses in the individual nerve fascicles. Therefore, the red region is homogenized as a single fascicle. Since the inner epineurium is not included in this model, the blue region is henceforth simply referred to as 'epineurium'.

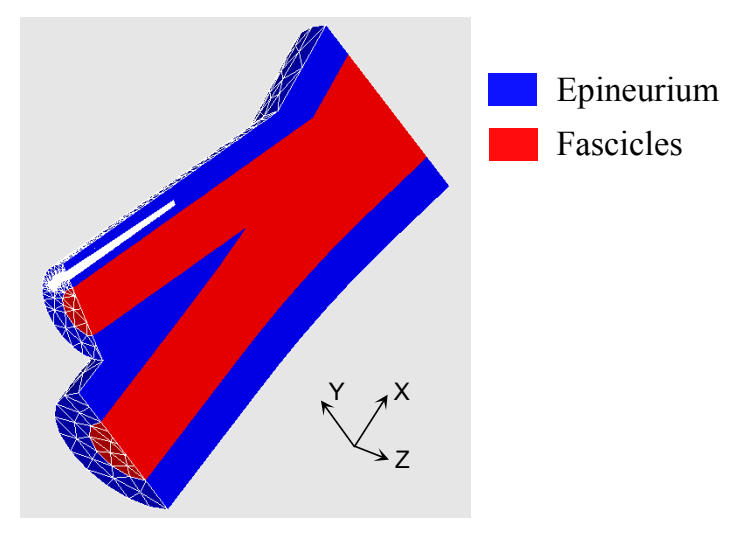

Figure 4.9 Material Discretization

The following are two reasons why two separate regions were necessary in the FE model.

a) Topp et al. (Topp \& Boyd, 2006) and Sunderland et al. (Sunderland \& Ray, 1948) mention that the fascicle is stiffer in tension than any other part of the nerve. Hence to be able to declare separate material properties, a separate material was needed for the fascicle.

b) IGCs usually occur and propagate only in the epineurium. Hence, the epineurium was created as a separate material to constrain the cyst to propagate only in the epineurium. 
Only half of the FEA model is shown so that the internal structure of the fascicle is visible. The mesh consisted of ten noded tetrahedral elements with each node having three degrees of freedom, namely translations in the global coordinate directions. Tetrahedral elements were chosen since a complicated geometry such as this could not be meshed with hexahedral brick elements in Ansys 11. The element technology incorporated reduced integration capability and mixed $\mathrm{U} / \mathrm{P}$ formulation for simulating nearly incompressible behavior. No experiments have been done to investigate the compressibility of the nerve constituents. However, it was assumed as an incompressible material due to the large amount of trapped water (Topp \& Boyd, 2006) in the nerve. The finite element analysis also accounted for the geometric non-linearity in the structure.

\subsubsection{FE Material Properties}

The mechanical properties of nerve tissue components (e.g. fascicle, inner/outer epineurium) have not been previously explored in detail. The only reported mechanical properties (Sunderland \& Bradley, 1961; Topp \& Boyd, 2006) were linear properties measured from the tensile response of a whole nerve. Therefore, attention was focused on understanding the load bearing components of a nerve. This would help in selecting properties of a material with a similar reinforcing architecture and whose properties are already known.

It is known that the inner and the outer epineurium consist of elastin fibrils and collagen fibrils (type $1 \& 3$ ) aligned along the length of the nerve (Topp \& Boyd, 
2006). The main load-bearing portion of the nerve is the perineurium, the outer sheath of the fascicles, which can be made by up to fifteen layers of collagen fibrils (type $1 \& 2$ ). These fibrils may be alternately aligned in the longitudinal, circumferential and oblique directions (Topp \& Boyd, 2006). The inner matrix of the fascicle (endoneurium) consists of endoneurial fluid and collagen fibrils (type 1 \& 2) aligned along the length of the nerve (Topp \& Boyd, 2006). While the load bearing components of a nerve are known, the relative proportion of each is yet to be known. Because of the nature of the cyst geometry (cyst geometry is explained in the next sections), it is expected that the cyst pressure (which represents intraarticular pressure) will result in forces that are mostly applied in the y-direction (Figure 4.9) in the fascicle and $\mathrm{z}$-direction (Figure 4.9) in the epineurium. If the YZ plane is considered as the transversely isotropic plane, then the $\mathrm{X}$-direction represents the axis of isotropy. Cyst pressure is expected to cause very small forces along the axis of isotropy and hence the properties of a nerve in that direction are not of much consequence in this study.

The $\mathrm{z}$-direction force results in stretching the epineurium in the direction transverse to the length of the nerve. Based on the reinforcing architecture (Sunderland \& Ray, 1948; Topp \& Boyd, 2006), this amounts to stretching the nerve in the direction across the collagen fiber direction. Hence a material whose reinforcing architecture is similar to that of a nerve and whose transverse direction properties are available might be an ideal approximation for the current situation. 
Ligaments are reinforced in the direction of their length by collagen (type I and III) and elastin fibers (Cowin \& Doty, 2007) in a similar manner to nerves. Ligaments contain proteoglycans, structural glycoproteins, plasma proteins and fibroblasts (Cowin \& Doty, 2007; Weiss \& Gardiner, 2001). The epineurium of nerves consist of fibroblasts, mast cells and fat cells (Topp \& Boyd, 2006). Despite the slight dissimilarities between the nerve epineurium and ligaments, the properties of human medial collateral ligament (MCL) measured in the direction transverse to the ligament's length (Quapp \& Weiss, 1998) is used for the epineurium. A description of how ligament properties were adapted to our study is detailed later in this section.

The fascicular region experiences compression in the yz-plane (Figure 4.9). Apart from collagen, fascicles are made up of glycoproteins, proteoglycans, fibroblasts, mast cells, macrophages and endoneurial fluid (Topp \& Boyd, 2006). There is no guiding data on the stress-strain response of a nerve's fascicle. Therefore for simplicity, it is approximated to be equal to the tensile behavior of the human MCL in the transverse direction to the ligament's length. Hence both the epineurium and the fascicle are assigned similar properties.

A simple and effective strain energy function for hyperelastic materials is the Mooney-Rivlin model (Holzapfel, 2000) given by

$$
\Psi=c_{1}^{m}\left(I_{1}-3\right)+c_{2}^{m}\left(I_{2}-3\right)+\frac{1}{d}\left(I_{3}-1\right)^{2}
$$


where $\Psi$ is the strain energy density, $c_{1}^{m}$ and $c_{2}^{m}$ are material property constants for material $m$ and $I_{1}, I_{2}$ and $I_{3}$ are the first, second and third invariants of the right Cauchy-Green deformation tensor (Holzapfel, 2000). The term ' $1 / d$ ' represents the pressure that the U/P formulation applies to maintain incompressibility and here $d$ takes the value 0.001 . In the Lagrangian frame, the stress is given by the $2^{\text {nd }}$ PiolaKirchoff stress given by

$$
\mathbf{S}=2\left[\left(\frac{\partial \Psi}{\partial I_{1}}+I_{1} \frac{\partial \Psi}{\partial I_{2}}\right) \mathbf{I}-\frac{\partial \Psi}{\partial I_{2}} \mathbf{C}+I_{3} \frac{\partial \Psi}{\partial I_{3}} \mathbf{C}^{-1}\right]
$$

where $\mathbf{C}$ represents the right Cauchy-Green deformation tensor and I represents the identity tensor. Alternately, the stress may be measured in the Eulerian frame which is given by the Cauchy stress written as

$$
\boldsymbol{\sigma}=2 \tilde{J}^{-1}\left[\left(I_{2} \frac{\partial \Psi}{\partial I_{2}}+I_{3} \frac{\partial \Psi}{\partial I_{3}}\right) \mathbf{I}+\frac{\partial \Psi}{\partial I_{1}} \mathbf{L}-I_{3} \frac{\partial \Psi}{\partial I_{2}} \mathbf{L}^{-1}\right]
$$

where $\tilde{J}$ refers to the ratio of volumes before and after deformation, L represents the left Cauchy-Green deformation tensor. In equation (4.3), $I_{1}, I_{2}$ and $I_{3}$ refer to the invariants of the left Cauchy-Green deformation tensor which are the same as the invariants of the right Cauchy-Green deformation tensor. For incompressible materials, the ratio $\tilde{J}$ is 1 . The values of $c_{1}^{m}$ and $c_{2}^{m}$ were obtained based on the 
data reported by Quapp et al. (Quapp \& Weiss, 1998). Seven sets of values for $c_{1}^{m}$ and $c_{2}^{m}$ were determined experimentally by them for the properties transverse to the collagen fiber direction in the human MCL. In order to obtain the best approximation, the average value of $c_{1}^{m}$ from seven experiments was obtained. In a similar manner, the average value for $c_{2}^{m}$ was also obtained. This is illustrated by the following equation.

$$
\begin{aligned}
c_{1-\text { avg }}^{m} & =\frac{\sum_{e=1}^{7} c_{1}^{m}}{7} \\
c_{2-\text { avg }}^{m} & =\frac{\sum_{e=1}^{7} c_{2}^{m}}{7}
\end{aligned}
$$

where 'e' represents the experiment number from Quapp et. al. (Quapp \& Weiss, 1998). Based on Quapp et al.'s data, $c_{1-a v g}^{m}$ was equal to $22.7 \mathrm{MPa}$ and $c_{2-\text { avg }}^{m}$ was equal to $-9.4 \mathrm{MPa}$. The above values could not be used as is because negative coefficients can cause problems in finite element simulations. Therefore, a new curve with coefficients $c_{1-\text { new }}^{m}$ and $c_{2-\text { new }}^{m}$ was fit to the average coefficient curve. The aim of this refitting was to obtain a good match with the average constant curve with positive coefficients. This is shown by the graph in Figure 4.10. The two curves show good correlation especially between stretch ratios of 1 and 1.25. 


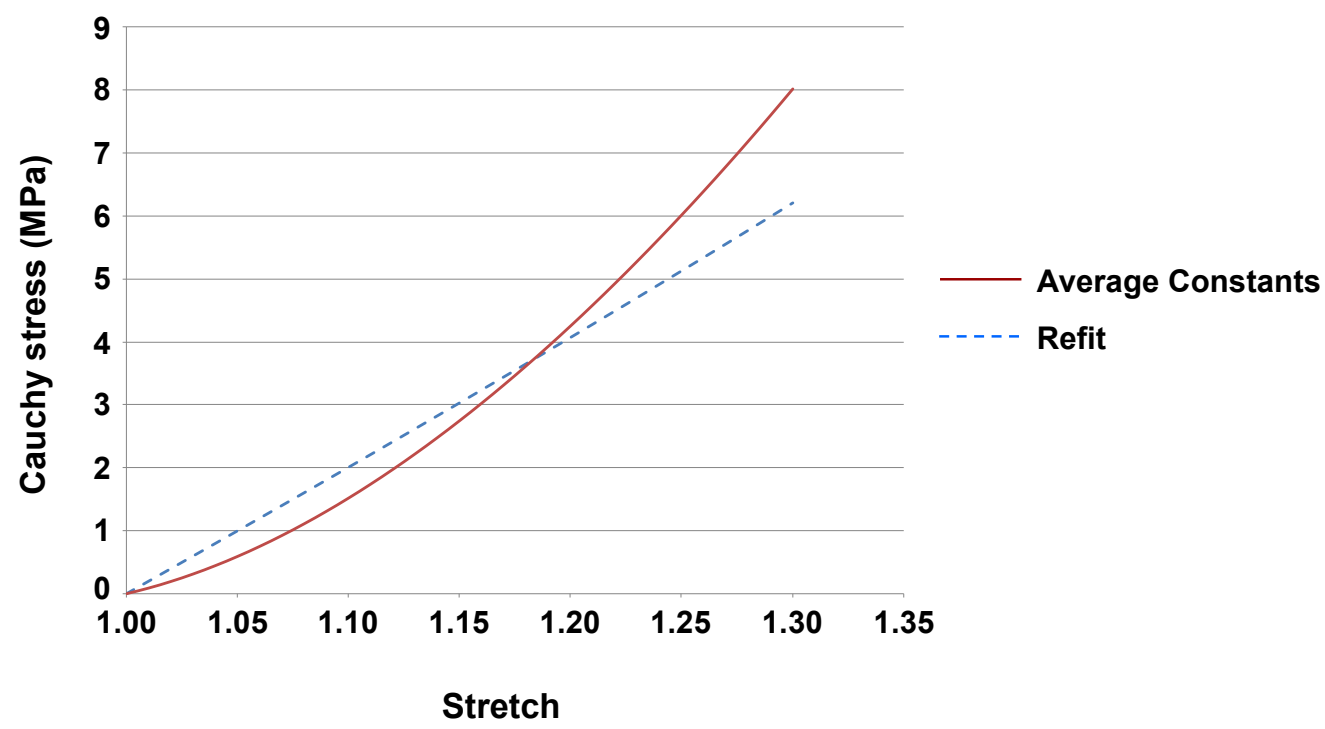

Figure 4.10 Material Properties for FE Model

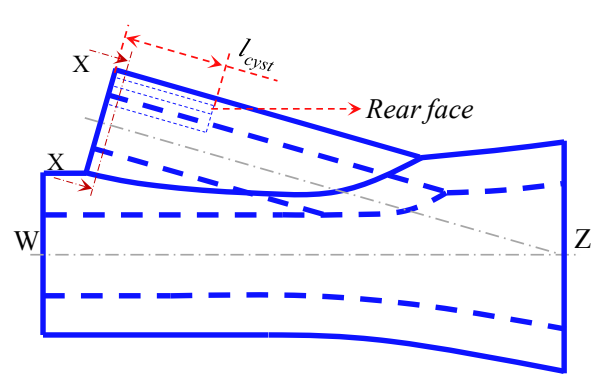

a. Stage-I cyst location

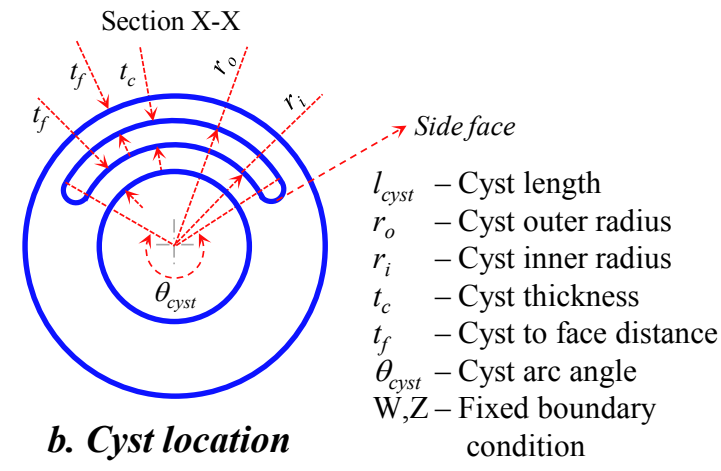

Figure 4.11 Cyst Location and Dimensions 
This is important since the FE model is expected to develop stretch ratios within this limit. The new refitted coefficients $c_{1-n e w}^{m}$ and $c_{2-n e w}^{m}$ are given by $7 \mathrm{MPa}$ and 0.95 MPa respectively.

\subsubsection{Cyst Dimensions}

The cyst is represented by the hollow crescent-like region shown in the epineurium in Figure 4.11. The length of the cyst $\left(l_{\text {cyst }}\right)$ is the length measured along the AB and the cyst arc angle $\left(\theta_{c y s t}\right)$ is the angle subtended by the arc of the cyst. The cyst thickness $\left(t_{c}\right)$ represents the distance between the top and bottom surfaces of the cyst. The values for these dimensions are given in Table 4.1. The cyst length is chosen to be one-third the length of the $\mathrm{AB}$ and the cyst thickness is one-third the thickness of the epineurium. The cyst is located to be equidistant from the outer and the inner epineurium surfaces. The rear face of the cyst is a crescent shaped surface as indicated in Figure 4.11a.

\begin{tabular}{cc} 
Initial Values & Stage-I \\
\hline$l_{\text {cyst }}(\mathrm{mm})$ & 2.74 \\
$\theta_{\text {cyst }}($ degree $)$ & 270 \\
$r_{0}(\mathrm{~mm})$ & 0.8 \\
$r_{i}(\mathrm{~mm})$ & 0.64
\end{tabular}

Table 4.1 Stage-I Cyst Dimensions 
The side face of the cyst is a semi-cylindrical surface at the sides of the cyst as indicated in Figure 4.11b. There are no guiding data on the shape of a cyst in the epineurium. The above mentioned shape and dimensions are best estimates of what they might be.

\subsubsection{Boundary Conditions}

As mentioned in section 4.1.3, the cyst is pressurized by the continuous production of cyst fluid in the superior tibiofibular joint and the biomechanical loading of the joint. This leads to its continued accumulation in the epineurium. In the FEA model, this cyst fluid pressure is represented by a pressure load applied on the inner surfaces of the cyst except at the rear face. This is because of the cyst's similarity to a crack in traditional fracture mechanics. The rear face then represents the crack tip of a mode-I crack (Anderson, 2004). Since no load is applied at the crack tip itself, no load was applied on the rear face. Since it is very difficult to measure the pressure of the cyst fluid, an assumed pressure was chosen. An examination of the range of pressures that existed within synovial joints was then conducted. Pressure in knee synovial joints was investigated since no data was available of superior tibiofibular joint intraarticular pressure. An article on joints in the university of Washingtonorthopaedics and sports medicine website (Medicine, 2010) reports that the intraarticular pressure in a resting, normal, human knee is about $-4 \mathrm{mmHg}$ (equivalent to $-5.33 \mathrm{e}-4 \mathrm{MPa}$ ). The article further reports that the sub-atmospheric pressure within the joint helps provide a stabilizing force for holding joint members together. It also mentions that in the abnormal/diseased joint, the intraarticular 
pressure is higher than atmospheric pressure. Knight et. al. (Knight \& Levick, 1982) studied the pressure--volume relationships above and below atmospheric pressure in a normal rabbit knee synovial joint. Synovial joint rupture occurred at $17 \mathrm{cmH}_{2} 0$ (16.67e-4 MPa). They verify that intraarticular pressure in a resting, undiseased joint condition is sub-atmospheric and that it is supra-atmospheric while diseased (e.g. knee effusion). However, joint disease may not be the only reason for a positive intraarticular pressure; in a resting undiseased human knee, intraarticular pressure can become positive when the knee is flexed. These references validate the positive values of pressures used in this study. This is because as said in section 4.1.3, IGC are always associated with a joint disease. However, the exact value of pressure cannot be validated. Also, the biomechanical loading experienced by the superior tibiofibular joint is dynamic in nature (Hunt et al., 2010). It is necessary to understand the static behavior of cyst growth before its dynamic behavior is studied. Therefore, as a first level of approximation, a static pressure is applied in this study. The applied pressure varied between 1.5-2 $\mathrm{MPa}$, which was based on the maximum value that the FEA model would converge for. Lack of convergence occurred either due to element distortions or the solution's inability to maintain incompressibility. A discussion on the variation of pressure is given in section 5.7.2. To prevent rigid body motion errors, the fascicle surfaces, corresponding to locations $\mathrm{W}$ and $\mathrm{Z}$ noted in Figure 4.11a, were fixed with respect to all three coordinate axes. 


\subsubsection{Mesh Sensitivity Analysis}

A FEA model is an approximate mathematical representation of a real structure and it is important to make sure that the finite element model accurately represents the real structure. It is also important that the model is constructed in a manner that ensures efficiency in the computational solution process. Hence it is necessary to make sure that a sufficiently refined mesh is used for both accuracy and efficiency in the FEA model.

Therefore, a mesh sensitivity analysis was performed on the FEA model. In this model the main regions of interest were the surfaces of the cyst. The number of elements on the cyst surfaces was increased progressively in individual steps, with the resulting stress distribution in the cyst side face and cyst rear face being monitored in each step. Starting from a very fine mesh size of 95,000 elements, simulations were performed and stress variations were monitored while reducing 5000 elements from the region near the cyst faces for each simulation. A constant pressure of $2 \mathrm{MPa}$ was applied in each case.

The coarsest mesh size whose elements were within the software's (ANSYS) limits of allowed element aspect ratios and whose results did not significantly vary from the 95,000 elements simulation's results was a simulation performed with 75,000 elements. This is demonstrated by Figure 4.12 where the von Mises stress is plotted at the side and rear face of the cyst versus the point numbers for different number of elements contained in the overall model. 


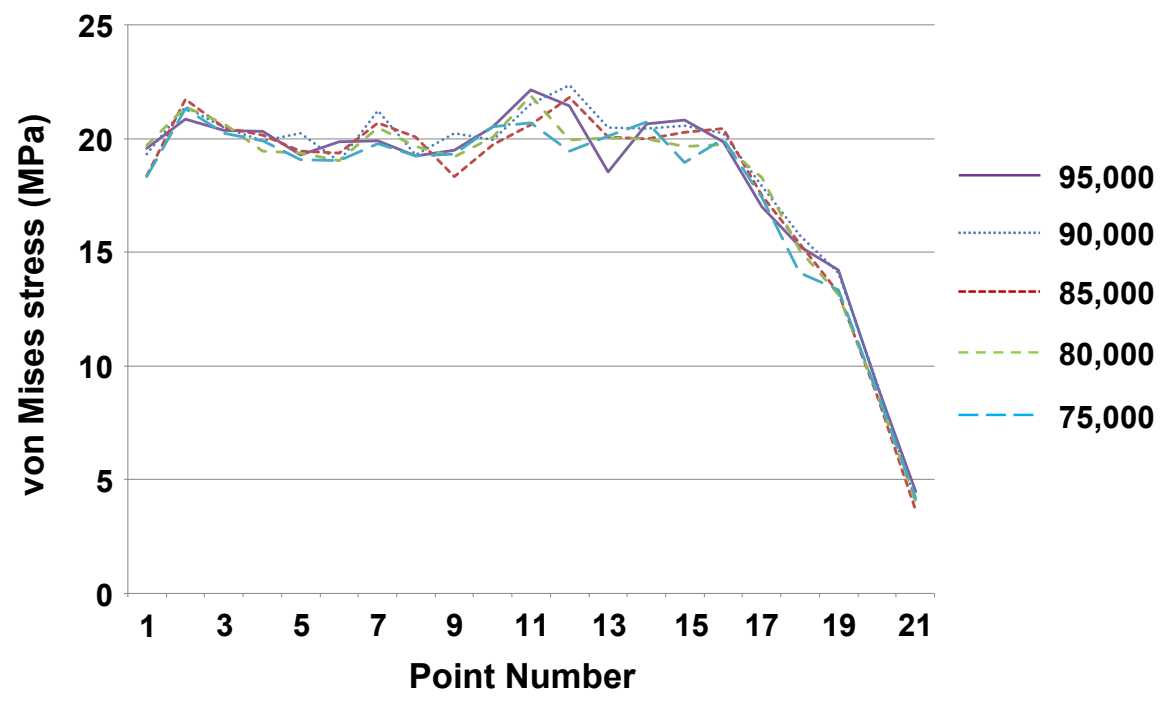

a. Side face stress variation

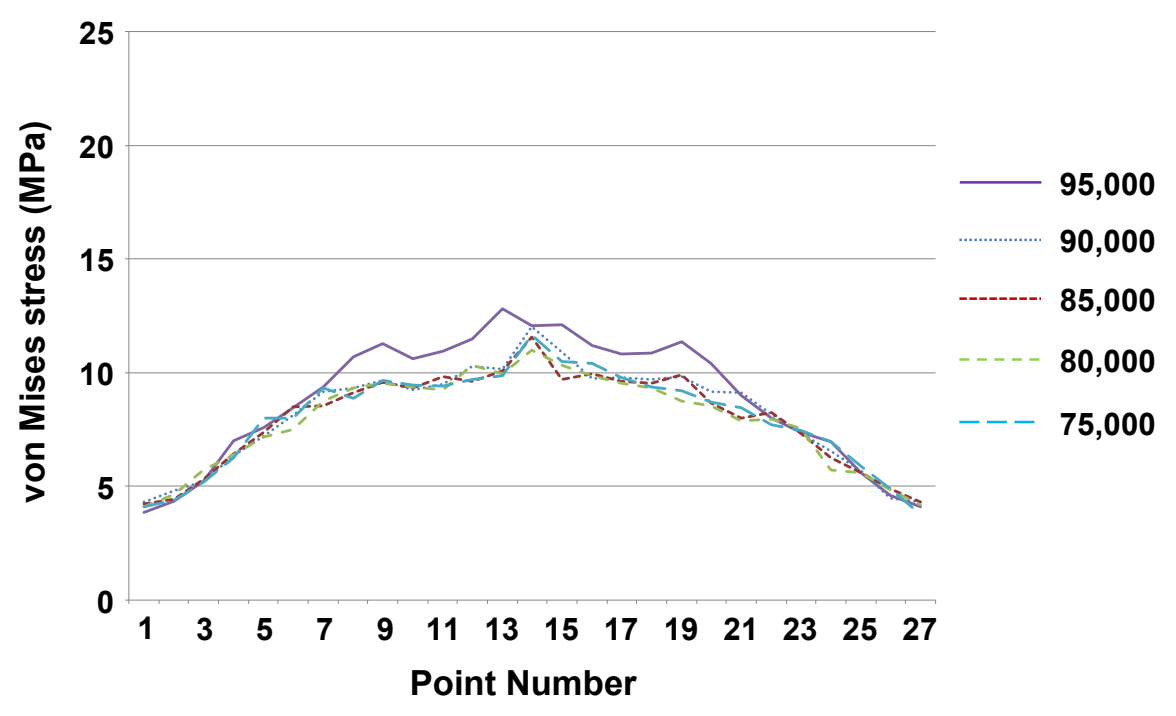

b. Rear face stress variation

Figure 4.12 Mesh Sensitivity Analysis Results 
Point number on the $\mathrm{X}$-axis refers to equidistant points along the length of the side face and rear face. On the side face, the point number 1 is closer to the distal end of the $\mathrm{AB}$ and point 21 is closer to the proximal end of the $\mathrm{AB}$. The mesh density corresponding to the 75,000 element model was used in all subsequent simulations.

\subsection{STAGE-I RESULTS}

All stress and strain measures are referred to in the Lagrangian reference frame. Figure $4.13 \mathrm{a}$ shows the strain in the Z-direction that was predicted from the FEA model. The maximum tensile strain was $19 \%$. The large strain gradient that is caused by the cyst (cyst blow-out) is consistent with intra-operative observations. The von Mises stress is henceforth used as the principle stress measure in the model because it is expected that it is the most accurate measure to predict the failure of the material (and hence cyst propagation). The von Mises stress at the point in a material is the norm of the distortion energy theory, that is, the energy associated with shear-related deformation. According to the distortion energy theory, failure occurs at a point when the distortion energy per unit volume at the point equals the distortion energy at failure in a simple tension test. The distortion energy theory was selected because it conveniently takes into account all stress components in a multi-axial stress state. Alternatively, the maximum principle stress could be used as a governing stress measure; however, it typically functions better for more brittle solids and is unable to account for a multiaxial stress state (Dowling, 2006). Figure 4.13b shows that the maximum von Mises stress on the side face which varied from 15.08 to $30.16 \mathrm{MPa}$. 


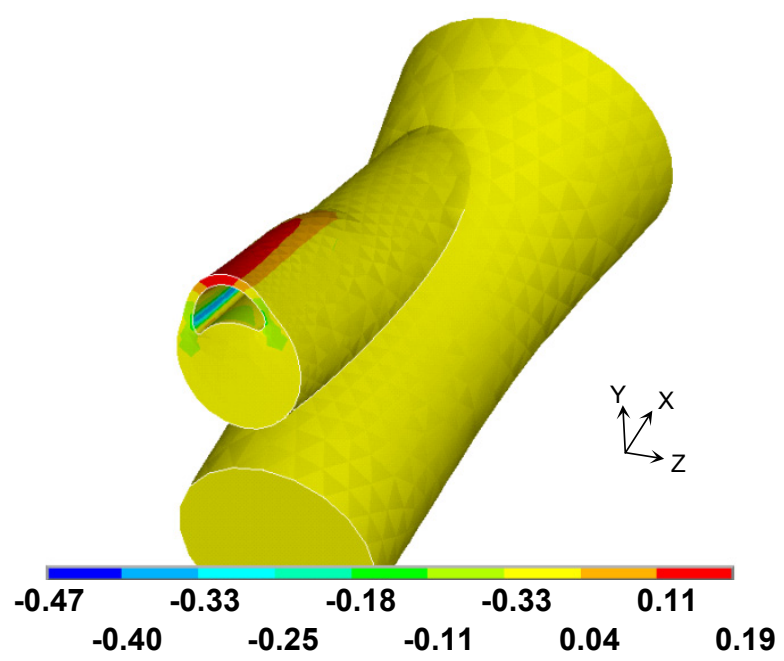

a. Z-direction strain

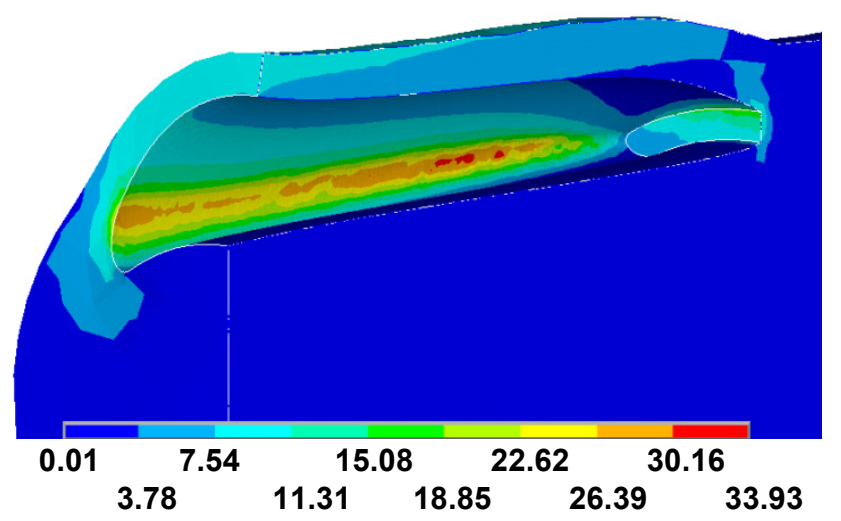

b. Side face von Mises stress distribution (MPa)

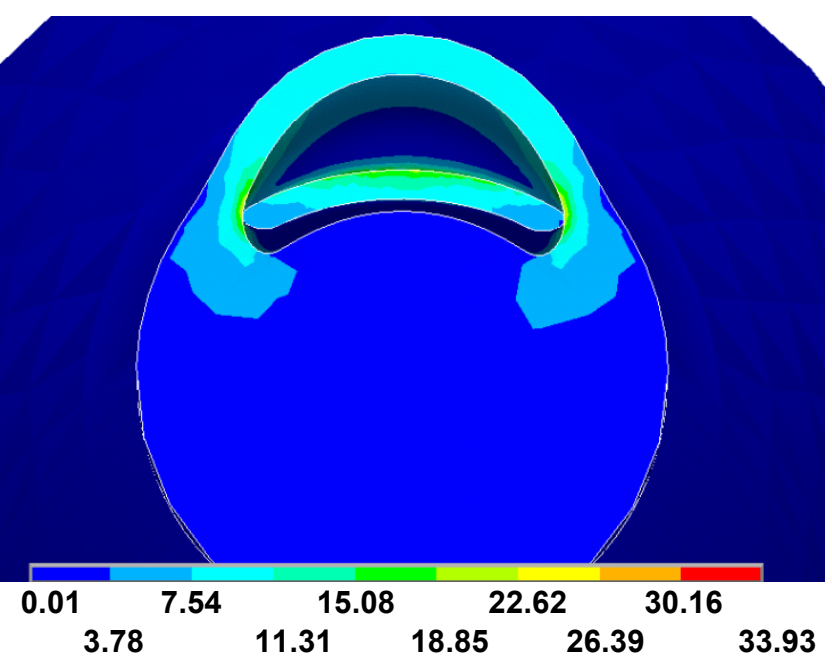

c. Rear face von Mises stress distribution (MPa)

Figure 4.13 Stage-I Results (Applied Pressure = 2 MPa) 
The von Mises stress distribution on the left side face, as shown in Figure 4.13b, was the same as the right side face (not shown), which is expected since the structure is symmetric. The stresses on the rear face, as shown in Figure $4.13 \mathrm{c}$, varied between 3.78 to $18.02 \mathrm{MPa}$ (ignoring spurious stress concentrations). Spurious stress concentrations refer to those that have been caused by sharp edges in the model or due to element distortion. A comparison of the stresses along the left side face against the rear face is plotted in Figure 4.14. The side face point numbers refer to equidistant points along the length of the side face. Similarly, rear face point numbers are equidistant points spanning the cyst arc angle, $\theta_{c y s t}$, on the rear face of the cyst. Comparing the stress values on the side against that on the rear face, it is found that the magnitude at the sides is greater. This indicates that the cyst in this stage tends to engulf the sides by growing circumferentially along the side faces as opposed to growing along the length of the branch towards the junction.

\subsection{CYST GROWTH}

\subsubsection{Growth Methodology}

The analysis described in the previous section describes a single step in the growth of an IGC. It is well-known from clinical observations (Spinner, Wang, Carmichael, Amrami, \& Scheithauer, 2007) that a cyst will grow along and/or around a nerve branch (referred to as 'expansion' and 'extension' in section 4.1.3.2). The cyst growth process was simulated by selecting a threshold value of von Mises stress above which failure occurs. 


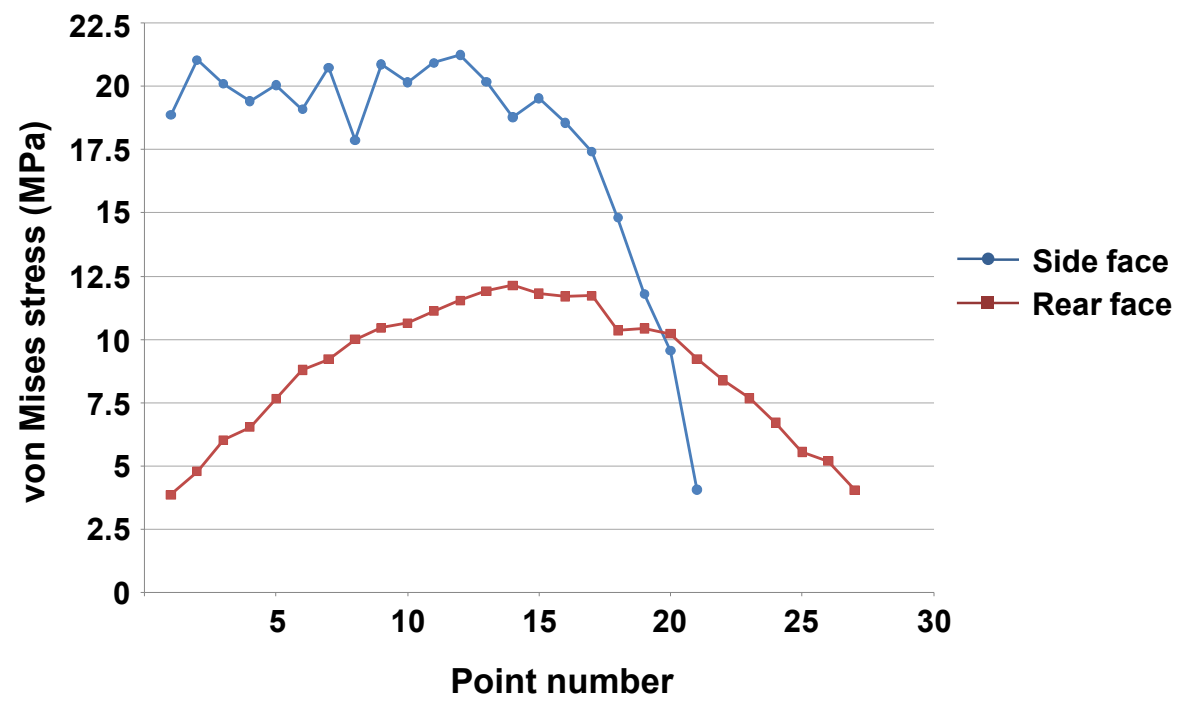

Figure 4.14 Side Face V Rear Face Stresses

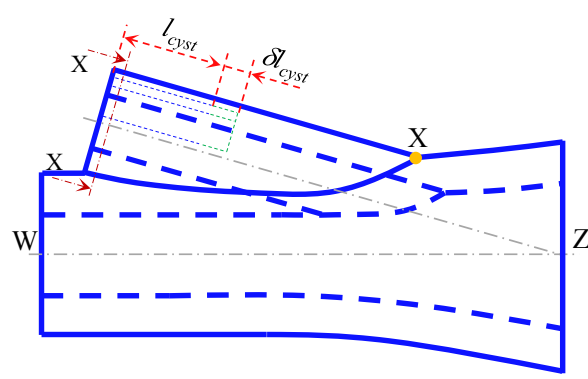

a. Modified cyst length

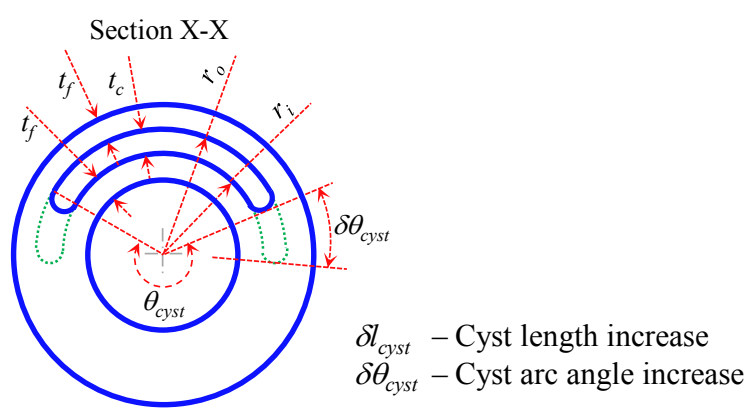

b. Modified cyst arc angle

Figure 4.15 Re-modeled Cyst Dimensions 
All elements in which this maximum value of von Mises stress was exceeded were determined. The set of these elements constituted an envelope around the cyst in which the material was assumed to fail (could no longer bear any load because the tissue "ripped"). The dimensions of the envelope were noted, and the cyst arc angle and cyst length were increased by values based on the dimensions of the envelope in the respective directions for the subsequent modeling step. The cyst was remodeled in this manner as shown in Figure 4.15a and b by increasing the cyst dimensions by $\delta 1_{\text {cyst }}$ and $\delta \theta_{\text {cyst. }}$ Therefore remodeling corresponds to an increase in cyst volume and in this subsequent step, the cyst was said to have 'grown' in the side and the rear. To understand how a cyst grows in the $\mathrm{AB}$, the cyst propagation was simulated along the $\mathrm{AB}$ approaching the nerve branch junction. For the cyst to propagate the length of the modeled $\mathrm{AB}$, multiple cyst propagation steps like the one just described were performed iteratively. A flowchart depicting this methodology is shown in Figure 4.16. The number of times the loop needs to be repeated along with the first simulation represents the total number of growth steps. It must be noted that due to the cyst dimensions described in section 4.2.3, the cyst rear face is modeled sufficiently far away from the AB-DPN junction. Being farther enough ensures that the cyst can exhibit its growth behavior during subsequent growth steps without any bias. This helps simulate a more natural growth process. The threshold value of stress in this study describes failure of tissue in the direction transverse to the collagen fiber direction. No guiding data or experiment exists for understanding the threshold value of stress in the direction transverse to the collagen fiber direction. 


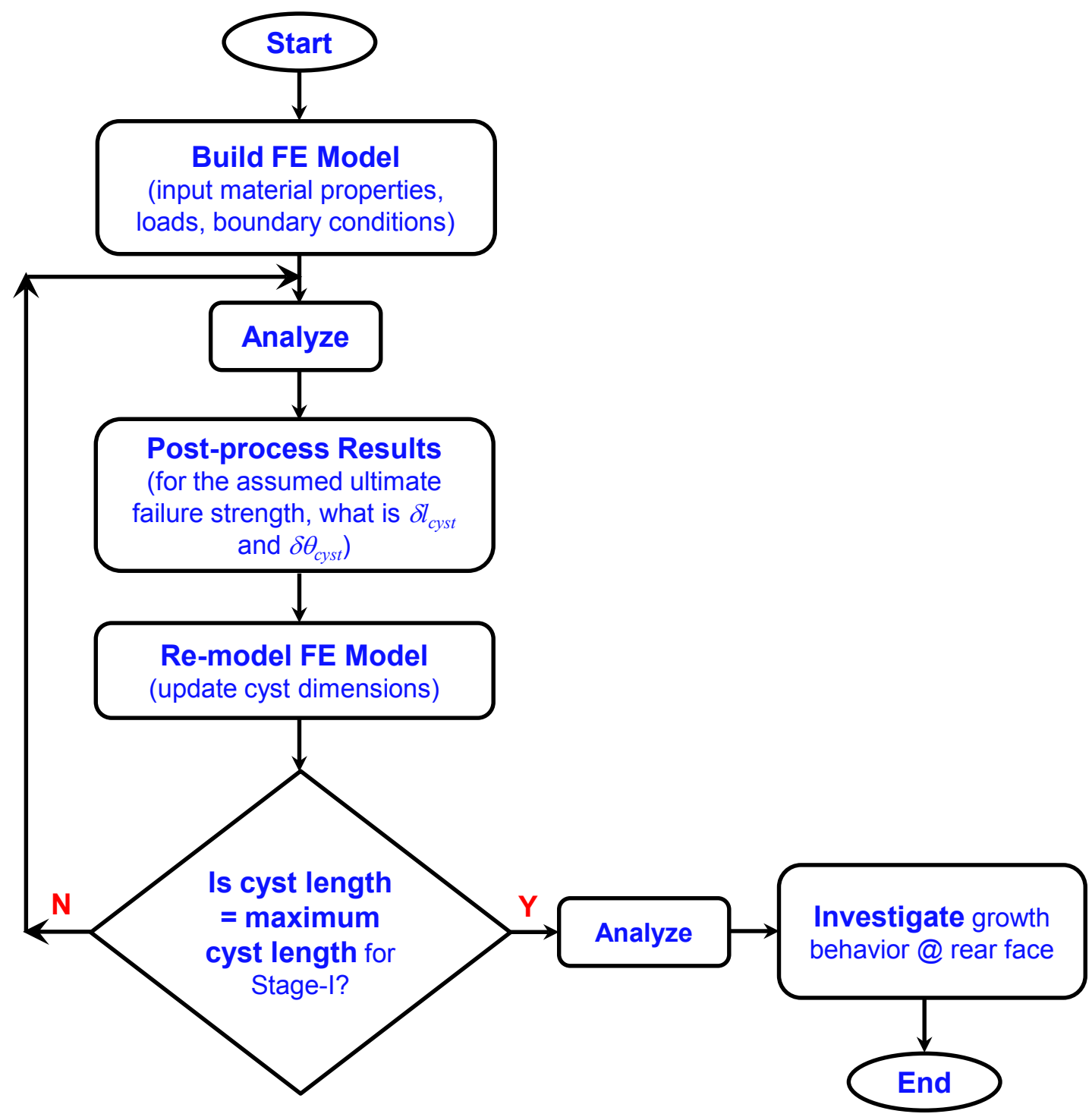

Figure 4.16 Cyst Growth Technique 
However, from the construction of the nerve discussed in section 4.2.1, it was known that the transverse direction failure strength must be lesser than the longitudinal value of failure strength. The ultimate longitudinal failure strength was measured by Sunderland et al. (Sunderland, 1961) in the direction of the collagen fiber direction for $15 \mathrm{CPN}$ specimens. The average value of those 15 experimental values (13.07 $\mathrm{MPa}$ ) is taken as the longitudinal failure strength in this study. The transverse failure strength was taken to be approximately $70 \%$ of this value $(9.5$ $\mathrm{MPa})$.

\subsubsection{Model Approximations}

The total number of growth steps it took for growing the cyst to the end of the $A B$ was 15. An elaborate investigation of the results is dealt with in the following section. This paragraph is intended to detail some modeling approximations that were necessary during the course of the cyst growth study in the AB. Initially, the cyst was thought of as a crack in a material. Hence, initially the cyst thickness gradually decreased from the distal end to the proximal end by half its value. Growth steps were performed like this until growth step 7. At growth step 8, a decreasing thickness cyst geometry could not be created due to a failure in the Boolean operation in Ansys 11. Therefore the cyst thickness at this stage was made to be uniform. Later at growth step 10 when the cyst was created, the proximal end of the cyst side face penetrated into the fascicle. 
Since this represents an unrealistic situation the cumulative value of side growth was reverted to the cumulative value of side growth at growth step 5. This is because the cumulative side growth at growth step 5 was the maximum value of side

growth with which the rear face could reach point $\mathrm{X}$ (Figure 4.15) without penetrating into the fascicle. What this indicates is that the maximum value of side growth was reached in 5 growth steps. Also, after growth step 10, the rear growth was fixed at $0.4 \mathrm{~mm}$ for all further growth steps. This is because the rear growth was a very small value; the average rear face growth for the first 9 growth steps was $0.13 \mathrm{~mm}$. With the side growth value being fixed since growth step 5, each growth step with this very small value yielded very small difference in results. Hence, the rear face growth value was changed to $0.4 \mathrm{~mm}$.

\subsection{RESULTS AND DISCUSSION}

\subsubsection{Cyst Growth Results}

The number of growth steps required for the cyst to progress along the entire length of the $\mathrm{AB}$ was 15 . This corresponds to the rear face of the cyst being at point $\mathrm{X}$ in Figure 4.15a. A plot indicating the stress variation at the side and at the rear face in each of these growth steps is shown in Figure 4.17. A comparison of plots Figure 4.17a and $\mathrm{b}$ indicates that the trend of the maximum stress value at the side face being greater than the rear cyst face is true for all of the growth steps (except growth step 7). 


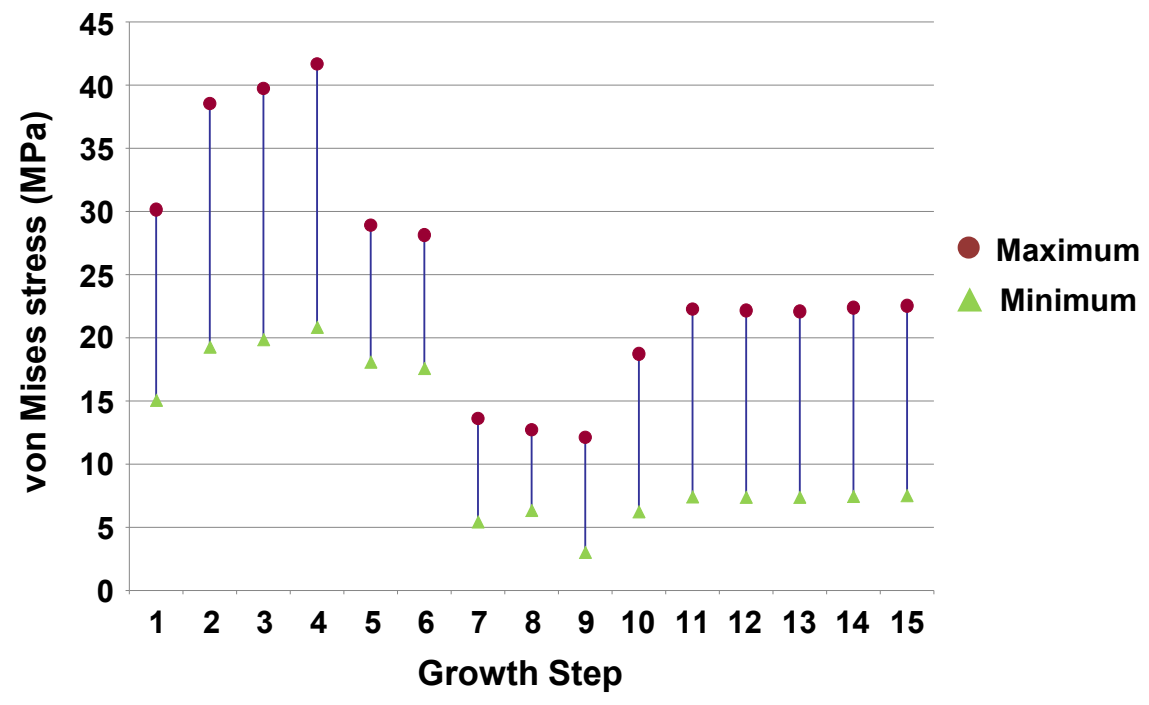

a. Side face stress variation

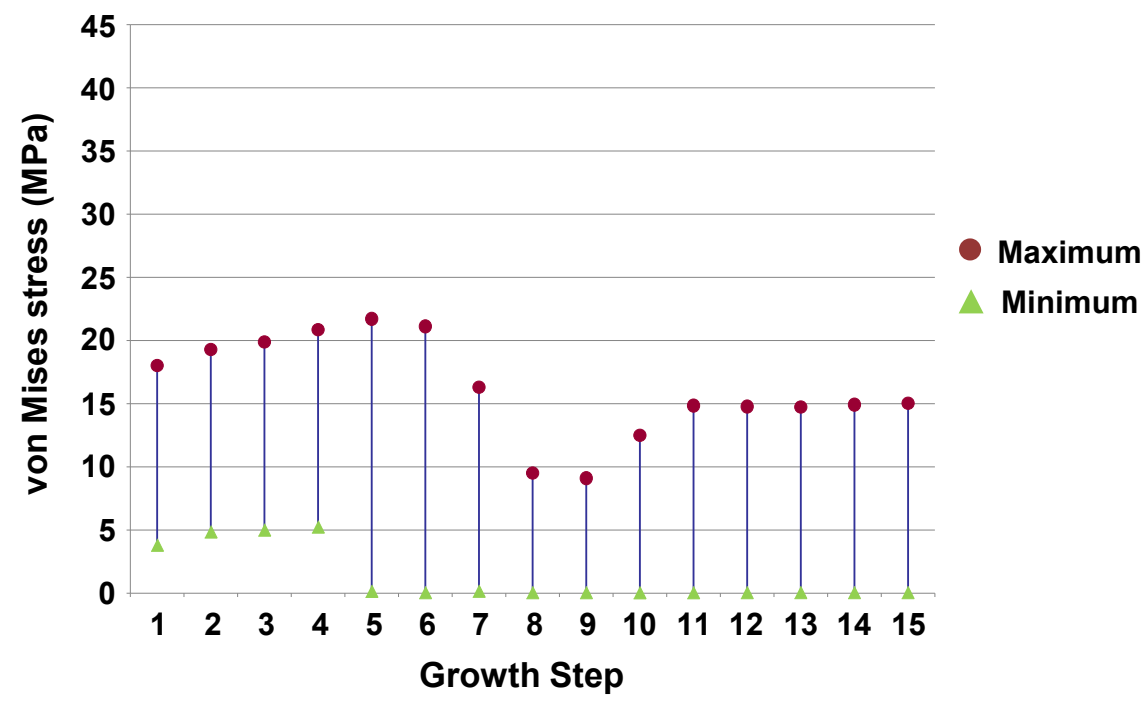

b. Rear face stress variation

Figure 4.17 Cyst Propagation Results 
Comparing Figure 4.17a and b also shows that, until growth step 6, the maximum rear cyst face stress was close to the minimum side face stress value indicating the predominantly higher stress values at the sides. Growth step 7 represents the only step where the side face stresses are lower than the rear face stresses.

Beyond growth step 7, greater overlap existed between the side and rear face stress ranges. The change in trend from less overlap in the first six growth steps to greater overlap in the rest can be explained due to the change in cyst shape. Once considerable side growth occurs, due to the change in cyst shape, stresses tend to be lesser in the side faces. The trend of higher stresses at the side faces when compared to the rear face indicates the tendency for greater growth along the side faces. While growth at the rear face will also occur, it will be smaller in magnitude compared to the side faces.

\subsubsection{Cyst Behavior at Junction}

It is important to analyze the stress state at the rear face of the cyst in growth step 15. Figure 4.18 is a plot of stresses for an applied pressure of $1.75 \mathrm{MPa}$ at the rear face of the cyst in growth step 15 i.e. when the rear face is at point $\mathrm{X}$ in Figure 4.15a. An examination of the stress distribution in the rear face at this stage can give information on whether the cyst will propagate proximal to the $\mathrm{AB}-\mathrm{DPN}$ junction or distal. The stresses in the rear face vary between 0.02 and $7.53 \mathrm{MPa}$ with $3.77-7.53$ MPa being the most predominant stress band. 


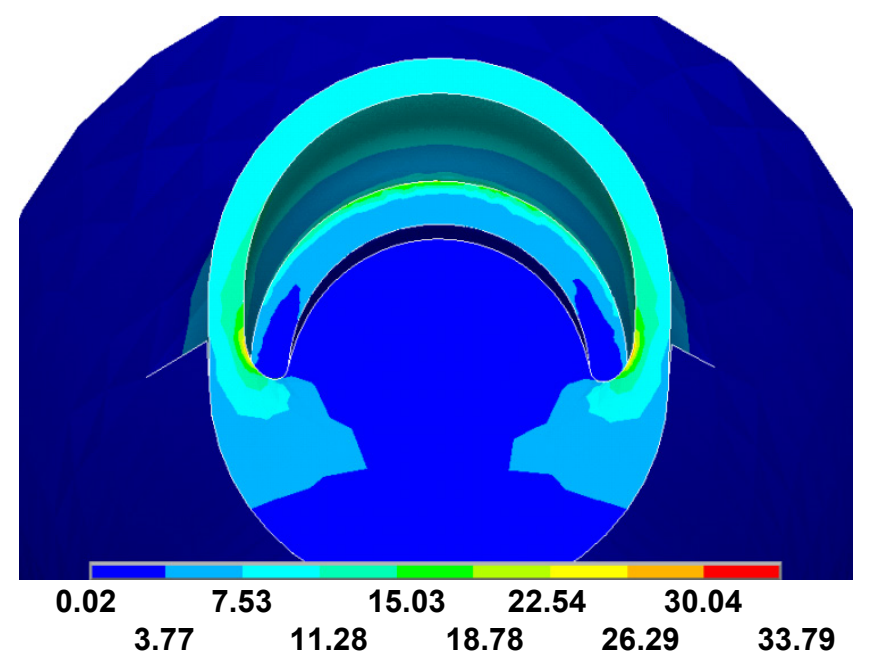

Figure 4.18 Rear Face Stresses at Growth Step $15(\mathrm{MPa})$

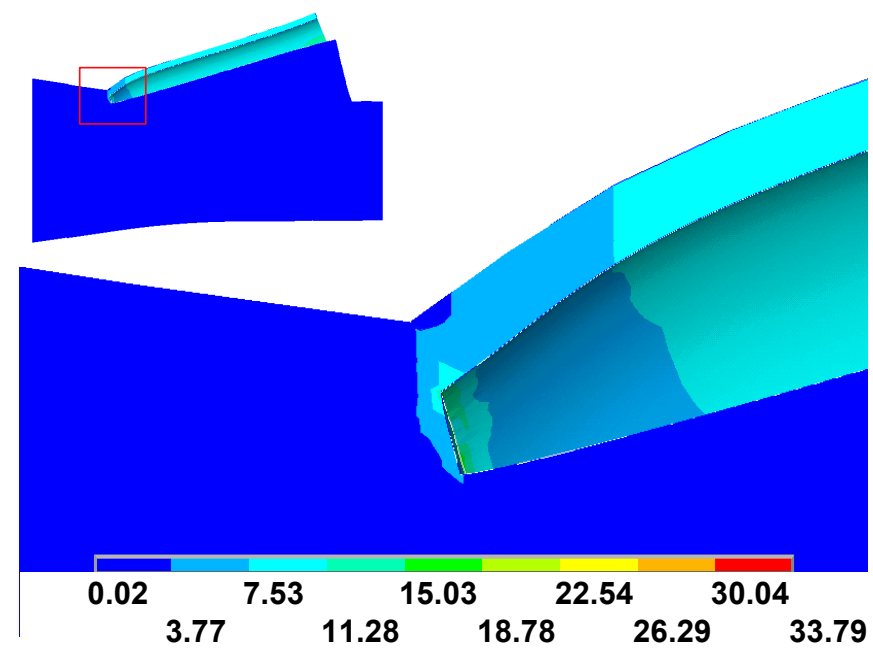

Figure 4.19 Stresses Behind Rear Face at Growth Step 15 (MPa) 
Figure 4.19 shows the cutaway model of the stresses just behind the rear face. Once again the predominant stress band is $3.77-7.53 \mathrm{MPa}$. The failure value selected in the cyst growth steps was 9.5 MPa. Clearly on the rear face and behind it stresses are much lesser than 9.5 MPa. Hence this indicates that the cyst will not propagate proximally. However, the value 9.5 MPa was chosen as the best approximation to reality. An experimental value of failure stress might help explain the phenomena of proximal growth more accurately.

\subsection{SUMMARY}

IGC were described and their theory of evolution and growth was discussed. The need to improve on the current technique (i.e. dye experiments) for predicting cyst growth was noted. A FE model was created of a nerve junction that is a frequent site of IGCs, namely the AB-DPN-SPN nerve junction of the CPN at the fibular neck. Material property assumptions were done based on reinforcing components and their layup in the nerve. A crescent-shaped cyst was modeled in the outerepineurial regions and increased intraarticular pressure was simulated using a pressure boundary condition. Rather than only simulating one static step in the cyst growth process, a criterion for cyst growth was formulated using which cyst growth was simulated in the $\mathrm{AB}$. This cyst growth technique was based on removing material that had failed in the model. The results indicate a trend of predominantly higher maximum value of stress in the side faces of the cyst when compared to the stresses in the rear face of the cyst. Such a condition causes the cyst to engulf the sides by propagating circumferentially rather than propagating along the length of a 
nerve. Further an examination of stresses in the rear face when the cyst is the end of the $\mathrm{AB}$ indicates that the stresses do not favor the growth of the cyst proximal to the AB-DPN junction based on the current material failure value. The analyses performed in this chapter show that they can predict quantitative values regarding the growth of IGC. Unlike dye experiments that can only indicate the path of growth, FEA has shown the ability to predict quantitative values. If the computational analyses are supplemented by laboratory measured properties, predictions will be more authoritative. 


\title{
5. ANISOTROPIC FAILURE ANALYSIS OF INTRANEURAL GANGLION CYSTS
}

\author{
Shreehari Elangovan, Gregory Odegard, \\ Michigan Technological University, Houghton, MI 49931, USA \\ Duane Morrow, Huan Wang, Marie-Noëlle Hébert-Blouin and Robert \\ Spinner \\ Mayo Clinic, Rochester, MN 55905, USA
}

\subsection{INTRODUCTION}

Cyst propagation studies in the $\mathrm{AB}$ performed in the previous chapter indicated that the stresses at the cyst side faces were much greater that at the rear face. This indicated that the cyst would engulf the sides circumferentially well before the rear face reached the junction i.e. point $\mathrm{X}$ in Figure 4.15a. Clinical studies (Spinner, Atkinson, Tiel, et al., 2003) however indicate that in the segment of the nerve proximal to the AB-DPN junction, the cyst tends to propagate within a certain circumferential portion of the nerve, i.e. it is restricted to a quadrant of the epineurium. This would mean that the side growth is very restricted while the rear face growth is much higher comparatively. The objective of this chapter is to explain the restricted quadrant growth of IGC.

\subsection{ANISOTROPY HYPOTHESIS}

The discussion in the previous chapter in section 4.2 suggests that nerve is a 
heterogeneous material (Sunderland, 1948; Topp \& Boyd, 2006). Therefore any continuum-based model must be inherently anisotropic to accurately predict the overall mechanical response. However, for the same model described in the previous chapter a computational simulation performed with anisotropic material properties would multiply solution time. This can be explained in the following manner and the following details have been obtained from the book on FEA by Bathe (Bathe, 1996). A finite element solution seeks to evaluate $\mathbf{U}$ from known $\mathbf{K}$ and $\mathbf{R}$ according to the following equation

$$
\begin{aligned}
\mathbf{K U} & =\mathbf{R} \\
\mathbf{U} & =\mathbf{K}^{-1} \mathbf{R}
\end{aligned}
$$

where $\mathbf{U}$ is the displacement vector, $\mathbf{R}$ is the applied force vector and $\mathbf{K}$ is called the stiffness matrix of the finite element model. $\mathbf{R}$ is assembled based on the applied forces on the model. $\mathbf{K}$ is found from the following equation

$$
\mathbf{K}=\sum_{m} \int_{V^{(m)}} B^{(m) T} C^{(m)} B^{(m)} d V^{(m)}
$$

where ' $m$ ' refers to the element number, $\mathrm{V}^{(\mathrm{m})}$ refers to the volume of the $\mathrm{m}^{\text {th }}$ element, $\mathrm{B}^{(\mathrm{m})}$ is the strain-displacement matrix of the $\mathrm{m}^{\text {th }}$ element and $\mathrm{C}^{(\mathrm{m})}$ is the elasticity matrix of the $\mathrm{m}^{\text {th }}$ element, which contains details of the material properties. ' $\mathrm{T}$ ' in the superscript indicates a transpose matrix operator. For a heavily non-linear finite element solution using implicit time integration, the complexity of $\mathrm{C}^{(\mathrm{m})}$ will greatly 
affect simulation time. An anisotropic material model can complicate $\mathrm{C}^{(\mathrm{m})}$ more than an isotropic model. Therefore an alternate simpler strategy was adopted. Unlike what is seen conventionally, the anisotropy in this chapter deals only with strength values and not stiffness values. Hence the material properties mentioned in the previous chapter apply here exactly.

It is hypothesized that the failure strength (defined herein as the resistance of the material to tearing associated with cyst propagation) in the direction called the rear face failure direction in Figure 5.1 is different from the failure strength in the side face failure direction also shown in Figure 5.1. From here on, the failure strength in the rear face failure direction is referred to by the acronym RF. Similarly, the failure strength in the side face failure direction is designated SF. SF and $\mathrm{RF}$ are related by the anisotropy ratio

$$
\alpha=\frac{S F}{R F}
$$

where $\alpha$ is assumed to be greater than or equal to 1 . Therefore, for values of $\alpha$ greater than 1, greater magnitudes of stress are required to fail the material at the sides relative to the rear of the cyst. The anisotropy ratio $\alpha$ therefore helps quantify varying levels of strength anisotropy in the tissue. 


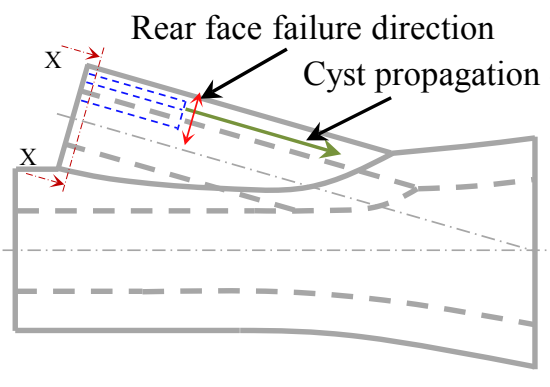

a. Stage-I cyst location

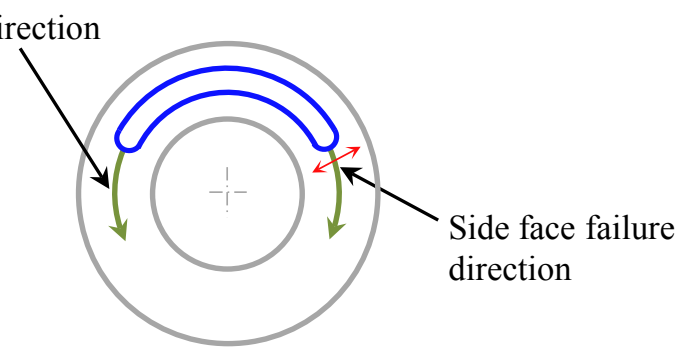

b. Section $X-X$

Figure 5.1 Directions of Material Failure

\subsection{FAILURE STRENGTH DETERMINATION}

An accurate determination of failure strength from experiments was performed by Mr. Morrow of Mayo clinic.

\subsubsection{Longitudinal Failure}

Two CPN specimens from the region immediately proximal to the AB-DPN-SPN junction were tested in tension until failure. The gage length for the two experiments was $20 \mathrm{~mm}$. The specimens were fresh and not fixed prior to testing. The nerves were strained at a constant rate of $0.025 \mathrm{~mm} / \mathrm{s}$ until failure. The test instrument used was ElectroForce 3000 and the specimens were mounted using custom made clamps with sinusoidal grip surfaces. Specimen hydration was maintained through the application of saline throughout testing. The force measured during the experiment was divided by the initial area to obtain the stress in the Lagrangian frame. The diameter of the CPN was obtained from Figure 4.8. The area 
of the CPN was calculated using the standard equation for a circle's area. The stretch was calculated from the following equation

$$
\lambda=\frac{\Delta l}{l_{g}}+1
$$

where $\lambda$ is the stretch along the length of the nerve, $l_{g}$ is the gage length and $\Delta l$ is the displacement. The stress-stretch curves are shown in Figure 5.2.

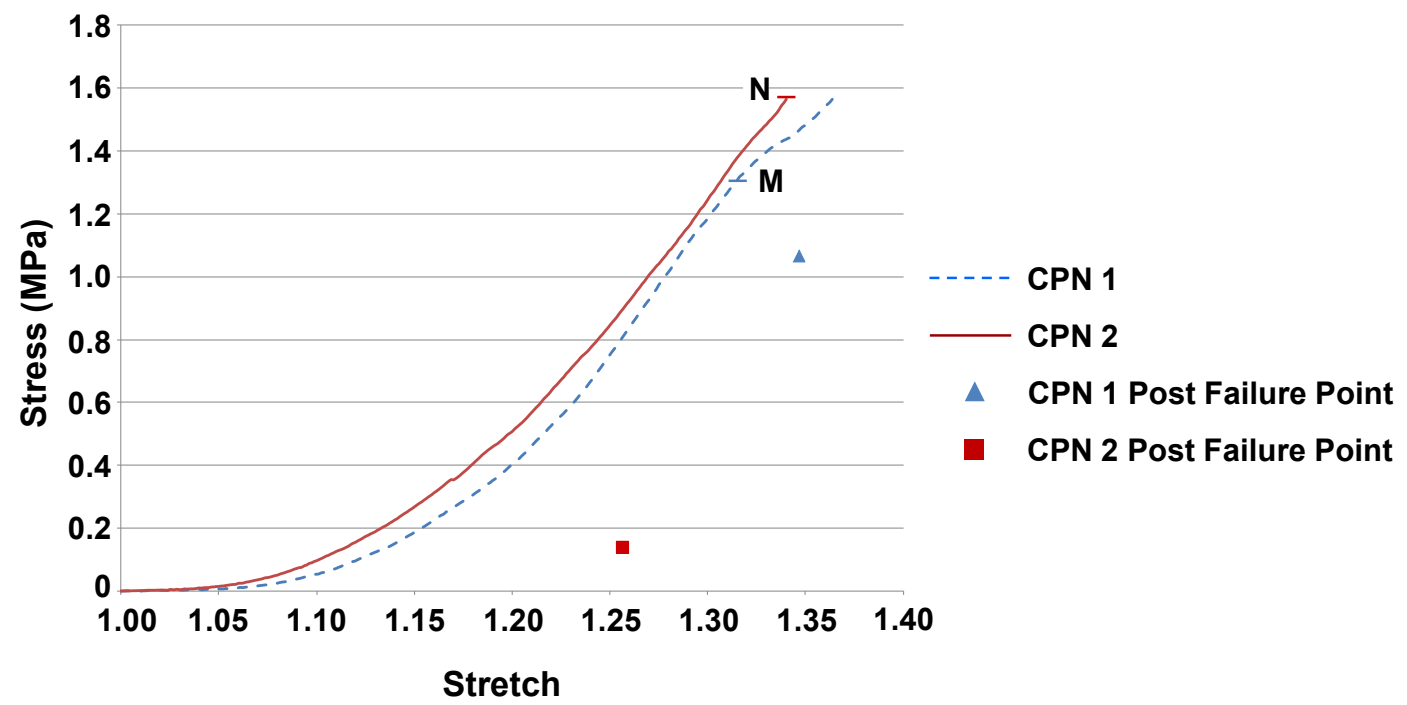

Figure 5.2 Experimental Failure Strength Determination

Post failure point load indicates the value indicated by the load cell once complete catastrophic failure of the nerve has occurred. The point $\mathrm{N}$ is the ultimate tensile point of CPN 2 with the corresponding stress being the ultimate tensile stress. This value is $1.57 \mathrm{MPa}$. For $\mathrm{CPN}$ 1, the point $\mathrm{M}$ is taken as the ultimate tensile point. This is because failure of the nerve is said to occur when there is onset of failure 
(material separation) in either the epineurium or the fascicle. Information on the failure of nerves was reviewed in a paper by Sunderland et. al. (Sunderland, 1961). They noted that in tensile tests the nerve failed progressively; the epineurium, nerve fibers and individual fascicles all failed separately at different load levels. This led to great uncertainty in assessing the failure strength of the nerve. Therefore to avoid confusion, in this study the nerve failure was correlated with the earliest failure onset in either the epineurium or the fascicle. In Figure 5.2, point $\mathrm{M}$ clearly indicates the beginning of yielding and this was verified by printing out the curve and using a straight-edge. Beyond point $\mathrm{M}$, there is also a stiffening effect that suggests progressive failure. Yielding is due to the onset of failure in either the epineurium or the fascicle. Hence the stress corresponding to point $\mathrm{M}$ is taken as the ultimate tensile strength for $\mathrm{CPN}$ 1. This value corresponds to $1.30 \mathrm{MPa}$. The average of the two values 1.57 and 1.30 (1.44) is taken as the longitudinal failure strength of the material.

\subsubsection{Transverse Failure Strength}

Properties of the nerve transverse to its length could not be measured. This is because Mr. Morrow of Mayo clinic reported that it was not possible to grip the nerve in the transverse direction with the existing apparatus. This same is also the reason why $\mathrm{RF}$ and $\mathrm{SF}$ values mentioned in section 5.2 could not be determined experimentally. No data on the transverse properties of nerve constituents could be found in the literature. 


\subsection{ANISOTROPIC FAILURE ANALYSIS}

\subsubsection{Stage-I Articular Branch}

The model used for the analysis of the $\mathrm{AB}$ was described in Chapter 4, section 4.2. For the work described in this chapter, the following changes were made:

(a) It was assumed that the anisotropy parameter, not used in Chapter 4, took values of 1,5 and 10 . The side face failure strength was determined with Equation (5.3) for each value of the anisotropy parameter.

(b) RF was $1.44 \mathrm{MPa}$ and this was fixed for all growth steps for every value of $\alpha$ (as opposed to $9.5 \mathrm{MPa}$ as was considered in the previous chapter). The value 1.44 $\mathrm{MPa}$ is the average value of the CPN longitudinal failure strengths whose measurements have been described in section 5.3.1. While RF and the longitudinal direction failure strength might be different, this approximation was adopted because of the great difficulties in measuring nerve properties in different directions.

(c) The applied pressure was $1.5 \mathrm{MPa}$ for all simulations performed except for Stage-I, $\alpha=1$, Growth step number 2 , in which case the applied pressure was $2 \mathrm{MPa}$. After performing step 1 for $\alpha=1$, the pressure was incremented to $2 \mathrm{MPa}$ in step 2 to see if the model could solve without convergence difficulties. Since step 2 solved with convergence problems, the pressure was reverted to $1.5 \mathrm{MPa}$. The influence of the variation in the absolute value of pressure on the predicted results is examined in section 5.7.2. 
(d) Being forewarned, the modeling approximations mentioned in the previous chapter (section 4.4.2) were avoided. This helps simulate a more natural cyst growth process.

\subsubsection{Stage-II *-branch}

The model for the *-branch analysis was the portion labeled "S-II" in Figure 4.7b, and its exterior dimensions were given in Figure 4.8. The configuration of the cyst in the epineurium remained the same as in Stage-I whereas its dimensions are different and are tabulated in Table 5.1.

\begin{tabular}{cc} 
Initial Values & Stage-II \\
\hline Cyst length, $l_{\text {cyst }}(\mathrm{mm})$ & 3.29 \\
Cyst arc angle, $\theta_{\text {cyst }}($ degree$)$ & 253.41 \\
Cyst outer radius, $r_{0}(\mathrm{~mm})$ & 1.705 \\
Cyst inner radius, $r_{i}(\mathrm{~mm})$ & 1.545
\end{tabular}

Table 5.1 Stage-II Cyst Dimensions

The length of the cyst was assumed to be one-third the total length of the model. This ensures that the rear face is farther enough from the AB-DPN junction. Being farther enough ensures that the cyst can exhibit its growth behavior during subsequent growth steps without any bias. This helps simulate a more natural growth process. The cyst arc angle was equal to the cyst arc angle of the last step of stage-I. This was the maximum value of the cyst arc angle that a cyst in the AB can 
have. The inner and the outer radii were chosen such that the cyst thickness remained the same as stage-I.

a) Similar to the $\mathrm{AB}$ model described in section 5.4.1, the rear face failure strength was fixed at $1.44 \mathrm{MPa}$ and the anisotropy parameter took values of 1, 5 and 10. The side face failure strength was determined with Equation(5.3) for each value of the anisotropy parameter.

b) The applied pressure value for every growth step in this branch was $1 \mathrm{MPa}$. Simulations for applied pressure values above $1 \mathrm{MPa}$ solved only with convergence problems and hence the pressure was reverted to $1 \mathrm{MPa}$. The influence of the variation in the absolute value of pressure on the predicted results is examined in section 5.7.2.

\subsection{ANISOTROPIC FAILURE ANALYSIS RESULTS}

Figure 5.3 shows the values of side and rear face growth in each growth step for values of $\alpha=1,5$ and 10 . Percentage growth values are plotted on the Y-axis. A growth percentage of $20 \%$ indicates that $20 \%$ of the maximum growth value was attained in that particular step. Maximum side growth value was the maximum value at which the proximal end of the cyst did not penetrate into the fascicle. The maximum rear face growth for stage-I was the value of growth when the rear face was at point $\mathrm{X}$ in Figure 4.15. Similarly in stage-II, it was the growth value when the rear face reached the proximal end of the stage-II model. Step 1 was the first growth step for each value of $\alpha$, which was performed with initial values of cyst dimensions (Table 4.1, Table 5.1). 


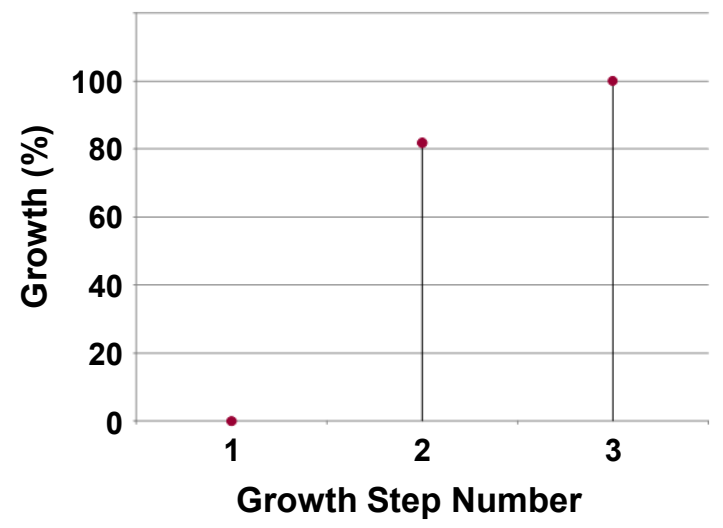

a. Side face growth for $\alpha=1$

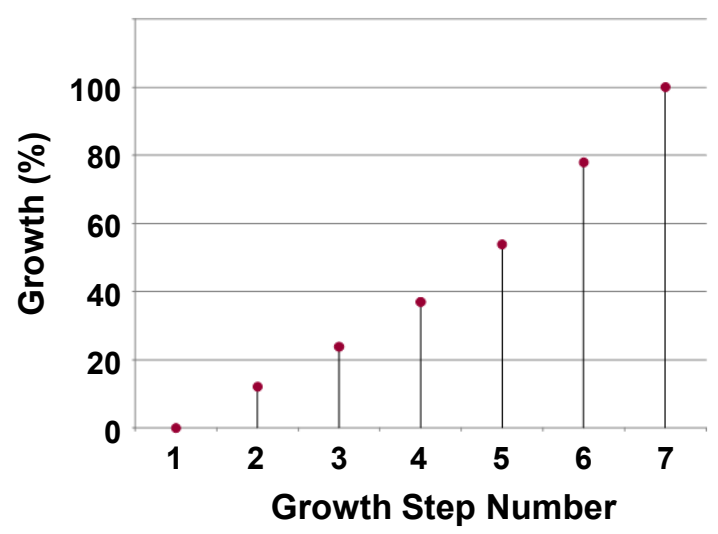

c. Side face growth for $\alpha=5$

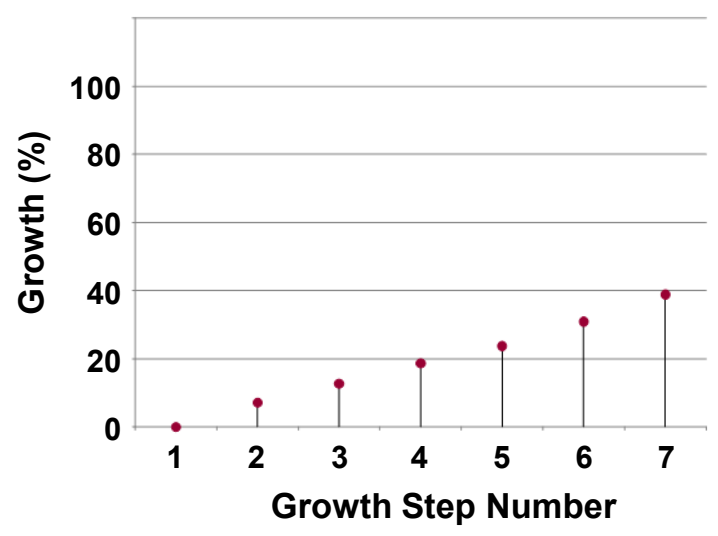

e. Side face growth for $\alpha=10$

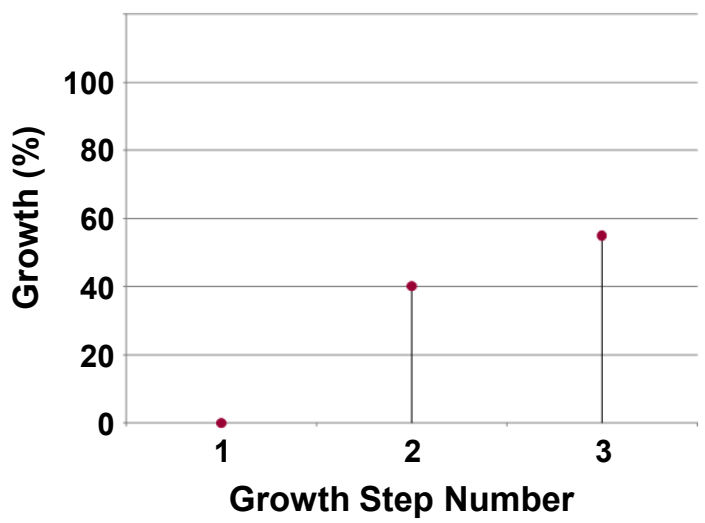

b. Rear face growth for $\alpha=1$

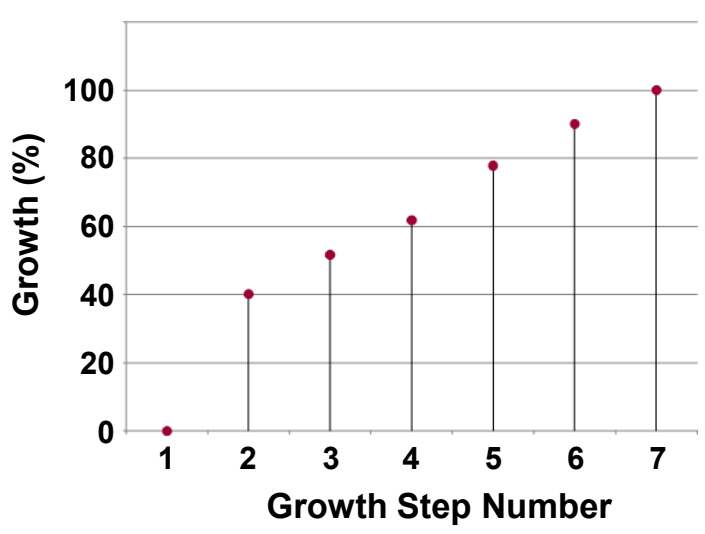

d. Rear face growth for $\alpha=5$

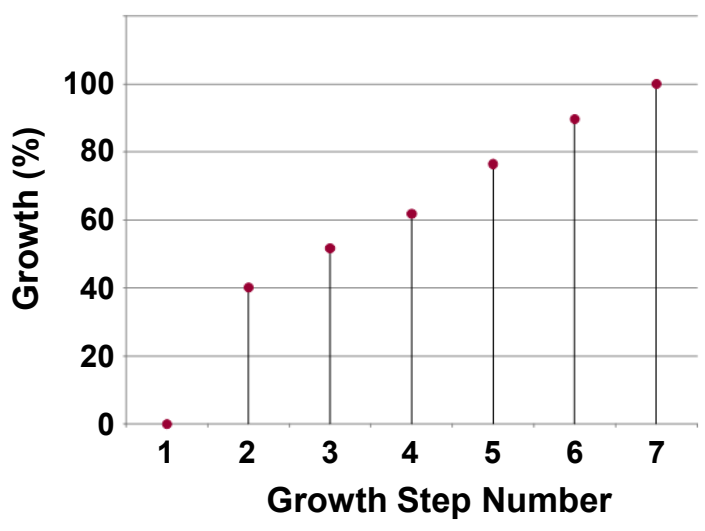

f. Rear face growth for $\alpha=10$

Figure 5.3 Stage-I Anisotropic Failure Analysis Results 
From the results of the step 1 simulations, growth values were determined and used to modify the cyst dimensions in step 2 as per the cyst growth methodology described in section 4.4 .

\subsubsection{Stage-I Results}

The trend of side face stress values being higher than rear face stress values was seen in all growth steps for every value of $\alpha$. The trend of side face stresses being predominantly higher than the rear face stresses is similar to the observation that was made in section 4.5.1. As shown in Figure 5.3a, for $\alpha=1$, the side face cyst growth reached its maximum value in three growth steps. As shown in Figure 5.3b, the rear face growth reached only $55 \%$ of the maximum possible growth value at the end of three growth steps. This difference in growth rates was due to greater stress magnitudes at the sides relative to the rear face. When $\alpha=5$, as shown in Figure 5.3c and Figure 5.3d, both the side and rear face cyst growth reached $100 \%$ growth in seven growth steps. Although there is greater stress magnitude at the cyst sides, there are fewer elements in which stresses exceeded the SF value. Hence, a larger number of steps were required to reach $100 \%$ growth relative to the case in which $\alpha=1$. When $\alpha=10$, as shown in Figure 5.3f, the rear face reaches $100 \%$ growth in seven steps. As shown in Figure 5.3e, the side-face cyst growth reaches only $38.84 \%$ in seven growth steps. Therefore, when the anisotropy parameter is high, cyst growth occurs much faster along the rear face. 


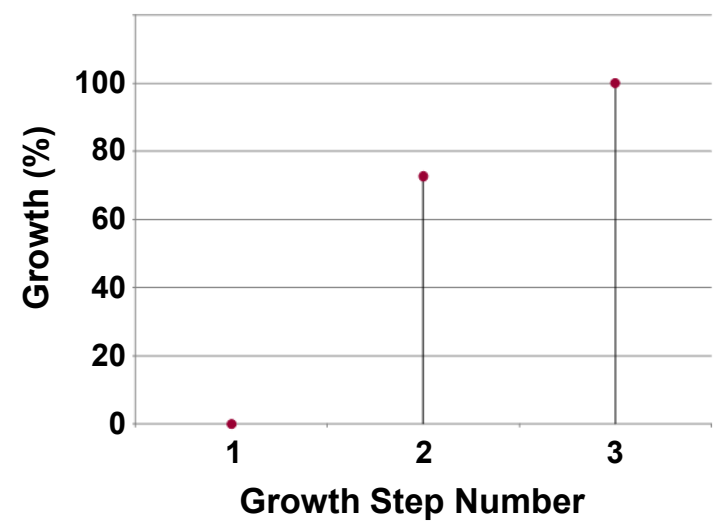

a. Side face growth for $\alpha=1$

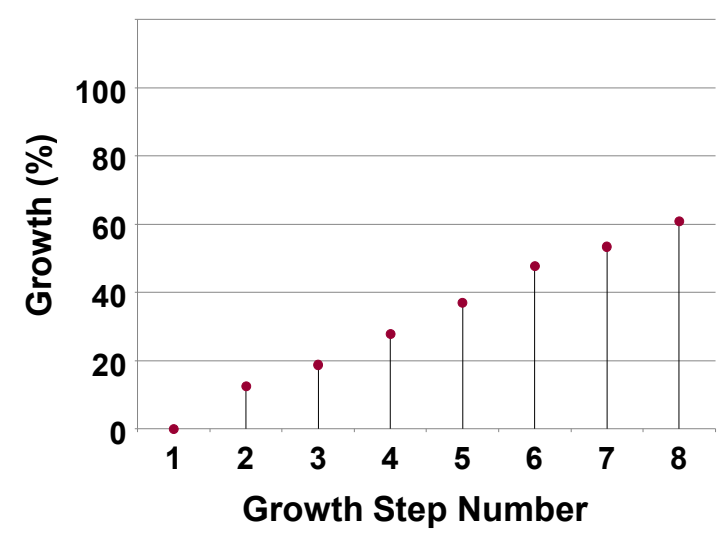

c. Side face growth for $\alpha=5$

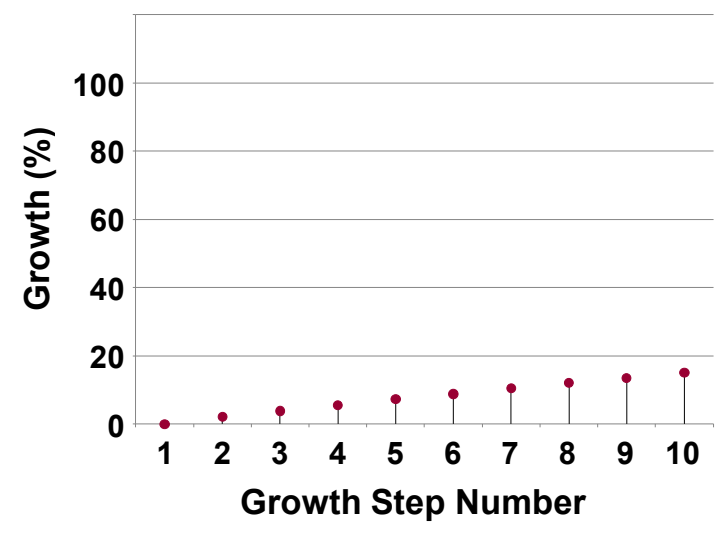

e. Side face growth for $\alpha=10$

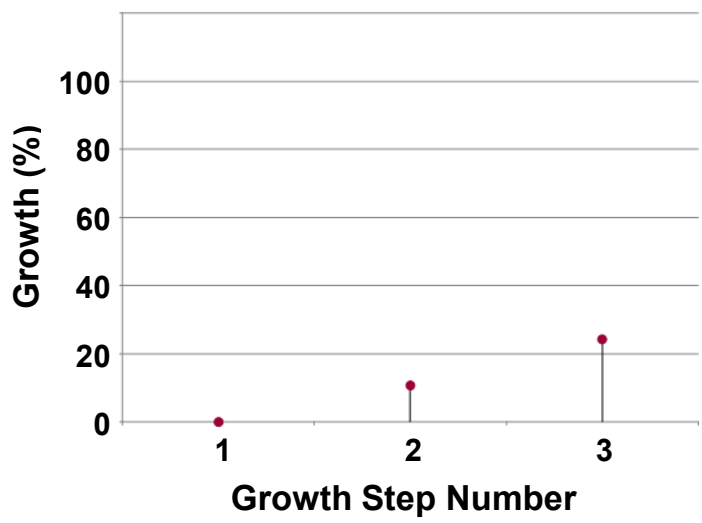

b. Rear face growth for $\alpha=1$

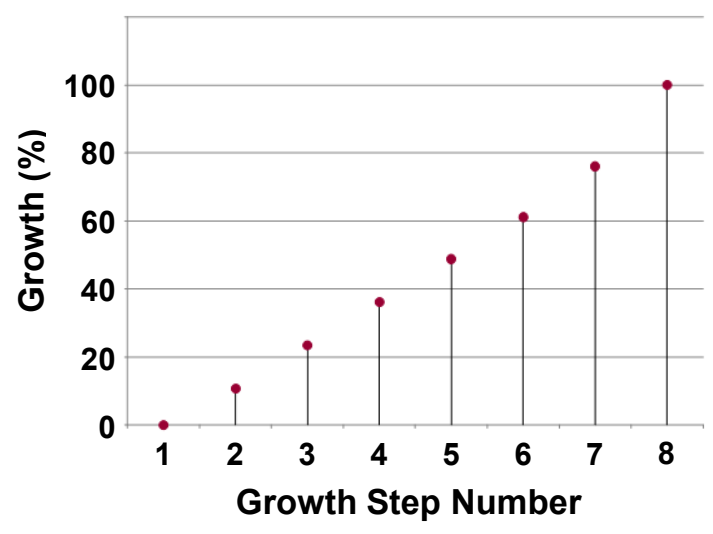

d. Rear face growth for $\alpha=5$

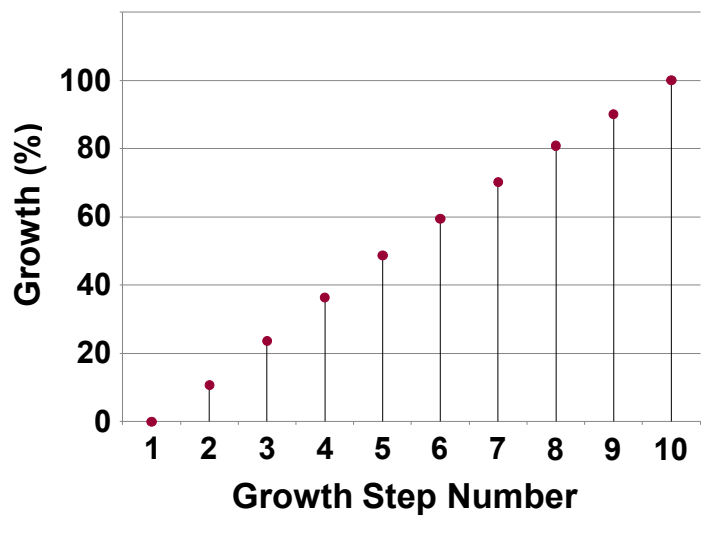

f. Rear face growth for $\alpha=10$

Figure 5.4 Stage-II Anisotropic Failure Analysis Results 


\subsubsection{Stage-II Results}

The trend of side face stress values being higher than rear face stress values was seen in all growth steps for all $\alpha$. Once again, this was similar to what was seen in section 5.5.1 and section 4.5.1. When $\alpha=1$, as shown in Figure 5.4a, the side face cyst growth reached $100 \%$ growth in three growth steps. As shown in Figure 5.4b, the rear face growth reached only $24.24 \%$ at the end of three steps. Clearly the higher stresses at the side faces caused quicker cyst growth compared to the rear face with the strength values being equal in both directions. As shown in Figure 5.4d for $\alpha=5$, the rear face cyst growth reached its maximum value in eight steps. As shown in Figure 5.4c, the side face growth reached only $60.8 \%$ of its total growth in eight growth steps. Comparatively, elements at the rear face in which stresses exceeded the corresponding failure strength were greater in number. When $\alpha=10$, as shown in Figure 5.4f, the rear face reached 100\% growth in ten steps. As shown in Figure $5.4 \mathrm{e}$, the side face cyst growth reached only $15.11 \%$ in ten steps. Under these conditions, very few elements at the sides failed in each step, leading to very little cyst side growth.

\subsection{CYST GROWTH ANALYSIS}

It has been clinically observed that the cyst growth proximal to the AB-DPN junction follows the pattern as shown in Figure 5.5a, where the cyst is restricted to a particular circumferential portion (i.e. a certain quadrant) of the epineurium (Spinner, Atkinson, Tiel, et al., 2003). In this case, the cyst only affects certain fascicles of the whole nerve. 


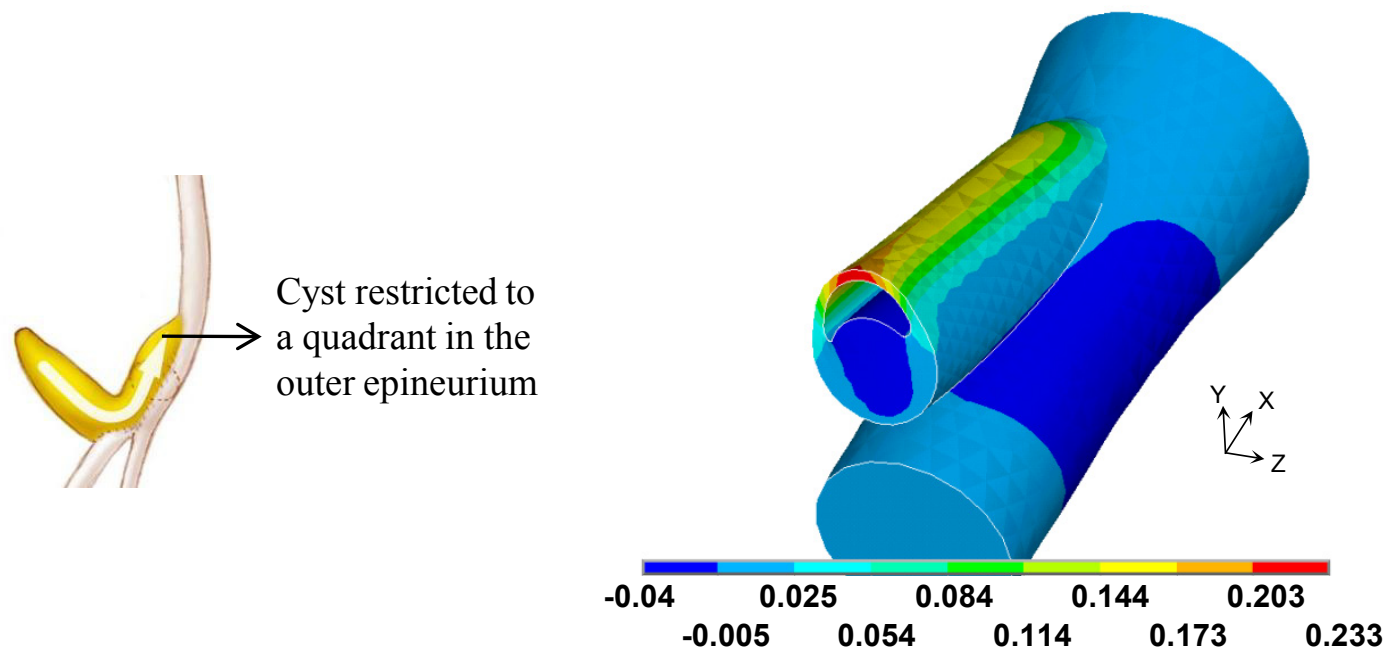

a. Cyst Propagation

b. Stage-I $\alpha=10 \mathrm{Y}$-direction displacement (mm)

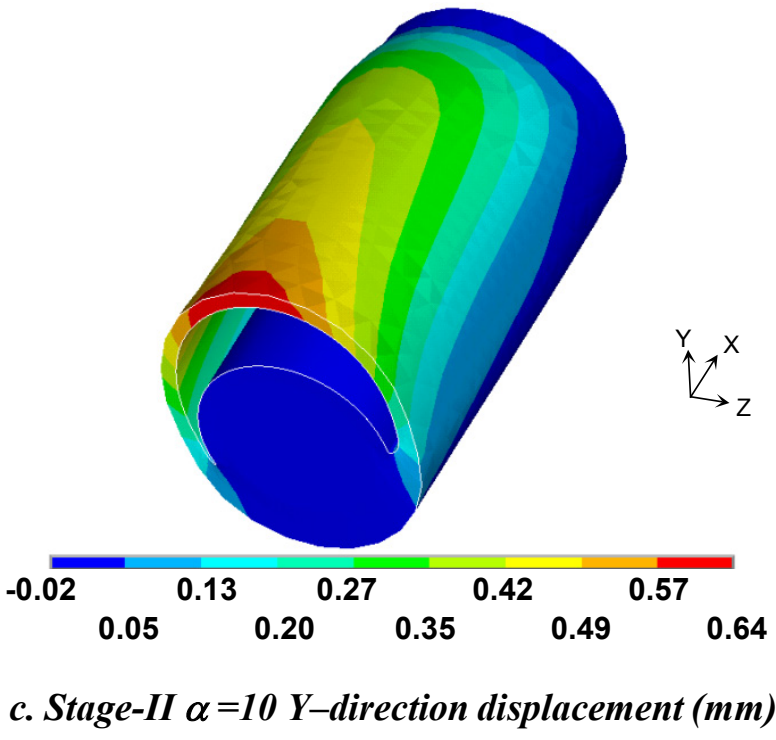

Figure 5.5 Restricted Quadrant Growth of IGC

(Figure 5.5 a copyrighted and used with permission of the Mayo Foundation for medical education and research, all rights reserved, see Appendix-A) 
This in turn causes problems in patients that pertain mostly to those specific fascicles (Spinner, Atkinson, Tiel, et al., 2003). Figure 5.5b shows the deformed shape for stage-I growth step seven when $\alpha=10$. The side growth is only $38.84 \%$ of its maximum value of growth while the rear growth has reached 100\%. Figure 5.5c shows the deformed shape for growth step 10 when $\alpha=10$ in stage-II. The side growth is only $15.23 \%$ of its maximum value of growth while the rear growth has reached $100 \%$. These images clearly correlate with the restricted circumferential pattern of cyst growth in Figure 5.5a. However, there are other variables in the study that need investigation. It is important to note that this model neglects the heterogeneous microstructure of the nerve by assuming it as a uniform continuum; how local tissue heterogeneity on the micro-scale affects cyst propagation and whether it influences restricted circumferential growth is beyond the scope of this dissertation. Also, anisotropy might exist in directions other than the mentioned directions in Figure 5.1, and the influence of those is not considered in this study.

\subsection{SENSITIVITY STUDIES}

Values used for the material properties or pressure are not exact values measured from experiments. They are best approximations of reality drawing on the information available regarding nerve structure and function. Therefore it is necessary to explore how a change in a material properties/pressure maintaining all other parameters constant affects predicted behavior. This is the subject of this section of the chapter. 


\subsubsection{Material Property Sensitivity}

Sensitivity to material properties is studied in the following manner: Cyst growth phenomena is investigated in stage-I for a material whose Mooney-Rivlin constants are an order of magnitude less than that used in section 4.2.2. No strength anisotropy is considered in this model (i.e. $\alpha=1$ ). The trend of the expected results is the same as that seen in section 5.5.1: that the side growth will reach its maximum value before the rear face growth. If this is true then it can be concluded that the predicted phenomena are independent of the material properties used within the scope of this study. The applied pressure for this model (0.15 $\mathrm{MPa})$ was an order of magnitude lesser compared to the original case. This is because since the structure is now less stiff due to the reduction in properties, the load it can bear is reduced. The material failure value (also a material property) is reduced by an order of magnitude. Therefore, in this study it is taken to be $0.144 \mathrm{MPa}$. The growth results are shown in Figure 5.6.
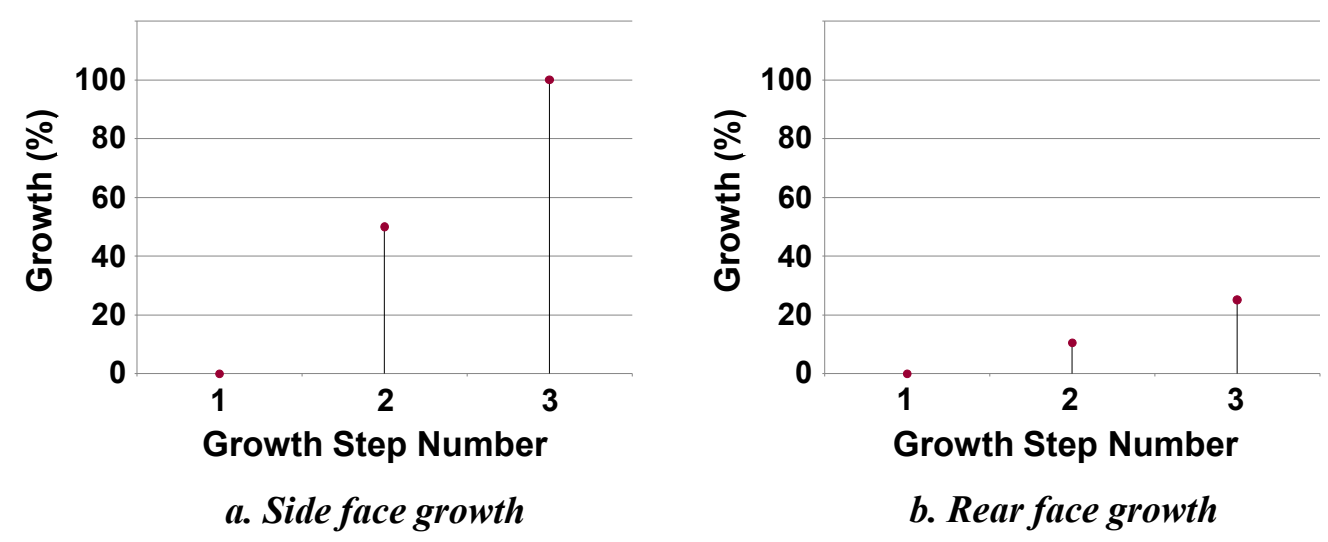

Figure 5.6 Material Property Sensitivity Studies 
The side face growth reached $100 \%$ of its maximum value in 3 growth steps. The rear growth at the end of three steps was only $25.15 \%$. Therefore the same trend in cyst growth has been predicted with an order of magnitude less properties. These results clearly indicate that the predicted phenomena in section 5.5.1 are independent of the material properties used within the scope of this study. A similar conclusion is suggested by the following observation. Cyst growth studies for $\alpha=1$ in both stage-I and stage-II (sections 5.5.1 and 5.5.2) indicate the same trend. When the same material properties predict the same trend in different nerve branches, the predicted phenomena should be independent of material properties. This of course pertains only to the hyperelastic incompressible properties used in this study.

\subsubsection{Pressure Sensitivity}

The supra-atmospheric pressure value in knee synovial joints (discussed in section 4.2.4) helps justify the positive values of pressure used in this study. However, the exact value of pressure inside IGC remains unknown. In this dissertation, the maximum value of pressure that the model could solve for is mentioned as the corresponding load. This is because it was necessary to find the envelope dimensions corresponding to the maximum value that the model could sustain. Hence it is necessary to understand if a change in the value of pressure maintaining all other parameters constant affects predicted phenomena. Therefore a stage-I cyst growth analysis was performed with the pressure being reduced to $0.75 \mathrm{MPa}$ and maintained constant throughout this study. This value of pressure was chosen such that it is significantly lower than currently used values (1.5-2 $\mathrm{MPa}$ ) and yet capable 
of producing failure in the nerve so that growth can be studied. The Mooney-Rivlin material constants described in section 4.2 .2 were used in this study. The material failure strength was fixed at $1.44 \mathrm{MPa}$ and no strength anisotropy was considered (i.e. $\alpha=1$ ). The growth results are shown in Figure 5.7. The side face growth reached $100 \%$ of its maximum value in 4 growth steps. The rear growth at the end of three steps was only $22.53 \%$. Therefore the same trend in cyst growth has been predicted with a reduced magnitude of pressure. These results clearly indicate that the predicted phenomena in sections 5.5.1 and 5.5.2 are independent of the value of pressure.
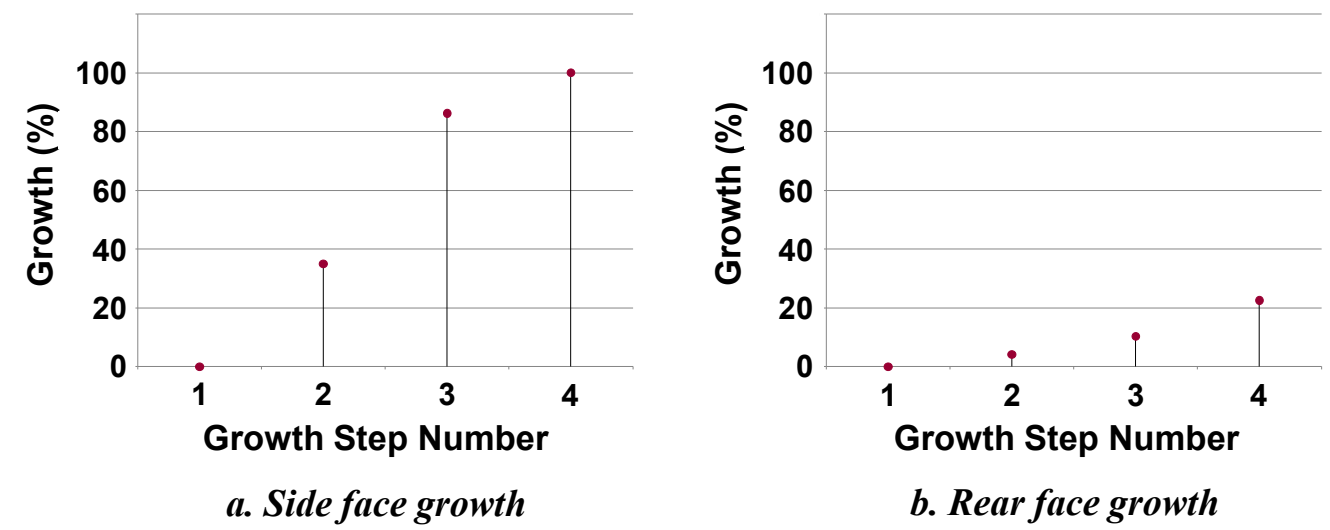

\section{Figure 5.7 Pressure Sensitivity Studies}

\subsection{SUMMARY}

An FEA model was developed that takes into account the anisotropy that arises out of the heterogeneity of the epineurium in nerve tissue. An anisotropy ratio that quantifies the degree of anisotropy in the material, in terms of material strength, was formulated and incorporated in the FEA model. For varying levels of the 
anisotropy ratio, cyst propagation analysis was performed in the $\mathrm{AB}$ and the *branch (for stage-I and stage-II, respectively). A plot of cyst growth per simulation step for each stage shows that cyst propagation varies significantly with the anisotropy parameter. The results in both stage-I and stage-II simulations for high levels of anisotropy match the clinically-observed circumferential cyst propagation pattern in the region of the nerve proximal to the AB-DPN junction. 


\title{
6. CROSS-SECTION ANALYSIS OF AN INTRANEURAL GANGLION CYST AFFECTED NERVE
}

\author{
Shreehari Elangovan, Gregory Odegard, \\ Michigan Technological University, Houghton, MI 49931, USA \\ Duane Morrow, Huan Wang, Marie-Noëlle Hébert-Blouin and Robert \\ Spinner, \\ Mayo Clinic, Rochester, MN 55905, USA
}

\subsection{INTRODUCTION}

Chapters 4 and 5 studied cyst growth behavior in a nerve junction in three dimensions. The nerve cross-section was assumed to be circular in those studies in view of reducing simulation time and modeling complexities. However, the crosssection of a nerve is more close to elliptical than circular. Studying the evolution of a cyst in a nerve cross-section in two dimensions can provide valuable information on the growth of a cyst. Accordingly, in this chapter the outer geometry of the epineurium of the $\mathrm{CPN}$ cross-section at the fibular neck was traced and replicated to actual nerve dimensions in Abaqus 6.8. The cyst was represented in a location that best corresponds to a cyst in the AB. A two dimensional cyst growth technique was used to simulate cyst growth. Results indicate a resemblance with MRI images and also emphasize the need to be able to simulate larger strains to obtain better correlations with MRI images. 


\subsection{NERVE CROSS-SECTION DETAILS}

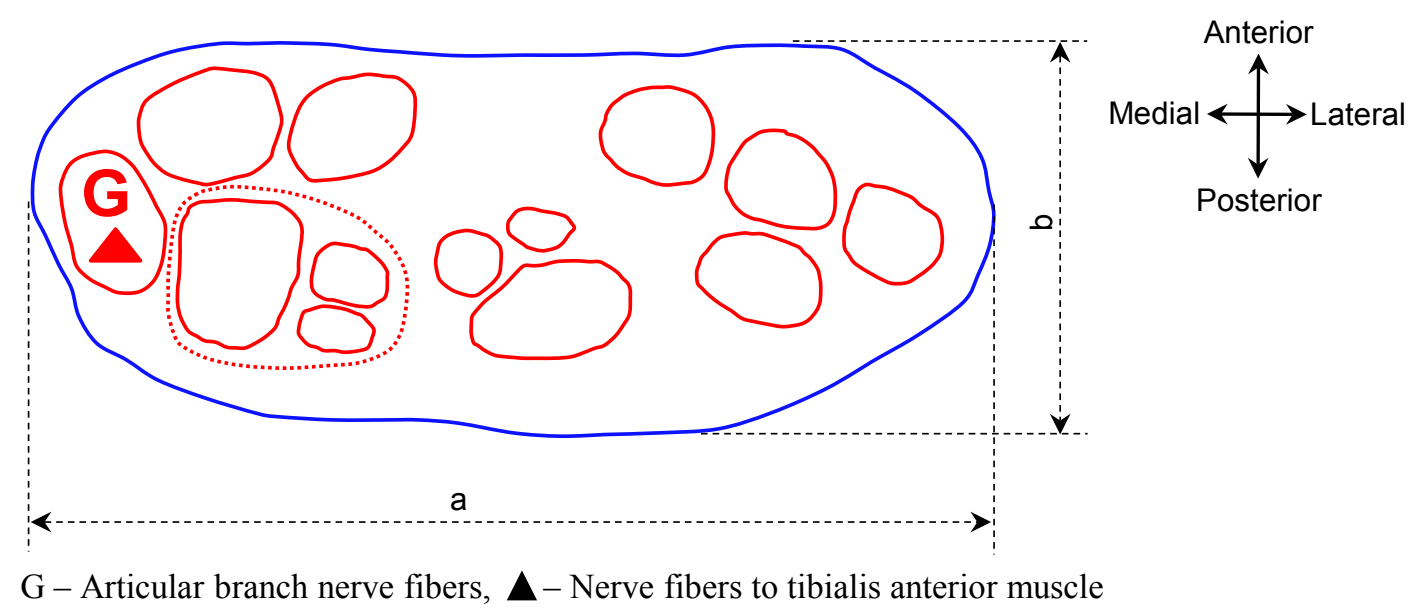

Figure 6.1 CPN Cross-Section Details

(Reproduced with permission of Oxford university press: Sunderland $S$, The intraneural topography of the sciatic nerve and its popliteal divisions in man, Brain, v. 71, p. 242-273, 1948, see Appendix-A)

An elaborate investigation of the complicated internal architecture of the CPN at various levels distal to the sciatic bifurcation has been previously published (Sunderland \& Ray, 1948). Figure 6.1 shows the details of the CPN cross-section at the level just before it splits into the *-branch and the SPN near the neck of the fibula (Figure 4.7a). The outer blue elliptical line in Figure 6.1 represents the outer boundary of the epineurium. The red, oval shapes inside this blue boundary represent the fascicles. Interspersed in the regions between the red oval shapes is the epineurial tissue. The fascicles have been labeled according to specific muscle they innervate. Only the fascicles that are relevant in the context of the current study have been labeled in Figure 6.1. In this study, the aim is to investigate the growth of a cyst in two-dimensions in the location most probable for a cyst propagating proximal from the AB. Therefore the fascicles of interest are fascicle ' $\mathrm{G}$ ' 
that refers to the nerve fibers of the $\mathrm{AB}$ and the solid triangle that represents the nerve fibers of the tibialis anterior muscle, which is the muscle associated with the clinical condition of foot drop. The details about foot drop are given in section 4.1.

\subsection{FINITE ELEMENT MODEL}

The geometry of the outer boundary of the epineurium shown in Figure 6.1 was scanned and imported into Abaqus 6.8. The finite element model of the cross-sectiion is shown in Figure 6.2. The major axis 'c' of the finite element model was adopted as the CPN dimension measured by Drs. Wang and Spinner. The value of dimension 'c' is $5.7 \mathrm{~mm}$ (as shown in Figure 4.8). The minor axis 'd' was scaled down by using the following relation

$\frac{\text { Major axis dimension when printed (a) }}{\text { Minor axis dimension when printed (b) }}=\frac{\text { Major axis dimension in FEA model (c) }}{\text { Minor axis dimension in FEA model (d) }}$

In equation (6.1), 'a' and 'b' are measured by obtaining a print out of Figure 6.1 on paper. Then according to equation (6.1), dimension 'd' was obtained to be $2.52 \mathrm{~mm}$. Although the initial objective of this two-dimensional model was to model the individual fascicles and epineurium discretely, the entire nerve cross-section was modeled as a solid material of homogenous properties. This assumption was made for two reasons. First, the mechanical properties of the individual nerve constituents are not currently known, so an FEA model incorporating individual fascicles would not be any more accurate than a FEA model that is homogeneous. 


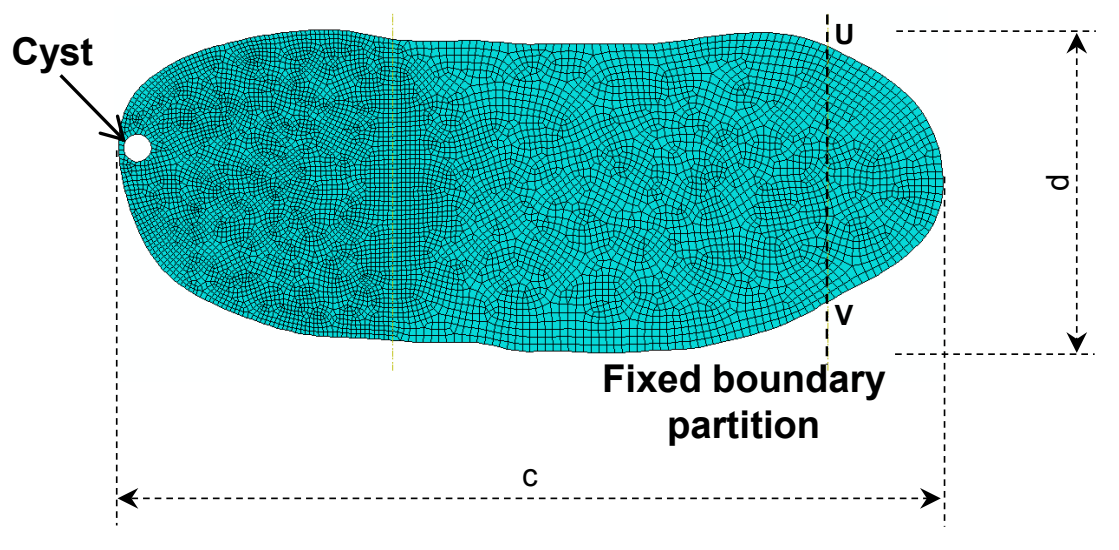

Figure 6.2 Finite Element Model

Second, because of the approach adopted herein for modeling cyst growth (described in section 6.4), the presence of discrete entities in the modeled nerve created modeling problems. This is explained at the end of section 6.4 since it is necessary to understand the cyst growth technique used herein to understand this problem.

In the FEA model, the cyst was located in the region medial to the fascicle labeled 'G', which contains the $\mathrm{AB}$ nerve fibers as shown in Figure 6.1. This cyst location was chosen since this is the most probable location for a cyst originating in the $\mathrm{AB}$ and propagating proximally into the CPN, according to Drs. Wang, Hebert-Blouin, and Spinner of Mayo Clinic. Due to the lack of any guiding data, an initial cyst diameter of $0.18 \mathrm{~mm}$ was chosen. This dimension helps locate the cyst between the fascicle ' $G$ ' boundary and the outer epineurium boundary.

The model was meshed with four-node quadrilateral elements with reduced integration ('S4R' elements in Abaqus 6.8). The incompressible isotropic Mooney- 
Rivlin hyperelastic material model discussed in section 4.2.2 was used. Geometric nonlinearity was accounted for and implicit time integration was used. The boundary conditions consisted of an internal pressure load and an external displacement constraint. The pressure boundary condition was applied on the cyst edges. The applied pressure ranged between $0.1-0.006 \mathrm{MPa}$ for the individual growth steps, depending on what the maximum pressure the model could solve for in a given step. A discussion on the selection of pressures for the finite element model is in sections 4.2.4 and 5.7.2. The displacement constraint was applied in all directions to a segment of the outer epineurium boundary to the right of the fixed boundary partition between the points marked by letters $U$ and V, shown in Figure 6.2. This was done so that rigid body motion of the model does not cause errors in the finite element solution.

\subsection{CYST GROWTH TECHNIQUE}

The ideal approach to modeling the growth of the cyst is to simulate the internal pressurization and the subsequent expansion of the cyst cavity. For this it is necessary to simulate strains in excess of $100 \%$ in the material. However, in the previous chapters the maximum strain obtained was only $19 \%$. Indeed FEA can only simulate strains for such a complicated problem to such an extent. Because this research was focused on using FEA to simulate the growth of the cyst, an alternative approach was taken. Instead of simulating the balloon-like expansion of the material around the cyst (which would require simulated strains well beyond 100\%), the cyst growth was modeled in the same manner as described in Chapters 4 and 5 . 
That is, it was assumed that the cyst grew via local material failure instead of extensive hyperelastic deformation. The following are the steps in the cyst propagation process:

a) The failure strength of the material was fixed at 1.44 MPa. The details about the measurement of this value are given in section 5.3.1. Even though this value was measured along the length of the nerve, it is used here in a different direction since it is the most realistic failure strength value available. Any other assumption will have to be completely arbitrary.

b) After the first finite element simulation was performed, all elements around the cyst in which the stresses exceeded 1.44 MPa were determined ('display groups' option in the Abaqus 6.8). A finite element simulation that corresponds to a certain initial cyst diameter is referred to as a growth step.

c) A circular envelope centered at the cyst center was established around the failed elements. The difference in radius between the initial cyst radius and the circular envelope radius represented the growth increment for the next growth step. This approach is based on the same assumption discussed in Section 4.4, that is, the elements in which the failure strength is exceeded can no longer sustain the load, and hence they are torn. Hence in the threedimensional case cyst growth referred to an increase in cyst volume and in this two-dimensional case it corresponds to a change in cyst area.

d) The modified cyst radius was calculated as the sum of the initial cyst radius and the growth increment. This modified cyst radius was then used as the initial cyst dimension in the subsequent growth step. This step-by-step procedure was performed until the cyst reached its maximum size in the 
cross-section. The maximum size reachable in the cross-section is dictated by the length of line segment UV in Figure 6.2. How the maximum cyst size in the cross-section was determined is explained in the results section.

Two points need to be noted. First, after 4 steps the cyst could not be grown further as perfectly circular. This is because the circular envelope dimensions would have exceeded the boundaries of the nerve cross-section. Hence beyond this step, the cyst shape was changed to elliptical. The minor axis of the ellipse was fixed at the value of the envelope diameter in growth step 4. The growth in further steps was incremented only in the major axis of the ellipse.

Second, at step 13, the size of the cyst was significantly large. At this stage, the fixed boundary partition shown in Figure 6.2 was moved to the right by $0.4 \mathrm{~mm}$ thereby reducing the portion of the edge that was completely constrained from displacing in all directions. This was done to prevent the boundary conditions from interfering with the deformation of the large cyst.

In Abaqus 6.8, the regions corresponding to fascicles if created would have separate boundaries with different edge numbers. As the cyst radius was increased from one growth step to another, the cyst boundary would have interfered with individual fascicle boundaries. This would have made tracking the edge numbers of the cyst very difficult. This was the second reason why individual fascicle boundaries were not modeled in the finite element model in section 6.3. 


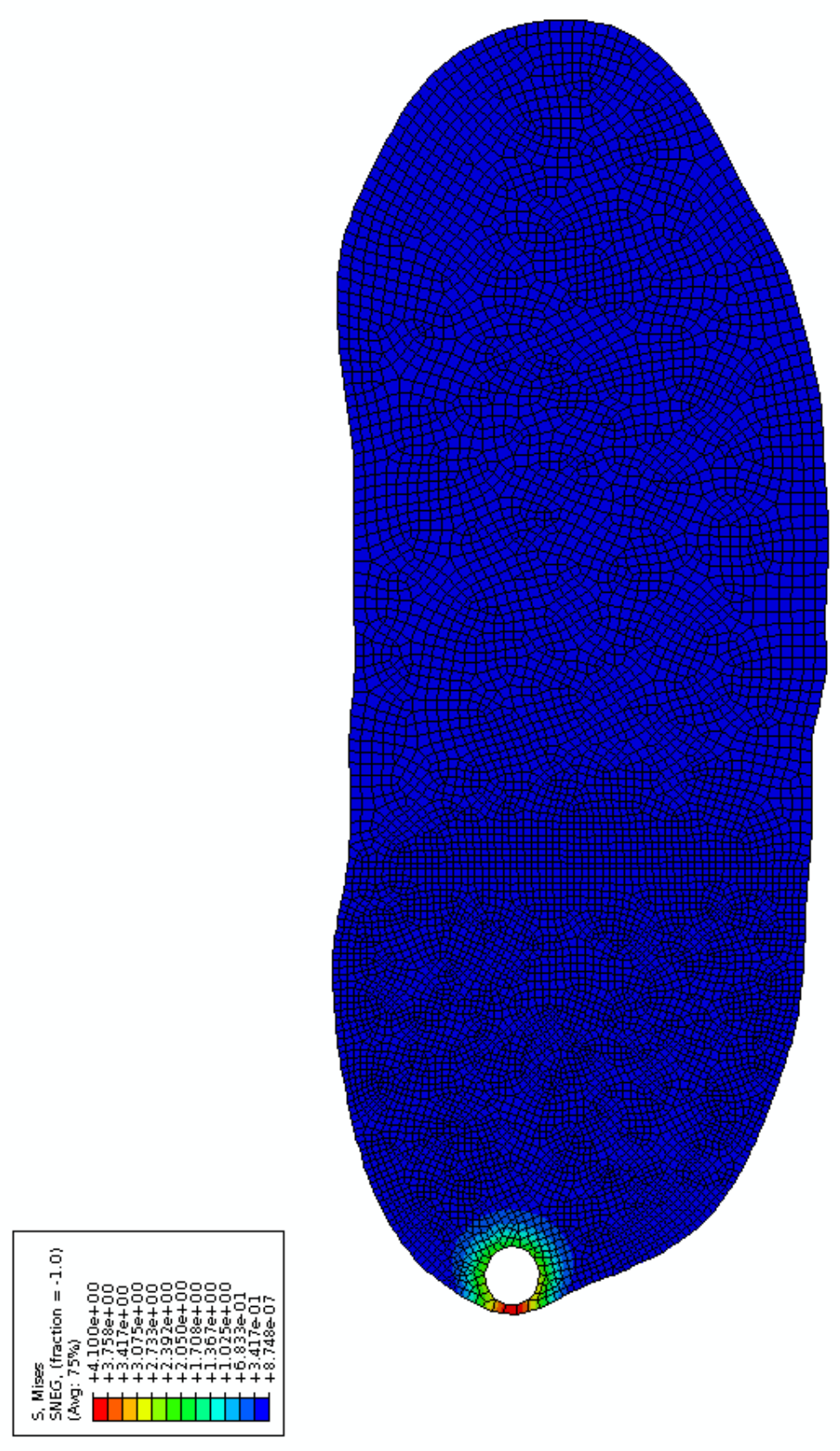

Figure 6.3 von Mises Stress (MPa) Distribution - Growth Step 1 


\subsection{RESULTS}

A total of 13 cyst growth steps were performed including the initial simulation to reach the maximum cyst size reachable in this cross-section. This was determined based on the biggest cyst growth possible with the smallest region of displacement constraint on line segment UV. For further cyst growth beyond this growth step the fixed boundary condition partition in Figure 6.2 would have to have been moved much further to the right of the model in order to prevent the fixed boundary condition from hampering cyst deformation. If this were done, then the model would be constrained in a very limited location that would have caused rigid body motion errors in the software. A plot of von Mises stresses on the CPN cross-section for the initial simulation is shown in Figure 6.3. The stresses around the cyst varied from $0.683 \mathrm{MPa}$ to $4.1 \mathrm{MPa}$. The emphasis in this chapter is not on the exact value of stresses around the cyst but rather on the deformed shape of the cyst in each growth step. Therefore a plot of the deformed shape for each growth step starting with the first growth step is shown in Figure 6.4. Growth step-1 represents the simulation performed with the initial cyst size and growth step-13 was the maximum size to which the cyst could be grown. Growth step-5's deformed shape is different from the previous growth steps since the shape from then on was changed to elliptical.

\subsection{CYST GROWTH ANALYSIS}

Figure 6.5a (Spinner, Scheithauer, et al., 2006) shows the MRI image of a CPN cyst at the level of the fibular neck. 


$$
\begin{aligned}
& 0000 \\
& 000 \\
& 010 \\
& 10
\end{aligned}
$$


The bright white region seen in the zoomed inset is the cystic region filled with cyst fluid. At the base of this white region a little to the right is seen a light grayish region that represents the fascicles of the $\mathrm{CPN}$ that have been compressed due to cyst blow-out in the nerve. Spinner et. al. (Spinner, Desy, et al., 2006) have coined the name 'signet ring sign' for this cystic representation since the eccentrically displaced fascicles along with circumference of the white cystic region strongly resembles a signet ring. The signet ring sign represents adverse compression of the fascicles by the accumulating cyst fluid.

Figure $6.5 \mathrm{~b}$ shows the deformed shape of step-13. Comparing Figure $6.5 \mathrm{~b}$ with Figure 6.5a, the manner in which the cyst has blown out in Figure $6.5 \mathrm{~b}$ bears resemblance to the cyst blow out in Figure 6.5a. The MRI image shows eccentric accumulation of compressed matter whereas the FEA result indicates unfailed material around the circumference of the cyst. Though Figure 6.5a and Figure 6.5b bear resemblance, the deformed shape in Figure 6.5a has been caused due to compression of the fascicular material whereas in Figure 6.5b it has been caused due to the progressive removal of failed material. Therefore correlations are counterintuitive. This however emphasizes the need to be able to produce large compressive strains in the fascicular matter so that correlations are possible with the MRI image. Therefore it is necessary to select a simulation tool that can produce strains in excess of $100 \%$ unlike FEA which can only simulate few tens of percents of strain. 


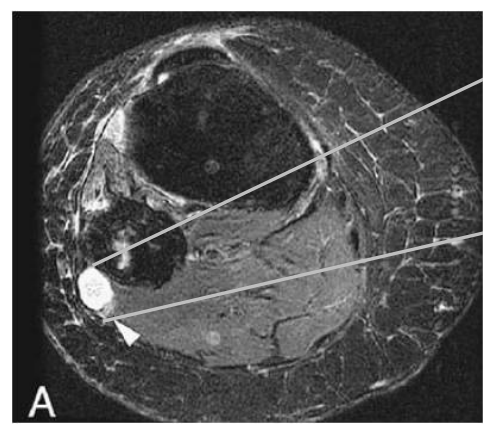

a. MRI Image of a CPN Cyst

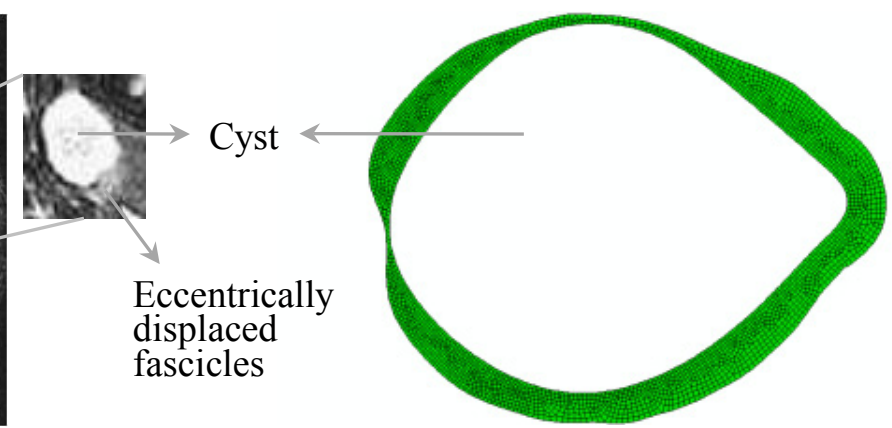

b. Deformed shape of growth step-13

Figure 6.5 Signet Ring Sign Correlation

(Image 'a' reprinted with kind permission from Springer Science+Business Media: Skeletal Radiology, Coexisting secondary intraneural and vascular adventitial ganglion cysts of joint origin: a causal rather than a coincidental relationship supporting an articular theory, v.35, 2006, p.734-744, Authors - Spinner RJ, Scheithauer BW, Desy NM, Rock MG, Holdt FC and Amrami KK, Fig. 1, see Appendix-A)

\subsection{SUMMARY}

The primary objective of this study was to predict the growth of an IGC with a twodimensional FEA model. The two-dimensional model of the CPN at the neck of the fibula was constructed using dimensions provided by clinicians and the geometry provided by Sunderland et al. (Sunderland \& Ray, 1948). The initial cyst was located in the region medial to the nerve fibers that distally branched-out into the AB. Cyst fluid pressure was simulated by a pressure boundary condition on the edges of the cyst. Boundary condition constraints were placed in a small region of the boundary away from the cyst to prevent rigid-body errors. A cyst growth technique was used according to which elements in which stresses exceeded a critical strength value were removed from the model to simulate material failure (tearing). The cyst was grown to the maximum possible extent in this manner and the deformed shape of the final growth step resembles the 'signet ring sign' pattern observed in MRI 
images of CPN cysts. However, the MRI image and the FEA result represent different scenarios and hence correlations are not possible. To be able to correlate with MRI images, a simulation tool that can accurately replicate the large strains in the fascicular region is needed. 


\section{FEA OF INTRANEURAL GANGLION CYSTS - CONCLUSIONS}

\subsection{RESEARCH SIGNIFICANCE}

IGC have been considered curiosities for nearly 2 centuries. Different theories without a scientific basis have been proposed (Elangovan et al., 2009). Dye experiments have been used by clinicians to demonstrate the path of cyst growth. While they are capable of indicating the path of cyst growth, they are unable to answer why it does so quantitatively in a particular direction. Herein a novel mechanistic approach (FEA) was adopted in this dissertation to study IGC growth. Chapter-4's objective was to devise a mechanistic approach for predicting the growth of IGC in the $\mathrm{AB}$ of the $\mathrm{AB}-\mathrm{DPN}$ junction. FEA, a computational tool that has been popularly used to study the mechanical behavior of biological systems, was chosen for this purpose. The FEA model considered nerve dimensions, material properties based on reinforcing architecture and knowledge of pressures inside knee synovial joints in studying cyst growth. Unlike dye experiments, the FEA model made it possible to view the forces causing cyst growth inside the cyst. Based on the stresses inside the cyst, cyst growth was simulated assuming a material failure criterion. This helped understand the parameters of cyst growth in a nerve branch. The methodology developed in Chapter-4 can be applied to other nerve branches as well. This was applied to study the restricted quadrant growth of IGC (in the AB and *branch) in Chapter-5. The restricted quadrant growth of IGC has not been studied 
using any technique previously. Using a strength anisotropy assumption, FEA results were computed and found to match the real behavior. However, the validity of strength anisotropy in nerve tissue needs to be validated using experiments. Chapter-6's objective was to study the evolution of cyst growth in two-dimensions. A cyst growth assumption using a material failure criterion was used to simulate cyst growth in two-dimensions. The model at the final stage of the cyst growth phase resembles the signet ring sign MRI image of the CPN. FEA was however incapable of replicating the large strains necessary for predicting cyst growth.

The above studies confirm the promise in using a mechanistic method to quantitatively predict forces causing growth in IGC. Therefore the contribution of this thesis was to validate mechanistic methods as tools to predict cyst growth. Clearly the necessity to be able to produce large strains in the material is also seen. Also, the ability to predict results that are accurate in any chosen mechanistic method need accurate representation of material microstructure, material property input to the model and extensive comparative studies between the mechanistic method and reality (discussed in the next section).

\subsection{FUTURE WORK}

The current study has yielded valuable inferences which can be used to better the FEA model in the future. The first and foremost of these are the computational issues. The FEA models in both Ansys 11 and Abaqus 6.8 could produce only tens of percents of strain for the current geometry and material model. Element distortions 
prevented the models from converging for higher values of load. For producing the high strains in nerve tissue, a new method that tackles element distortion effectively is necessary. Various meshless methods (Nguyen, Rabczuk, Bordas, \& Duflot, 2008) have been shown to effectively tackle mesh distortions. However, the promise of any new method has to be checked by looking for its capability to produce large deformations through large strains not large displacements. The three-dimensional modeling was carried out only in Ansys 11. As mentioned in section 4.4.2, important Boolean operations could not be performed. It is necessary that software chosen in the future be capable of modeling complicated geometries. Another issue is that of computational efficiency. In Ansys 11, all simulations could only be run on a single processor because a different license would have been necessary to run it on multiple processors. For more realistic simulations incorporating complicated physics, parallelizing the simulation is necessary.

FEA is a tool that relies heavily on its input data to produce reliable outputs. The current material properties have been assumed based on strong similarities with other biological materials. Providing real experimental data will increase the certainty of the results. The experimental estimation of material properties of a greatly anisotropic material as nerve is very difficult. For a start, differences in morphology between different nerve branches may be safely ignored. Therefore, properties might be estimated from a sufficiently large nerve such as the sciatic nerve. Herein, properties in every direction are not important. As mentioned in section 4.2.2, properties in two directions are crucial for this problem: tensile behavior of the epineurium transverse to the nerve's length and compressive 
behavior of the fascicle transverse to the nerve's length. Once this information is available realistic deformations can be expected in the FEA model (provided large strains without distortion can be produced). The failure strength in the direction transverse to the nerve's length is also important. This will have a huge say on the growth values for each growth step.

The following are suggestions that may be considered only in the long run. Sunderland et. al. (Sunderland \& Ray, 1948) suggest that the morphology of a nerve varies between different regions of the body. For example, a small nerve branch as the $\mathrm{AB}$ can differ significantly from a large nerve such as the sciatic nerve. Incorporating such differences require explicit modeling of the microstructure. While this is computationally very intensive, only such models can be used for predictions of clinical phenomena with high levels of accuracy. Also, influence of extrinsic resisting forces (defined in section 4.1.3.2) has to be determined. They may introduce an additional variability in dictating cyst growth. 


\section{REFERENCES}

Anderson, T. L. (2004). Fracture Mechanics: Fundamentals and Applications: CRC Press.

Bathe, K.-J. (1996). Finite Element Procedures (6 ed.): Prentice-Hall of India Private Limited.

Bedford, A., \& Stern, M. (1972). A Multi-Continuum Theory for Composite Elastic Materials. Acta Mechanica, 14(2-3), 85-102.

Beer, F. P., Johnston Jr., E. R., Mazurek, D. F., Cornwell, P. J., \& Eisenberg, E. R. (2010). Vector Mechanics for Engineers: Statics and Dynamics: The McGrawHill Companies, Inc.

Cowin, S. C., \& Doty, S. B. (2007). Tissue Mechanics: Springer Science + Business Media, LLC.

Daniel, I. M., \& Ishai, O. (1994). Engineering Mechanics of Composite Materials: Oxford University Press.

De Schrijver, F., Simon, J. P., De Smet, L., et. al. (1998). Ganglia of the superior tibiofibular joint: Report of three cases and review of the literature. Acta Orthopaedica Belgica, 64(2), 233-241.

Desy, N. M., Amrami, K. K., Spinner, R. J., \& Mp. (2006). Ganglion cysts and nerves. Neurosurgery Quarterly, 16(4), 187-194.

Dowling, N. E. (2006). Mechanical Behavior of Materials: Prentice Hall.

Easterling, K. E., Harrysson, R., Gibson, L. J., \& Ashby, M. F. (1982). On the Mechanics of Balsa and Other Woods. Proceedings of the Royal Society of London Series A-Mathematical Physical and Engineering Sciences, 383(1784), 31-41.

Elangovan, S., Odegard, G. M., Morrow, D. A., Wang, H., Hebert-Blouin, M. N., \& Spinner, R. J. (2009). Intraneural ganglia: a clinical problem deserving a mechanistic explanation and model. NEUROSURGICAL FOCUS, 26(2).

Ellis, V. H. (1936). Two Cases of Ganglia in the Sheath of the Peroneal Nerve. British Journal of Surgery, 24(93), 141-142.

Eringen, A. C. (1999). Microcontinuum Field Theories 1: Foundations and Solids: Springer-Verlag New York, Inc.

Eringen, A. C. (2003). Micropolar mixture theory of porous media. Journal of Applied Physics, 94(6), 4184-4190.

Faivre, J., Chatel, M., Le Beguec, P., et. al. (1975). Les pseudo-kystes mucoides de la gaine du nerf sciatique poplite externe. A propos de deux observations. Rev Neurol, 131(NA), 709-720.

Fung, Y. C. (2004). Biomechanics: Mechanical Properties of Living Tissues: Springer Science \& Business Media, LLC.

Gauthier, R. D., \& Jahsman, W. E. (1975). A Quest for Micropolar Elastic Constants. Journal of Applied Mechanics-Transactions of the ASME, 42(2), 369-374.

Gauthier, R. D., \& Jahsman, W. E. (1976). Bending of a Curved Bar of Micropolar Elastic Material. Journal of Applied Mechanics-Transactions of the ASME, 43 Ser E(3), 502-503.

Gibson, L. J., \& Ashby, M. F. (1999). Cellular Solids: Structure and Properties: Cambridge University Press. 
Godin, V., Huaux, J.P., Knoops, P.H. (1985). Une cause rare de paralysie des muscle releveurs du pied:Le kyste synovial intraneural du nerf sciatique poplite externe. Louv. Med., 104(NA), 281-286.

Gurdjian, E. S., Larsen, R.D., Lindner, D.W. (1965). Intraneural cyst of the peroneal and ulnar nerves. Report of two cases. Journal of Neurosurgery, 23(1), 76-78.

Hegemier, G. A., Gurtman, G. A., \& Nayfeh, A. H. (1973). A Continuum Mixture Theory of Wave Propagation in Laminated and Fiber Reinforced Composites. International Journal of Solids and Structures, 9(3), 395-414.

Hirokawa, S., \& Tsuruno, R. (1997). Hyper-elastic model analysis of anterior cruciate ligament. Medical Engineering \& Physics, 19(7), 637-651.

Holzapfel, G. (2000). Nonlinear Solid Mechanics: A Continuum Approach for Engineering (1 ed.).

Huaux J.P., M., J., Maldague, B., Noël, H., Rombouts, J.J., Courtois, C., Nagant de Deuxchaisnes, C. (1986). Pathology of the Upper Peroneotibial joint. History of Cysts. Apropos of 4 Cases. Rev Rhum Mal Osteoartic, 53(12), 726-726.

Hunt, M. A., Hinman, R. S., Metcalf, B. R., Lim, B.-W., Wrigley, T. V., Bowles, K.-A., et al. (2010). Quadriceps strength is not related to gait impact loading in knee osteoarthritis. Knee, 17(4), 296-302.

Jones, R. M. (1975). Mechanics of Composite Materials: Hemisphere Publishing Corporation.

Kanaun, S., \& Tkachenko, O. (2006). Mechanical properties of open cell foams: Simulations by Laguerre tesselation procedure. International Journal of Fracture, 140(1-4), 305-312.

Knight, A. D., \& Levick, J. R. (1982). PRESSURE VOLUME RELATIONSHIPS ABOVE AND BELOW ATMOSPHERIC-PRESSURE IN THE SYNOVIAL CAVITY OF THE RABBIT KNEE. Journal of Physiology-London, 328(JUL), 403-420.

Lagarrigue, J., Robert, R., Resche, F., Sindou, M., Lazzerini, P. (1982). Intraneural synovial cysts of the common peroneal nerve. Neurochirurgie., 28(2), 131-134.

Li, K., Gao, X. L., \& Subhash, G. (2006). Effects of Cell Shape and Strut CrossSectional Area Variations on the Elastic Properties of Three-Dimensional Open-Cell Foams. Journal of the Mechanics and Physics of Solids, 54(4), 783806.

Malghem, J., Vande Berg, B.C., Lebon, C., Lecouvet, F.E., Maldague, B.E. (1998). Ganglion Cysts of the Knee: Articular Communication Revealed by Delayed Radiography and CT after Arthrography. AMERICAN JOURNAL OF ROENTGENOLOGY, 170(6), 1579-1583.

Malghem, J., Vande, B. B., Lecouvet, F., et. al. (2002). Les kystes mucoides atypiques. $J B R-B T R, 85(\mathrm{NA}), 34-42$.

McNiven, H. D., \& Mengi, Y. (1979a). Mathematical Model for the Linear Dynamic Behavior of Two Phase Periodic Materials. International Journal of Solids and Structures, 15(4), 271-280.

McNiven, H. D., \& Mengi, Y. (1979b). Mixture Theory for Elastic Laminated Composites. International Journal of Solids and Structures, 15(4), 281-302.

McNiven, H. D., \& Mengi, Y. (1979c). Propagation of Transient Waves in Elastic Laminated Composites. International Journal of Solids and Structures, 15(4), 303-318. 
Medicine, U.-O. a. $\quad$ S. $\quad$ (2010). Joints. from http://www.orthop.washington.edu/uw/arthritisbasics/tabID 3376/ItemID 180/PageID 346/Articles/Default.aspx\#6651

Nayfeh, A. H., \& Gurtman, G. A. (1974). A Continuum Approach to the Propagation of Shear Waves in Laminated Wave Guides. Journal of Applied Mechanics Transactions of the ASME, 41(1), 106-119.

Nemat-Nasser, S., \& Hori, M. (1993). Micromechanics: Overall Properties of Heterogeneous Materials: North-Holland Publishing Company.

Nguyen, V. P., Rabczuk, T., Bordas, S., \& Duflot, M. (2008). Meshless methods: A review and computer implementation aspects. Mathematics and Computers in Simulation, $79(3), 763-813$.

Noor, A. K., \& Nemeth, M. P. (1980a). Analysis of Spatial Beam Like Lattices with Rigid Joints. Computer Methods in Applied Mechanics and Engineering, 24(1), 35-59.

Noor, A. K., \& Nemeth, M. P. (1980b). Micropolar Beam Models for Lattice Grids with Rigid Joints. Computer Methods in Applied Mechanics and Engineering, 21(2), 249-263.

Nowacki, W. (1974). Theory of Micropolar Elasticity: Springer.

Ostoja-Starzewski, M. (2002). Lattice models in micromechanics. Applied Mechanics Reviews, 55(1), 35-59.

Quapp, K. M., \& Weiss, J. A. (1998). Material characterization of human medial collateral ligament. Journal of Biomechanical Engineering-Transactions of the Asme, 1206), 757-763.

Roberts, A. P., \& Garboczi, E. J. (2002). Elastic Properties of Model Random ThreeDimensional Open-Cell Solids. Journal of the Mechanics and Physics of Solids, 50(1), 33-55.

Spinner, R. J., Amrami, K. K., Kliot, M., Johnston, S. P., \& Casanas, J. (2006). Suprascapular intraneural ganglia and glenohumeral joint connections. Journal of Neurosurgery, 104(4), 551-557.

Spinner, R. J., Amrami, K. K., \& Rock, M. G. (2006). The use of MR arthrography to document an occult joint communication in a recurrent peroneal intraneural ganglion. Skeletal Radiology, 35(3), 172-179.

Spinner, R. J., Amrami, K. K., Wolanskyj, A. P., Desy, N. M., Wang, H., Benarroch, E. E., et al. (2007). Dynamic phases of peroneal and tibial intraneural ganglia formation: a new dimension added to the unifying articular theory. Journal of Neurosurgery, 107(2), 296-307.

Spinner, R. J., Atkinson, J. L. D., Scheithauer, B. W., Rock, M. G., Birch, R., Kim, T. A., et al. (2003). Peroneal intraneural ganglia: the importance of the articular branch. Clinical series. Journal of Neurosurgery, 99(2), 319-329.

Spinner, R. J., Atkinson, J. L. D., Tiel, R. L., \& Tn. (2003). Peroneal intraneural ganglia: the importance of the articular branch. A unifying theory. Journal of Neurosurgery, 99(2), 330-343.

Spinner, R. J., Desy, N. M., \& Amrami, K. K. (2006). Cystic transverse limb of the articular branch: A pathognomonic sign for peroneal intraneural ganglia at the superior tibiofibular joint. Neurosurgery, 59(1), 157-166.

Spinner, R. J., Scheithauer, B. W., Desy, N. M., Rock, M. G., Holdt, F. C., \& Amrami, K. K. (2006). Coexisting secondary intraneural and vascular adventitial 
ganglion cysts of joint origin: a causal rather than a coincidental relationship supporting an articular theory. Skeletal Radiology, 35(10), 734-744.

Spinner, R. J., Wang, H., Carmichael, S. W., Amrami, K. K., \& Scheithauer, B. W. (2007). Epineurial compartments and their role in intraneural ganglion cyst propagation: An experimental study. Clinical Anatomy, 20, 826-833.

Stern, M., \& Bedford, A. (1972). Wave Propagation in Elastic Laminates Using a Multi-Continuum Theory. Acta Mechanica, 15(1-2), 21-38.

Sun, C. T., \& Yang, T. Y. (1973). Continuum Approach Toward Dynamics of Gridworks. Journal of Applied Mechanics-Transactions of the ASME, 4O(1), 186-192.

Sunderland, S. (1948). The connective tissues of peripheral nerves. Brain, 88,841 854.

Sunderland, S. (1961). Stress-strain Phenomena in Human Peripheral Nerve Trunks. Brain, 84(1), 102-119.

Sunderland, S., \& Bradley, K. (1961). Stress-Strain Phenomena in Denervated Peripheral Nerve Trunks. Brain, 84, 125-127.

Sunderland, S., \& Ray, L. J. (1948). The Intraneural Topography of the Sciatic Nerve and its Popliteal Divisions in Man. Brain, 71(3), 242-273.

Timoshenko, S. P. (1953). History of Strength of Materials. New York: McGraw-Hill Book Company, Inc.

Topp, K. S., \& Boyd, B. S. (2006). Structure and biomechanics of peripheral nerves: Nerve responses to physical stresses and implications for physical therapist practice. Physical Therapy, 86(1), 92-109.

Truesdell, C., \& Toupin, R. (1960). Encyclopedia of Physics (Vol. 3): Springer-Verlag OHG.

Valencia, A., \& Solis, F. (2006). Blood flow dynamics and arterial wall interaction in a saccular aneurysm model of the basilar artery. Computers \& Structures, 84(21), 1326-1337.

Weiss, J. A., \& Gardiner, J. C. (2001). Computational modeling of ligament mechanics. Critical Reviews in Biomedical Engineering, 29(3), 303-371.

Yoo, A., \& Jasiuk, I. (2006). Couple-stress moduli of a trabecular bone idealized as a 3D periodic cellular network. Journal of Biomechanics, 39(12), 2241-2252.

Zhu, H. X., Hobdell, J. R., \& Windle, A. H. (2000). Effects of cell irregularity on the elastic properties of open-cell foams. Acta Materialia, 48(20), 4893-4900. 


\title{
9. APPENDIX-A COPYRIGHT PERMISSIONS
}

\subsection{LICENSES FOR CHAPTER-2}

\subsubsection{License for Figure 2.1-Figure 2.4 and all text}

\author{
ELSEVIER LICENSE \\ TERMS AND CONDITIONS \\ Jun 21,2010 \\ This is a License Agreement between Shreehari Elangovan ("You") and Elsevier \\ ("Elsevier") provided by Copyright Clearance Center ("CCC"). The license consists of \\ your order details, the terms and conditions provided by Elsevier, and the payment \\ terms and conditions. All payments must be made in full to CCC. For payment \\ instructions, please see information listed at the bottom of this form. \\ Supplier \\ Registered Company Number \\ Customer name \\ Customer address \\ License Number \\ License date \\ Licensed content publisher \\ Licensed content publication \\ Licensed content title \\ Licensed content author \\ Licensed content date \\ Volume number \\ Issue number \\ Pages \\ Type of Use \\ Portion \\ Elsevier Limited, \\ The Boulevard, \\ Langford Lane \\ Kidlington, Oxford, OX5 \\ $1 \mathrm{~GB}, \mathrm{UK}$ \\ 1982084 \\ Shreehari Elangovan \\ Department of Mechanical Engineering \\ Houghton, MI 49931 \\ 2453800182257 \\ Jun 21, 2010 \\ Elsevier \\ Mechanics of Materials \\ An elastic micropolar \\ mixture theory for predicting \\ elastic properties of cellular \\ materials \\ S. Elangovan, B.S. Altan, \\ G.M. Odegard \\ July 2008 \\ 40 \\ 7 \\ 14 \\ Thesis / Dissertation \\ Full article
}


Format

You are an author of the Elsevier article

Are you translating?

Order Reference Number

Expected publication date

Elsevier VAT number

Permissions price

Value added tax

Total 0.00 USD

Terms and Conditions
Both print and electronic

Yes

No

Aug 2010

GB 494627212

0.00 USD

$0.0 \% 0.00 \mathrm{USD}$

\section{INTRODUCTION}

1. The publisher for this copyrighted material is Elsevier. By clicking "accept" in connection with completing this licensing transaction, you agree that the following terms and conditions apply to this transaction (along with the Billing and Payment terms and conditions established by Copyright Clearance Center, Inc. ("CCC"), at the time that you opened your Rightslink account and that are available at any time at http://myaccount.copyright.com).

GENERAL TERMS

2. Elsevier hereby grants you permission to reproduce the aforementioned material subject to the terms and conditions indicated.

3. Acknowledgement: If any part of the material to be used (for example, figures) has appeared in our publication with credit or acknowledgement to another source, permission must also be sought from that source. If such permission is not obtained then that material may not be included in your publication/copies. Suitable acknowledgement to the source must be made, either as a footnote or in a reference list at the end of your publication, as follows:

"Reprinted from Publication title, Vol /edition number, Author(s), Title of article / title of chapter, Pages No., Copyright (Year), with permission from Elsevier [OR APPLICABLE SOCIETY COPYRIGHT OWNER]." Also Lancet special credit "Reprinted from The Lancet, Vol. number, Author(s), Title of article, Pages No., Copyright (Year), with permission from Elsevier."

4. Reproduction of this material is confined to the purpose and/or media for which permission is hereby given.

5. Altering/Modifying Material: Not Permitted. However figures and illustrations may be altered/adapted minimally to serve your work. Any other abbreviations, additions, deletions and/or any other alterations shall be made only with prior written authorization of Elsevier Ltd. (Please contact Elsevier at permissions@elsevier.com)

6. If the permission fee for the requested use of our material is waived in this instance, please be advised that your future requests for Elsevier materials may attract a fee.

7. Reservation of Rights: Publisher reserves all rights not specifically granted in the combination of (i) the license details provided by you and accepted in the course of this licensing transaction, (ii) these terms and conditions and (iii) CCC's Billing and Payment terms and conditions. 
8. License Contingent Upon Payment: While you may exercise the rights licensed immediately upon issuance of the license at the end of the licensing process for the transaction, provided that you have disclosed complete and accurate details of your proposed use, no license is finally effective unless and until full payment is received from you (either by publisher or by CCC) as provided in CCC's Billing and Payment terms \& conditions. If full payment is not received on a timely basis, then any license preliminarily granted shall be deemed automatically revoked and shall be void as if never granted. Further, in the event that you breach any of these terms and conditions or any of CCC's Billing and Payment terms and conditions, the license is automatically revoked and shall be void as if never granted. Use of materials as described in a revoked license, as well as any use of the materials beyond the scope of an unrevoked license, may constitute copyright infringement and publisher reserves the right to take any and all action to protect its copyright in the materials.

9. Warranties: Publisher makes no representations or warranties with respect to the licensed material.

10. Indemnity: You hereby indemnify and agree to hold harmless publisher and CCC, and their respective officers, directors, employees and agents, from and against any and all claims arising out of your use of the licensed material other than as specifically authorized pursuant to this license.

11. No Transfer of License: This license is personal to you and may not be sublicensed, assigned, or transferred by you to any other person without publisher's written permission.

12. No Amendment Except in Writing: This license may not be amended except in a writing signed by both parties (or, in the case of publisher, by CCC on publisher's behalf).

13. Objection to Contrary Terms: Publisher hereby objects to any terms contained in any purchase order, acknowledgment, check endorsement or other writing prepared by you, which terms are inconsistent with these terms and conditions or CCC's Billing and Payment terms and conditions. These terms and conditions, together with CCC's Billing and Payment terms and conditions (which are incorporated herein), comprise the entire agreement between you and publisher (and CCC) concerning this licensing transaction. In the event of any conflict between your obligations established by these terms and conditions and those established by CCC's Billing and Payment terms and conditions, these terms and conditions shall control.

14. Revocation: Elsevier or Copyright Clearance Center may deny the permissions described in this License at their sole discretion, for any reason or no reason, with a full refund payable to you. Notice of such denial will be made using the contact information provided by you.

Failure to receive such notice will not alter or invalidate the denial. In no event will Elsevier or Copyright Clearance Center be responsible or liable for any costs, expenses or damage incurred by you as a result of a denial of your permission request, other than a refund of the amount(s) paid by you to Elsevier and/or Copyright Clearance Center for denied permissions. 


\section{LIMITED LICENSE}

The following terms and conditions apply only to specific license types:

15. Translation: This permission is granted for non-exclusive world English rights only unless your license was granted for translation rights. If you licensed translation rights you may only translate this content into the languages you requested. A professional translator must perform all translations and reproduce the content word for word preserving the integrity of the article. If this license is to reuse 1 or 2 figures then permission is granted for non-exclusive world rights in all languages.

16. Website: The following terms and conditions apply to electronic reserve and author websites:

Electronic reserve: If licensed material is to be posted to website, the web site is to be password-protected and made available only to bona fide students registered on a relevant course if:

This license was made in connection with a course, This permission is granted for 1 year only. You may obtain a license for future website posting, All content posted to the web site must maintain the copyright information line on the bottom of each image, A hyper-text must be included to the Homepage of the journal from which you are licensing at http://www.sciencedirect.com/science/journal/xxxxx or the Elsevier homepage for books at http://www.elsevier.com , and Central Storage: This license does not include permission for a scanned version of the material to be stored in a central repository such as that provided by Heron/XanEdu.

17. Author website for journals with the following additional clauses:

All content posted to the web site must maintain the copyright information line on the bottom of each image, and he permission granted is limited to the personal version of your paper. You are not allowed to download and post the published electronic version of your article (whether PDF or HTML, proof or final version), nor may you scan the printed edition to create an electronic version, A hyper-text must be included to the Homepage of the journal from which you are licensing at http://www.sciencedirect.com/science/journal/xxxxx , As part of our normal production process, you will receive an e-mail notice when your article appears on Elsevier's online service ScienceDirect (www.sciencedirect.com). That e-mail will include the article's Digital Object Identifier (DOI). This number provides the electronic link to the published article and should be included in the posting of your personal version. We ask that you wait until you receive this e-mail and have the DOI to do any posting.

Central Storage: This license does not include permission for a scanned version of the material to be stored in a central repository such as that provided by Heron/XanEdu.

18. Author website for books with the following additional clauses:

Authors are permitted to place a brief summary of their work online only.

A hyper-text must be included to the Elsevier homepage at http://www.elsevier.com All content posted to the web site must maintain the copyright information line on the bottom of each image. You are not allowed to download and post the published electronic version of your chapter, nor may you scan the printed edition to create an electronic version. Central Storage: This license does not include permission for a 
scanned version of the material to be stored in a central repository such as that provided by Heron/XanEdu.

19. Website (regular and for author): A hyper-text must be included to the Homepage of the journal from which you are licensing at http://www.sciencedirect.com/science/journal /xxxxx. or for books to the Elsevier homepage at http://www.elsevier.com

20. Thesis/Dissertation: If your license is for use in a thesis/dissertation your thesis may be submitted to your institution in either print or electronic form. Should your thesis be published commercially, please reapply for permission. These requirements include permission for the Library and Archives of Canada to supply single copies, on demand, of the complete thesis and include permission for UMI to supply single copies, on demand, of the complete thesis. Should your thesis be published commercially, please reapply for permission.

21. Other Conditions: None

v1.6

Gratis licenses (referencing $\$ 0$ in the Total field) are free. Please retain this printable license for your reference. No payment is required.

If you would like to pay for this license now, please remit this license along with your payment made payable to "COPYRIGHT CLEARANCE CENTER" otherwise you will be invoiced within 48 hours of the license date. Payment should be in the form of a check or money order referencing your account number and this invoice number RLNK10803254.

Once you receive your invoice for this order, you may pay your invoice by credit card. Please follow instructions provided at that time.

Make Payment To:

Copyright Clearance Center

Dept 001

P.O. Box 843006

Boston, MA 02284-3006

If you find copyrighted material related to this license will not be used and wish to cancel, please contact us referencing this license number 2453800182257 and noting the reason for cancellation.

Questions? customercare@copyright.com or +1-877-622-5543 (toll free in the US) or $+1-978-646-2777$.

\subsubsection{License for Figure 2.5}

Subject: RE: Inquiry from Dennis Kunkel Microscopy, Inc. - Scientific Stock Photography

From: "Dennis Kunkel" <kunkel@denniskunkel.com>

Date: Mon, 21 Jun 2010 10:23:13 -1000

To: "'Shreehari Elangovan"' < selangov@mtu.edu>

Dear Shreehari,

Thank you for writing and I do remember your professor and use of the balsa wood. You have my permission to use the image in your thesis. Please place a photo credit 
near the image or in the image caption as: Image copyright Dennis Kunkel Microscopy, Inc. Also in you acknowledgements please add a credit as: Balsa wood image (page ?) provided and copyright by Dennis Kunkel Microscopy, Inc.

Good luck with your thesis.

Regards, Dennis

* Dennis Kunkel Ph.D.

* Dennis Kunkel Microscopy, Inc.

* PO Box 2008

* Kailua, HI 96734

* 808-263-0583

* email-kunkel@denniskunkel.com

* web site - www.denniskunkel.com

-----Original Message-----

From: Shreehari Elangovan [mailto:selangov@mtu.edu]

Sent: Monday, June 21, 2010 10:19 AM

To: Dennis Kunkel

Subject: Inquiry from Dennis Kunkel Microscopy, Inc. - Scientific Stock

Photography

This message is from:

Shreehari Elangovan

Phone: 906-370-4098

E-mail: selangov@mtu.edu

I am a PhD student from Michigan Tech University, Houghton, MI. In 2008 my advisor Dr. Gregory M Odegard and I wrote an article that needed to use your image of balsa wood. He asked you for permission which you granted then. The paper was later published in a journal. Now I am in the process of writing my thesis and I need permission to use that image in my dissertation. Please let me know how I should go about this. Thanks.

\subsection{LICENSES FOR CHAPTER-4}

\subsubsection{License for Figure 4.1, Figure 4.2, Figure 4.3a \& b, Figure 4.7a}

Good Morning,

As Copyright Agent for Mayo Foundation for Medical Education and Research, I grant one-time permission for you to use the Mayo Clinic illustrations in your Thesis. This permission applies to three drawings published in J Neurosurg (Figure 14, Vol 107, 2007; Figure 1, Vol 99, 2003; Figure 6, Vol 99, 2003). This permission is contingent upon credit being given to the original reference, along with the phrase "Copyrighted and used with permission of Mayo Foundation for Medical Education and Research, all rights reserved." 
You will need to obtain permission to reuse Figure 4 from J Neurosurg, Vol 99, 2003 and from Springer to reuse Figure 3b (Skeletal Radiology Vol 36, 2007), because they own the copyright for those illustrations.

Thank you for requesting permission.

Roberta Schwartz

Copyright Agent for Mayo Foundation

Phone: 507-284-3335

Fax: 507-284-2107

e-mail: schwartz.roberta@mayo.edu

Mayo Foundation

200 First Street SW

Rochester, MN 55905

www.mayoclinic.org

\subsubsection{License for Figure 4.4 and Figure 4.5 and text in section 4.1.3}

Permission to reproduce the requested material is granted without charge by the copyright owner, AANS, provided that full acknowledgment is given to Neurosurgical FOCUS.

Best of luck with your dissertation!

thank you,

Gillian

Gillian Shasby

Director of Publications-Operations

The JNS Publishing Group

—Journal of Neurosurgery

—Journal of Neurosurgery: Spine

—Journal of Neurosurgery: Pediatrics

-Neurosurgical Focus

1224 Jefferson Park Ave

Suite 450

Charlottesville, VA 22903

434-924-5503 - main

434-924-5555 - direct

434-924-2702 - fax

gshasby@thejns.org

www.thejns.org

Begin forwarded message:

From: "subscriptions@thejns.org" <subscriptions@thejns.org>

From: "selangov@mtu.edu" <selangov@mtu.edu>

Date: June 30, 2010 9:37:25 AM EDT

To: permissions@thejns.org 
Subject: Mail from Reprints/Permissions Form

Reply-To: subscriptions@thejns.org

Reply-To: <selangov@mtu.edu>

Request to reprint the following

Intraneural ganglia: a clinical problem deserving a mechanistic explanation and model

Authors: Shreehari Elangovan, B.E., Gregory M. Odegard, Ph.D., Duane A. Morrow, M.S., Huan Wang, M.D., Ph.D., Marie-Noëlle Hébert-Blouin, M.D., and Robert J. Spinner, M.D.

Publication: Neurosurgical Focus

Month: Feb

Year: 2009

Volume:26

Issue:2

Pages:

Permission Category:

Original Author Seeking Permission to Use Content in non-AANS Publication

Reprint Material Specifics: ALL

Media Type: Print and Electronic

Media: Book (not textbook)

Language: English (as originally published)

Title and Edition of New Work: Advanced Mechanics of Materials with Microstructure

Anticipated Republication Date: Aug 2010

Quantity: 5

Publisher of New Work: Michigan Tech University

Other Notes or Comments:

I am a PhD student at Michigan Tech University and am including this paper on which I am an author as part of my PhD dissertation. MTU dissertations are not used for commercial purposes.

Request from:

Mr. Shreehari ELANGOVAN, PhD Student

Company: Michigan Tech University

Department of Mechanical Engineering - Engineering Mechanics

1400 Townsend Drive

Houghton MI 49931

United States

selangov@mtu.edu

Phone: 906-370-4098

Fax: 
Reference Number:

Company Web Site:

\subsubsection{License for Figure 4.6}

Subject: Fwd: Mail from Reprints/Permissions Form

From: Permissions <permissions@thejns.org>

Date: Thu, 24 Jun 2010 12:27:08 -0400

To: selangov@mtu.edu

Permission to reproduce the requested material in your dissertation is granted without charge by the copyright owner, AANS, provided that full acknowledgment is given to the Journal of Neurosurgery.

thank you,

Gillian

Gillian Shasby

Director of Publications-Operations

The JNS Publishing Group

- Journal of Neurosurgery

—Journal of Neurosurgery: Spine

—Journal of Neurosurgery: Pediatrics

-Neurosurgical Focus

1224 Jefferson Park Ave

Suite 450

Charlottesville, VA 22903

434-924-5503 - main

434-924-5555 - direct

434-924-2702 - fax

gshasby@thejns.org

www.thejns.org

Begin forwarded message:

From: "subscriptions@thejns.org" <subscriptions@thejns.org>

From: "selangov@mtu.edu" < selangov@mtu.edu>

Date: June 24, 2010 12:18:40 PM EDT

To: permissions@thejns.org

Subject: Mail from Reprints/Permissions Form

Reply-To: subscriptions@thejns.org

Reply-To: <selangov@mtu.edu>

Request to reprint the following

Peroneal intraneural ganglia: the importance of the articular branch. A unifying theory

Authors: ROBERT J. SPINNER, M.D., JOHN L. D. ATKINSON, M.D., AND ROBERT L. TIEL, M.D. 
Publication: Journal of Neurosurgery

Month: Aug

Year: 2003

Fwd: Mail from Reprints/Permissions Form

Volume: 99

Issue: 2

Pages: 330-343

Permission Category: Commercial Permission

Reprint Material Specifics: Figure 4 on page 332

Media Type: Print and Electronic

Media: Not listed/other

Language: English (as originally published)

Title and Edition of New Work: Advanced Mechanics of Materials with Microstructure

Anticipated Republication Date: Aug 2010

Quantity: 5

Publisher of New Work: Michigan Tech University

Other Notes or Comments: This is a PhD dissertation.

Request from:

Mr. Shreehari Elangovan, PhD Student

Company: Michigan Tech University

Department of Mechanical Engineering - Engineering Mechanics

1400 Townsend Drive

Houghton MI 49931

United States

selangov@mtu.edu

Phone: 906-370-4098

Fax:

Reference Number:

Company Web Site: Michigan Tech University

Request On Behalf Of:

\subsubsection{Licenses for other content in Chapter-4}

Figure 4.8-Figure 4.19 and all text (except section 4.1.3 which is noted above in section 9.2.2) have not been previously published or taken from another source.

\subsection{LICENSES FOR CHAPTER-5}

\subsubsection{License for Figure 5.5a}

This license is the same as the one for Figure 4.3 and Figure 4.7 in section 9.2.1. 


\subsubsection{Licenses for other content in Chapter-5}

Figure 5.1-Figure 5.4, Figure 5.6, Figure 5.5b \& c, Figure 5.7 and all text have not been previously published or taken from another source.

\subsection{LICENSES FOR CHAPTER-6}

\subsubsection{License for Figure 6.1}

OXFORD UNIVERSITY PRESS LICENSE

TERMS AND CONDITIONS

Jun 21,2010

This is a License Agreement between Shreehari Elangovan ("You") and Oxford University Press ("Oxford University Press") provided by Copyright Clearance Center ("CCC"). The license consists of your order details, the terms and conditions provided by Oxford University Press, and the payment terms and conditions.

All payments must be made in full to CCC. For payment instructions, please see information listed at the bottom of this form.

License Number 2453821271953

License date Jun 21, 2010

Licensed content publisher Oxford University Press

Licensed content publication Brain

Licensed content title THE INTRANEURAL TOPOGRAPHY OF THE SCIATIC NERVE AND ITS POPLITEAL DIVISIONS IN MAN

Licensed content author S. SUNDERLAND, et. al.

Licensed content date September 1948

Type of Use Thesis/Dissertation

Institution name

Title of your work Advanced Mechanics of Materials with Microstructure

Publisher of your work n/a

Expected publication date Aug 2010

Permissions cost 0.00 USD

Value added tax 0.00 USD

Total 0.00 USD

Total 0.00 USD

Terms and Conditions

STANDARD TERMS AND CONDITIONS FOR REPRODUCTION OF MATERIAL FROM AN OXFORD UNIVERSITY PRESS JOURNAL

1. Use of the material is restricted to the type of use specified in your order details.

2. This permission covers the use of the material in the English language in the following territory: world. If you have requested additional permission to translate this material, the terms and conditions of this reuse will be set out in clause 12 . 
3. This permission is limited to the particular use authorized in (1) above and does not allow you to sanction its use elsewhere in any other format other than specified above, nor does it apply to quotations, images, artistic works etc that have been reproduced from other sources which may be part of the material to be used.

4. No alteration, omission or addition is made to the material without our written consent. Permission must be re-cleared with Oxford University Press if/when you decide to reprint.

5. The following credit line appears wherever the material is used: author, title, journal, year, volume, issue number, pagination, by permission of Oxford University Press or the sponsoring society if the journal is a society journal. Where a journal is being published on behalf of a learned society, the details of that society must be included in the credit line.

6. For the reproduction of a full article from an Oxford University Press journal for whatever purpose, the corresponding author of the material concerned should be informed of the proposed use. Contact details for the corresponding authors of all Oxford University Press journal contact can be found alongside either the abstract or full text of the article concerned, accessible from www.oxfordjournals.org. Should there be a problem clearing these rights, please contact journals .permissions@oxfordjournals.org

7. If the credit line or acknowledgement in our publication indicates that any of the figures, images or photos was reproduced, drawn or modified from an earlier source it will be necessary for you to clear this permission with the original publisher as well. If this permission has not been obtained, please note that this material cannot be included in your publication/photocopies.

8. While you may exercise the rights licensed immediately upon issuance of the license at the end of the licensing process for the transaction, provided that you have disclosed complete and accurate details of your proposed use, no license is finally effective unless and until full payment is received from you (either by Oxford University Press or by Copyright Clearance Center (CCC)) as provided in CCC's Billing and Payment terms and conditions. If full payment is not received on a timely basis, then any license preliminarily granted shall be deemed automatically revoked and shall be void as if never granted. Further, in the event that you breach any of these terms and conditions or any of CCC's Billing and Payment terms and conditions, the license is automatically revoked and shall be void as if never granted. Use of materials as described in a revoked license, as well as any use of the materials beyond the scope of an unrevoked license, may constitute copyright infringement and Oxford University Press reserves the right to take any and all action to protect its copyright in the materials.

9. This license is personal to you and may not be sublicensed, assigned or transferred by you to any other person without Oxford University Press's written permission.

10. Oxford University Press reserves all rights not specifically granted in the combination of (i) the license details provided by you and accepted in the course of this licensing transaction, (ii) these terms and conditions and (iii) CCC's Billing and Payment terms and conditions.

11. You hereby indemnify and agree to hold harmless Oxford University Press and $\mathrm{CCC}$, and their respective officers, directors, employs and agents, from and against 
any and all claims arising out of your use of the licensed material other than as specifically authorized pursuant to this license.

12. Other Terms and Conditions:v1.4 Gratis licenses (referencing $\$ 0$ in the Total field) are free. Please retain this printable license for your reference. No payment is required. If you would like to pay for this license now, please remit this license along with your payment made payable to "COPYRIGHT CLEARANCE CENTER" otherwise you will be invoiced within 48 hours of the license date. Payment should be in the form of a check or money order referencing your account number and this invoice number RLNK10803300. Once you receive your invoice for this order, you may pay your invoice by credit card. Please follow instructions provided at that time. Make Payment To:

Copyright Clearance Center

Dept 001

P.O. Box 843006

Boston, MA 02284-3006

If you find copyrighted material related to this license will not be used and wish to cancel, please contact us referencing this license number 2453821271953 and noting the reason for cancellation.

Questions? customercare@copyright.com or +1-877-622-5543 (toll free in the US) or $+1-978-646-2777$.

\subsubsection{License for Figure 6.5}

\section{SPRINGER LICENSE}

\section{TERMS AND CONDITIONS}

Jun 24,2010

This is a License Agreement between Shreehari Elangovan ("You") and Springer

("Springer") provided by Copyright Clearance Center ("CCC"). The license consists of your order details, the terms and conditions provided by Springer, and the payment terms and conditions. All payments must be made in full to CCC. For payment instructions, please see information listed at the bottom of this form.

License Number 2455440193597

License date Jun 24, 2010

Licensed content publisher Springer

Licensed content publication Skeletal Radiology

Licensed content title Coexisting secondary intraneural and vascular adventitial ganglion cysts of joint origin: a causal rather than a coincidental relationship supporting an articular theory

Licensed content author Robert J. Spinner

Licensed content date Jan 1, 2006

Volume number 35

Issue number 10

Type of Use Thesis/Dissertation

Portion Figures 
Author of this Springer article No

Order reference number

Title of your thesis / dissertation Advanced Mechanics of Materials with Microstructure

Expected completion date Aug 2010

Estimated size(pages) 100

Total 0.00 USD

Terms and Conditions

Introduction

The publisher for this copyrighted material is Springer Science + Business Media. By clicking "accept" in connection with completing this licensing transaction, you agree that the following terms and conditions apply to this transaction (along with the Billing and Payment terms and conditions established by Copyright Clearance Center, Inc. ("CCC"), at the time that you opened your Rightslink account and that are available at any time at http://myaccount.copyright.com).

Limited License

With reference to your request to reprint in your thesis material on which Springer Science and Business Media control the copyright, permission is granted, free of charge, for the use indicated in your enquiry. Licenses are for one-time use only with a maximum distribution equal to the number that you identified in the licensing process. This License includes use in an electronic form, provided it is password protected or on the university's intranet, destined to microfilming by UMI and University repository. For any other electronic use, please contact Springer at (permissions.dordrecht@springer.com or permissions.heidelberg@springer.com)

The material can only be used for the purpose of defending your thesis, and with a maximum of 100 extra copies in paper. Although Springer holds copyright to the material and is entitled to negotiate on rights, this license is only valid, provided permission is also obtained from the (co) author (address is given with the article/chapter) and provided it concerns original material which does not carry references to other sources (if material in question appears with credit to another source, authorization from that source is required as well). Permission free of charge on this occasion does not prejudice any rights we might have to charge for reproduction of our copyrighted material in the future.

Altering/Modifying Material: Not Permitted However figures and illustrations may be altered minimally to serve your work. Any other abbreviations, additions, deletions and/or any other alterations shall be made only with prior written authorization of the author(s) and/or Springer Science + Business Media. (Please contact Springer at permissions.dordrecht@springer.com or permissions .heidelberg@springer.com)

Reservation of Rights

Springer Science + Business Media reserves all rights not specifically granted in the combination of (i) the license details provided by you and accepted in the course of this licensing transaction, (ii) these terms and conditions and (iii) CCC's Billing and Payment terms and conditions. 
Copyright Notice:

Please include the following copyright citation referencing the publication in which the material was originally published. Where wording is within brackets, please include verbatim.

"With kind permission from Springer Science+Business Media: <book/journal title, chapter/article title, volume, year of publication, page, name(s) of author(s), figure number(s), and any original (first) copyright notice displayed with material>."

Warranties: Springer Science + Business Media makes no representations or warranties with respect to the licensed material.

Indemnity You hereby indemnify and agree to hold harmless Springer Science + Business Media and CCC, and their respective officers, directors, employees and agents, from and against any and all claims arising out of your use of the licensed material other than as specifically authorized pursuant to this license.

No Transfer of License This license is personal to you and may not be sublicensed, assigned, or transferred by you to any other person without Springer Science + Business Media's written permission. No Amendment Except in Writing This license may not be amended except in a writing signed by both parties (or, in the case of Springer Science + Business Media, by CCC on Springer Science + Business Media's behalf).

Objection to Contrary Terms

Springer Science + Business Media hereby objects to any terms contained in any purchase order, acknowledgment, check endorsement or other writing prepared by you, which terms are inconsistent with these terms and conditions or CCC's Billing and Payment terms and conditions. These terms and conditions, together with CCC's Billing and Payment terms and conditions (which are incorporated herein), comprise the entire agreement between you and Springer Science + Business Media (and $\mathrm{CCC}$ ) concerning this licensing transaction. In the event of any conflict between your obligations established by these terms and conditions and those established by CCC's Billing and Payment terms and conditions, these terms and conditions shall control.

Jurisdiction

All disputes that may arise in connection with this present License, or the breach thereof, shall be settled exclusively by the country's law in which the work was originally published.

Other terms and conditions: v1.2 Gratis licenses (referencing $\$ 0$ in the Total field) are free. Please retain this printable license for your reference. No payment is required. If you would like to pay for this license now, please remit this license along with your payment made payable to "COPYRIGHT CLEARANCE CENTER" otherwise you will be invoiced within 48 hours of the license date. Payment should be in the form of a check or money order referencing your account number and this invoice number RLNK10805238. Once you receive your invoice for this order, you may pay your invoice by credit card. Please follow instructions provided at that time. Make Payment To:

Copyright Clearance Center

Dept 001 
P.O. Box 843006

Boston, MA 02284-3006

If you find copyrighted material related to this license will not be used and wish to cancel, please contact us referencing this license number 2455440193597 and noting the reason for cancellation. Questions? customercare@copyright.com or +1-877-6225543 (toll free in the US) or +1-978-646-2777.

\subsubsection{Licenses for other content in Chapter-6}

Figure 6.2-Figure 6.4 and all text have not been previously published or taken from another source. 